\title{
PERFORMANCE TESTING OF MULTI-METAL CONTINUOUS EMISSIONS MONITORS
}

William. J. Haas, Jr., Ames Laboratory

Nina Bergan French, Sky+, Inc.

Clifton H. Brown, Oak Ridge National Laboratory

Daniel B. Burns, Westinghouse Savannah River Company

Paul M. Lemieux, U. S. EPA National Risk Management Research Laboratory Stephen J. Priebe, Idaho National Engineering and Environmental Laboratory Jeffrey V. Ryan, U. S. EPA National Risk Management Research Laboratory and

Larry R. Waterland, Acurex Environmental Corporation

\section{Prepared for:}

U. S. Department of Energy Office of Environmental Management

Office of Science and Technology

Characterization, Monitoring and Sensor Technology Crosscutting Program

and

Mixed Waste Focus Area

and

U. S. Environmental Protection Agency National Risk Management Research Laboratory

Date Transmitted: November 17, 1997

DISTRIBUTION OF THIS DOCUMENT IS UNLIMTED Prepared by:

MASTER<smiles>CC1=CC=C2C=CC1C2</smiles>

Ames Laboratory*

U. S. Department of Energy

Iowa State University

Ames, Iowa 50011

* Operated by Iowa State University for the U. S. Department of Energy under Contract No. W-7405-ENG-82 


\section{DISCLAIMER}

This report was prepared as an account of work sponsored by an agency of the United States Government. Neitber the United States Government nor any agency thereof, nor any of their employees, makes any warranty, express or implied, or scrumes any legal liability or responsibility for the accuracy, completeness, or usefulness of any information, apparatus, produch, or process disclosed, or represents that its use would not infringe privately owned rights. Reference herein to any specinc commercial produch procese, or service by trade name, trademart, manufacturer, or otherwise does nor necessarily constitute or imply its endorsement, recommendation, or favoring by the United States Government or any ageacy thereof. The views and opinions of authors expressed herein do not pecesearily state or reflect those of the United States Government or any agency thereof. 


\section{DISCLAIMER}

Portions of this document may be illegible electronic image products. Images are produced from the best available original document. 


\section{DISCLAIMER}

This work was completed under funding provided by the U.S. Department of Energy and the U.S. Environmental Protection Agency. Neither the United States Government nor any agency thereof, nor any of their employees, makes any warranty, express or implied, or assumes any legal liability or responsibility for the accuracy, completeness, or usefulness of any information, apparatus, product, or process disclosed, or represents that its use would not infringe privately owned rights. Reference herein to any specific commercial product, process, or service by trade name, trademark, manufacturer, or otherwise, does not necessarily constitute or imply its endorsement, recommendation, or favoring by the United States Government or any agency thereof. The views and opinions of the authors expressed herein do not necessarily state or reflect those of the United States Government or any agency thereof.

\section{ACKNOWLEDGMENTS}

This work was jointly sponsored and executed by the U. S. Department of Energy (DOE) and the U. S. Environmental Protection Agency (EPA). The DOE sponsorship was through the Characterization, Monitoring, and Sensor Technology Crosscutting Program (CMST-CP) and.the Mixed Waste Focus Area (MWFA), both of the Office of Science and Technology, Office of Environmental Management. The EPA sponsorship involved the National Risk Management Research Laboratory, Air Pollution Prevention and Control Division, Research Triangle Park (RTP), North Carolina, and the National Exposure Research Laboratory, Air Measurements Division, RTP, and Characterization Research Division, Las Vegas, Nevada.

The testing described in this report adds to the information and experience gained during previous DOE/EPA testing of metal and organic compound CEMs conducted in August 1995 at the EPA Incineration Research Facility (IRF) in Jefferson, Arkansas. The success of this testing owes much to many of the same persons who planned and carried out the IRF test program.

Most importantly, all the persons named in this report, and others, from high organizational levels and principal investigators to workers, deserve real praise for the exemplary degree to which each contributed to this multi-organizational and multi-disciplinary team achievement. 


\section{ABSTRACT}

Three prototype multi-metals continuous emissions monitors (CEMs) were tested in April 1996 at the Rotary Kiln Incinerator Simulator facility at the U. S. Environmental Protection Agency (EPA) National Risk Management Research Laboratory, Research Triangle Park, North Carolina. The CEM instruments, participating developer organizations, and sponsors were:

- Inductively Coupled Plasma - Atomic Emission Spectrometry (ICP-AES), U. S. Department of Defense (DoD) Naval Air Warfare Center, sponsored by the U. S. Army Demilitarization Technology Office;

- Laser Induced Breakdown Spectrometry - Atomic Emission Spectroscopy (LIBS), Diagnostic Instrumentation and Analytical Laboratory (DIAL), Mississippi State University, sponsored by the U. S. Department of Energy (DOE) Characterization, Monitoring, and Sensor Technology Crosscutting Program (DOE CMST-CP); and

- Laser Spark Spectrometry, another LIBS instrument, provided by Sandia National Laboratories (SNL) under the sponsorship of the DOE CMST-CP and the DoD / DOE Joint Munitions Technology Program.

The three CEMs were tested simultaneously during test periods in which low, medium, and high concentration levels of seven toxic metals - antimony, arsenic, beryllium, cadmium, chromium, lead, and mercury - were maintained under carefully controlled conditions. Two methods were used to introduce the test metals into the flue gas: (1) solution atomization, introducing metalcontaining aerosol directly into the secondary combustion burner, and (2) injection of fly ash particulates. The prototype CEMs were of two types: one using inductively coupled argon plasma - atomic emission spectrometry to excite and determine the toxic metals in an extracted sample of the flue gas; and two systems using LIBS to excite and measure metals in situ in the flue gas. The testing addressed four measures of CEM performance ordinarily checked in a relative accuracy test audit (RATA) as described in 40 CFR 60 Appendix F - relative accuracy (RA), calibration drift, zero drift, and response time - but the primary focus was on the RA measurements. These were accomplished by comparing the toxic metal analyte concentrations reported by the CEMs to the concentrations measured using the EPA reference method (RM) for the same analytes. The tests included at least triplicate RM measurements at each of the three test metals concentrations.

The ICP-AES system provided quantitative CEM results for the seven toxic metals at all three concentration levels. For the seven metals, the ICP-AES system achieved average relative accuracies of 74,72 , and $67 \%$ for the low, medium, and high concentration levels, respectively. An RA value of $0 \%$ indicates complete agreement between the values measured by the instrument under test and the values determined by the EPA reference method. The RA values achieved by the ICP-AES system ranged between $16 \%$ and $143 \%$.

The LIBS systems provided quantitative CEM results for four toxic metals at the high concentration level, three and two toxic metals, respectively, at the medium concentration level, and only two and one, respectively, at the low concentration level. The DIAL LIBS system achieved average relative accuracies of 152,55 , and $65 \%$ for the low, medium and high concentration levels, respectively. The DIAL LIBS RA values ranged from 31 to $273 \%$. The SNL LIBS system achieved average relative accuracies of 91,241 , and $169 \%$ for the low, 
medium, and high concentration levels, respectively. The SNL LIBS RA values ranged from 68 to $413 \%$. These LIBS systems will need improved powers of detection to satisfy the RA requirement stated in the draft performance specification proposed by the EPA in April 1996.

Overall, the test results showed the prototype nature of the test CEMs and the clear need for further development. None of the CEMs tested consistently achieved RA values of $20 \%$ or less as required by the EPA draft performance specification. Instrument size reduction and automation will also likely need additional attention before multi-metal CEMs systems become commercially available for service as envisioned by regulators and citizens. 


\section{CONTENTS}

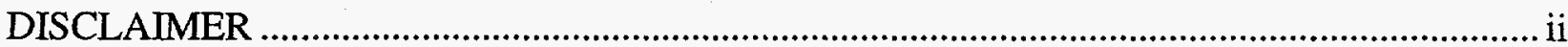

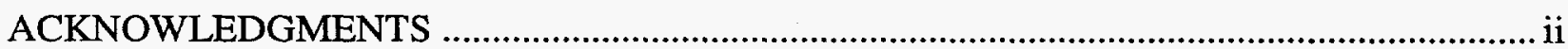

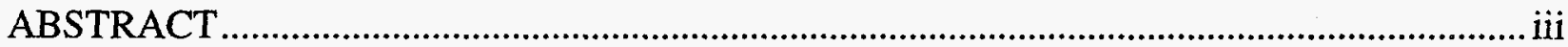

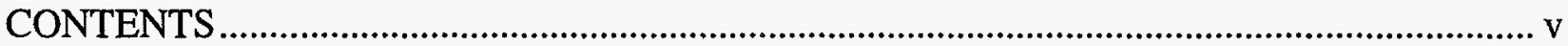

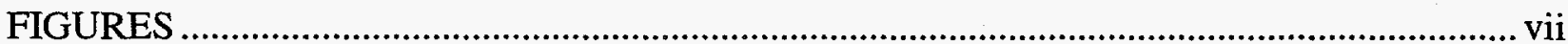

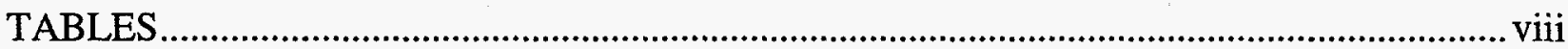

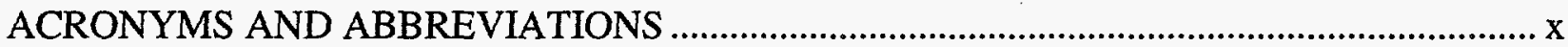

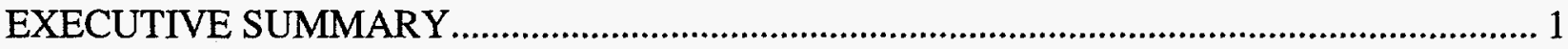

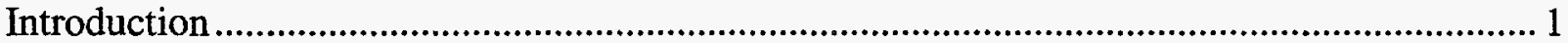

Test Objectives and Procedures .............................................................................................. 3

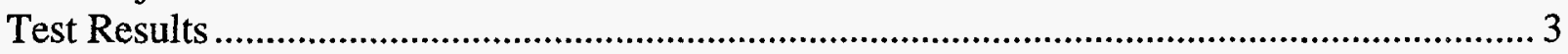

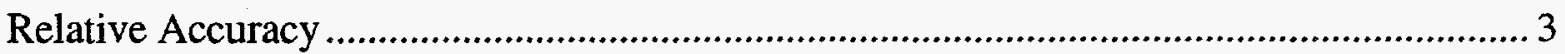

Estimated Method Detection Limits .................................................................................... 3

Sampling Duty Cycle and Data Reporting Frequency.......................................................... 5

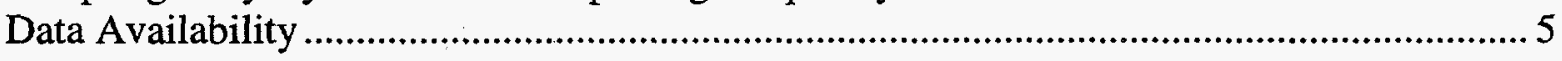

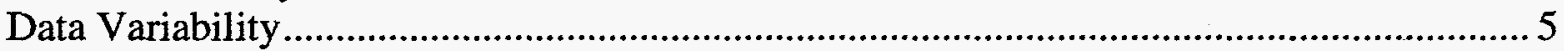

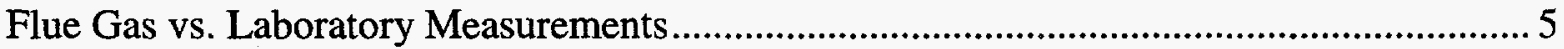

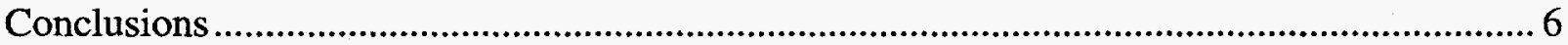

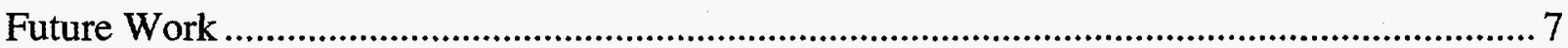

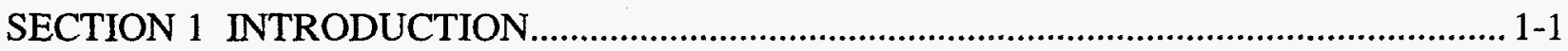

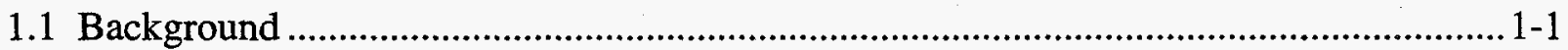

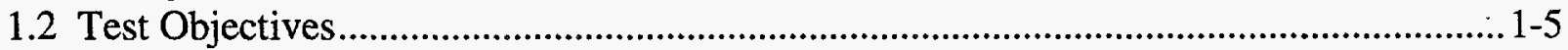

1.3 Outline of This Report ................................................................................................ 1-5

SECTION 2 TEST FACILITIES, PROCEDURES, AND CONDITIONS …............................. 2-1

2.1 Rotary Kiln Incinerator Simulator .......................................................................... 2-1

2.2 Multi-Metal Introduction ............................................................................................... 2-4

2.2.1 Multi-Metal Feed Via Solution Atomization ........................................................2-4

2.2.2 Multi-Metal Feed Via Particulate Injection ......................................................... 2-7

2.3 Test Procedure............................................................................................................ 2-10

2.4 Reference Method Sampling and Analysis Procedures ................................................2-16

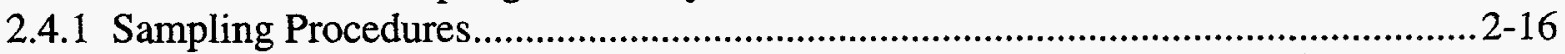

2.4.2 Sample Recovery, Shipment, and Custody Procedures ...........................................2-17

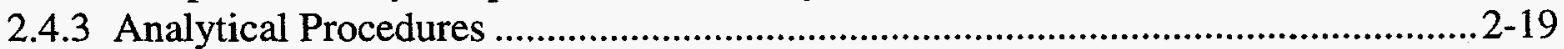

2.5 CEM Developer Procedures........................................................................................ 2-19

2.6 Combustion Gas CEM Measurements and CEM Test Conditions ..................................2-20

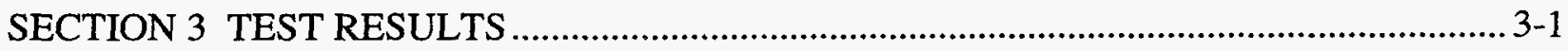

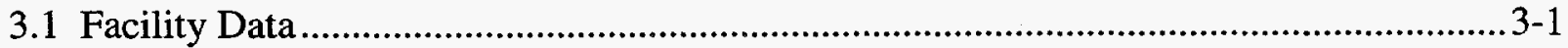

3.2 Reference Method Test Results ................................................................................ 3-1

3.3 Multi-Metal CEM Results........................................................................................ 3-5

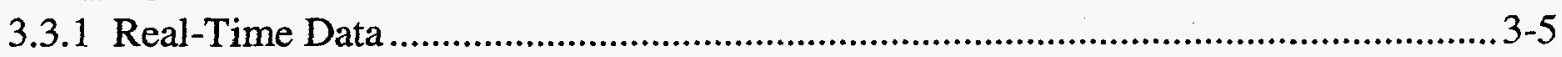

3.3.1.1 Data Variability ............................................................................................. 3-6

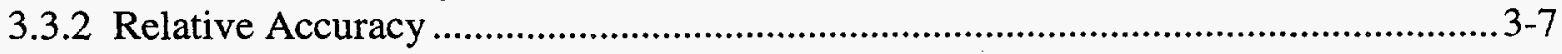

3.3.2.1 Relative Accuracy Computation .................................................................... 3-8

3.3.2.2 Relative Accuracy (RA) Results ..................................................................... 3-9 
3.3.2.3 Number of Data Pairs in Relative Accuracy Calculations 3-14

3.3.3 Method Detection Limits and Test Results.

3.3.4 Response Times 3-18

3.3.5 Calibration Drift and Zero Drift Checks 3-19

3.3.6 Data Availability

3.3.7 Spectral Interferences.

3.3.8 Sampling Duty Cycle and Data Reporting Frequency

3.3.9 Equipment Durability.

SECTION 4 CONCLUSIONS

APPENDIX A PROJECT ORGANIZATION AND PARTICIPANT

RESPONSIBILITIES A-1

APPENDIX B PROJECT SCHEDULE B-1

APPENDIX C QUALITY ASSURANCE SUMMARY

APPENDIX D FINAL REPORT OF DIAL CEM DEVELOPER TEAM D-1

APPENDIX E FINAL REPORT OF NAVY/TJA CEM DEVELOPER TEAM E-1 APPENDIX F FINAL REPORT OF SNL CEM DEVELOPER TEAM F-1 APPENDIX G DEVELOPER TEAM COMMENTS G-1 APPENDIX H PERFORMANCE SPECIFICATION 10 - SPECIFICATIONS AND TEST PROCEDURES FOR MULTI-METALS CONTINUOUS MONITORING SYSTEMS IN STATIONARY SOURCES

APPENDIX I DIAL DAILY LOGBOOK PAGES AND CEM DATA $\mathrm{I}-1$ APPENDIX J NAVY/TJA DAILY LOGBOOK PAGES AND CEM DATA $\mathrm{J}-1$ APPENDIX K SNL DAILY LOGBOOK PAGES AND CEM DATA $\mathrm{K}-1$ APPENDIX L MEASUREMENT DATA FROM INSITEC

PARTICLE COUNTER, SIZER, VELOCIMETER L-1

Appendices D through H (Appendix Volume 1) and I through L (Appendix Volume 2) will be distributed separately on request. 


\section{FIGURES}

Number

2-1 Schematic diagram of the RKIS $2-2$

2-2 Apparatus for metals injection via solution atomization ................................................ 2-5

2-3 Apparatus employed for metals introduction via fly ash injection ................................ 2-7

2-4. Sedigraph 5100 particle size data for coal fly ash before it was milled and fed into the flue gas

2-5 Typical test day schedule plans

$2-12$

2-6 Typical results of Insitec measurements of particle size distribution in the flue gas........ 2-15

3-1 Logarithmic plot showing correlation of RM results for the analyte elements in different RM measurement periods

3-2 Beryllium concentrations vs, time from the DIAL, Navy/TJA, and SNL CEMs during the second RM measurement period on April 26

3-3 Response of DIAL CEM to instantaneous changes in beryllium concentration 


\section{TABLES}

Number

1 Test CEMs, developer organizations, and sponsors 2

2 Summary of multi-metal CEM relative accuracy test results and other performance characteristics

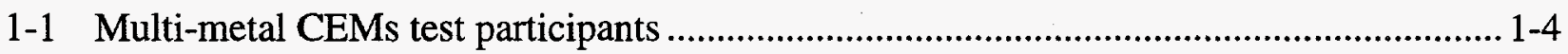

2-1 Design characteristics of the RKIS ……………............................................................ 2-3

2-2 Test metals and target flue gas concentrations.................................................................. 2-6

2-3 Metal concentrations in the highest concentration multi-metal feed solution ....................2-6

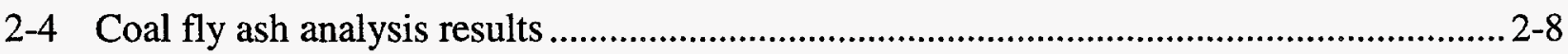

2-5 Trace metal concentrations in the injected fly ash ........................................................ 2-8

2-6 Sedigraph 5100 particle size data for coal fly ash before it was milled and fed into the flue gas ............................................................................................................... 2-9

2-7 Planned schedule for the test week ........................................................................... 2-11

2-8 Test dates, times, and metal concentration levels for reference method sampling periods

2-9 Results of Insitec real time particulate loading measurements

2-10 Method 0060 test matrix

2-11 Method 0060 sample fractions $2-18$

2-12 Sample containers, preservation methods, and hold times $2-18$

2-13 Trace metals quantitated in Method 0060 train samples

2-14 Combustion gas CEMs installed at the RKIS $2-20$

3-1 Test conditions as recorded by the EPA RKIS facility flue gas CEMs and thermocouples

3-2 Results from Reference Method measurements. 


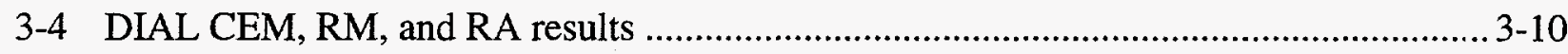

3-5 Navy/TJA CEM, RM, and RA results .............................................................. 3-11

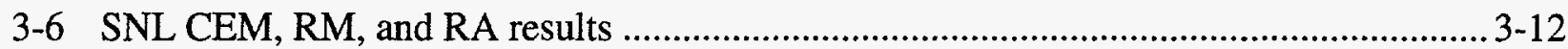

3-7 Relative accuracy results and average of RA results (\%) for the target metals at high, medium, and low concentrations

3-8 Summary of CEM performance test - Number of analytes determined 3-14

3-9 Summary of CEM performance test - Average RA (\%)

3-10 Comparison of target and estimated MDLs with metal concentrations measured by the EPA reference method and by the Navy/TJA, DIAL and SNL CEMs.

3-11 CEM sampling duty cycles and data reporting frequencies. 


\section{ACRONYMS AND ABBREVIATIONS}

AES

ALARA

ASME

CEM

CFR

CMST-CP

DIAI-

DoD

DOE

DOE EM

DRE

dscf

dscm

EPA

EQL

HAP

ICP-AES

ICP-MS

IFRF

IRF

LIBS

LVM

MACT

MDL

MS

MSD

MWFA

NIST

NPT
Atomic emission spectrometry

As low as reasonably achievable, a principle of exposure minimization

The American Society of Mechanical Engineers

Continuous emissions monitor

The Code of Federal Regulations

The Characterization, Monitoring, and Sensor Technology Crosscutting Program, within the U. S. DOE EM Office of Science and Technology

Diagnostic Instrumentation and Analysis Laboratory, at Mississippi State University, Starkville, Mississippi

The U. S. Department of Defense

The U. S. Department of Energy

The U. S. Department of Energy Office of Environmental Management

Destruction and removal efficiency

dry standard cubic foot or dry standard cubic feet

dry standard cubic meter

The U. S. Environmental Protection Agency

Estimated quantitation limit

Hazardous air pollutant

Inductively coupled plasma - atomic emission spectrometry

Inductively coupled plasma - mass spectrometry

International Flame Research Foundation

The EPA Incineration Research Facility in Jefferson, Arkansas

Laser-induced breakdown spectrometry

Low volatility metals

Maximum achievable control technology

Method detection limit

Matrix spike, a spiked sample used to evaluate analytical method recovery

Matrix spike duplicate, a duplicate MS sample

The Mixed Waste Focus Area, within the U. S. DOE EM Office of Science and Technology

National Institute for Standards and Technology

Nominal pipe thread 
POHC

PS

QA

QAO

QAPP

$\mathrm{QC}$

RA

RATA

RCRA

RKIS

$\mathrm{RM}$

RPD

RSD

RTP

scfm

SDC

SNL

SRM

SVM

THC

TJA

vS.

XRF
Principal organic hazardous constituent

Performance specification

Quality assurance

Quality assurance objective

Quality assurance project plan

Quality control

Relative accuracy

Relative accuracy test audit

The Resource Conservation and Recovery Act

Rotary kiln incinerator simulator

Reference method

Relative percent difference

Relative standard deviation

Research Triangle Park, North Carolina

standard cubic feet per minute

Sampling duty cycle

Sandia National Laboratories

Standard reference material

Semi-volatile metals

Total hydrocarbon

The Thermo Jarrell Ash Corporation

versus

$\mathrm{X}$-ray fluorescence 


\section{EXECUTIVE SUMMARY}

\section{Introduction}

Multi-metal continuous emission monitors (CEMs) are just becoming available to monitor air pollution from hazardous waste treatment processes. Other CEMs are already widely used to measure monitor oxygen $\left(\mathrm{O}_{2}\right)$ and carbon monoxide $(\mathrm{CO})$ as indicators of combustion efficiency and priority pollutants such as $\mathrm{NO}_{2}$ and $\mathrm{SO}_{2}$. Commercialization of these other CEMs has been driven by air pollution regulations that require these types of monitors. By contrast, current regulations do not require continuous monitoring of metals. The toxic compounds of eleven metals are governed under the Clean Air Act Amendments. The performance requirements for metals CEMs are more demanding than for these other CEMs. The oxygen and priority pollutants CEMs must be capable of measuring the pollutants at parts-per-million levels; the metals CEMs must measure at parts-per-billion levels. In addition, because of the number of toxic metals of concern, multi-metals CEMs can be considered more complex than the oxygen and priority pollutant CEMs.

The U. S. Department of Energy, Office of Environmental Management (DOE EM) will benefit from directly and continuously monitoring metals. DOE EM needs to treat a large inventory of poorly characterized mixed waste. (Mixed waste contains both hazardous substances and lowlevel radioactive material.) For such waste it is easier, safer, and much less expensive to control emissions in part by measuring and controlling metals in the effluent than by comprehensive waste feed characterization. Performance assurance is also a benefit of multi-metal CEMs. To operate mixed waste treatment systems, DOE must provide assurance to the public and to regulators that the processes are operating safely. Recognizing these factors, DOE EM has funded considerable technology development in this area. For similar reasons, DoD (specifically the U.S. Army demilitarization program) has funded multi-metal CEM technology development.

By 1996 multi-metal CEM developers and sponsor programs began to appreciate the desirability of testing the developing instruments under conditions more realistic than the simple simulations ordinarily used in the laboratory development environments. The most important test parameter was relative accuracy, a quantitative measure of agreement with the results of measurements performed with EPA reference methods. If a monitor cannot detect and accurately measure metals in real flue gas environments, other frequently touted performance characteristics such as in situ measurement capability, ruggedness, and portability, do not matter. The Method Detection Limit (MDL) is equally important, however. The MDL is defined by EPA as, "the minimum concentration of a substance that can be measured and reported with $99 \%$ confidence that the analyte concentration is greater than zero and is determined from analysis of a sample in a given matrix type containing the analyte." (Reference 1). The MDLs are important because 1) analytes cannot be detected with high confidence at levels less than the MDL and 2) quantitative measurements of amounts or concentrations of analytes can normally be performed with acceptable precision and accuracy at levels equal to or greater than 10 times the MDL. This level is referred to in EPA SW-846 as the Estimated Quantitation Limit (EQL).

The principal application of a multi-metal CEM is to perform quantitative measurements of emissions at levels approximately equal to the emission standard. Since quantitative measurements are only possible at levels of 10 times the MDL or higher, the target MDL for 
such an instrument is approximately one-tenth of the MACT (maximum achievable control technology) standard (Reference 2,3). The target MDLs for the MACT rule metals range from 2 $\mu \mathrm{g} / \mathrm{dscm}$ to $5 \mu \mathrm{g} / \mathrm{dscm}$.

In April 1996, DOE and EPA tested three prototype multi-metals CEMs at the Rotary Kiln Incinerator Simulator (RKIS) facility at the EPA National Risk Management Research Laboratory, Research Triangle Park, North Carolina. The participating test CEMs, developer organizations, and sponsors are identified in Table 1.

The three CEMs were tested side-by-side, under carefully controlled conditions, with low, medium, and high concentrations of seven toxic metals addressed by the proposed MACT ruleantimony, arsenic, beryllium, cadmium, chromium, lead, and mercury.

Table 1. Test CEMs, developer organizations, and sponsors.

\begin{tabular}{|c|c|c|}
\hline $\begin{array}{l}\text { CEM } \\
\text { METHOD }\end{array}$ & $\begin{array}{l}\text { DEVELOPER } \\
\text { ORGANIZATION }\end{array}$ & $\begin{array}{l}\text { SPONSOR } \\
\text { ORGANIZATION }\end{array}$ \\
\hline $\begin{array}{l}\text { Navy/TJA } \\
\text { Inductively Coupled } \\
\text { Plasma - Atomic } \\
\text { Emission Spectrometry } \\
\text { (ICP-AES) }\end{array}$ & $\begin{array}{l}\text { U. S. Department of Defense } \\
\text { Naval Air Warfare Center } \\
\text { and the Thermo Jarrell Ash } \\
\text { (TJA) Corporation }\end{array}$ & $\begin{array}{l}\text { U. S. Army Demilitarization } \\
\text { Technology Office }\end{array}$ \\
\hline $\begin{array}{l}\text { DIAL } \\
\text { Laser Induced } \\
\text { Breakdown } \\
\text { Spectrometry (LIBS) }\end{array}$ & $\begin{array}{l}\text { Diagnostic Instrumentation } \\
\text { and Analytical Laboratory } \\
\text { (DIAL), Mississippi State } \\
\text { University }\end{array}$ & $\begin{array}{l}\text { U. S. Department of Energy, } \\
\text { Office of Environmental } \\
\text { Management Characterization, } \\
\text { Monitoring, and Sensor } \\
\text { Technology Crosscutting } \\
\text { Program }\end{array}$ \\
\hline $\begin{array}{l}\text { SNL } \\
\text { Laser Induced } \\
\text { Breakdown } \\
\text { Spectrometry (LIBS) }\end{array}$ & $\begin{array}{l}\text { Sandia National Laboratories } \\
\text { (SNL), Livermore, } \\
\text { California }\end{array}$ & $\begin{array}{l}\text { DOE EM CMST-CP and the } \\
\text { U.S. Army Demilitarization } \\
\text { Technology Office }\end{array}$ \\
\hline
\end{tabular}

The three CEMs tested represent two different multi-metal CEM techniques currently under development. Both techniques subject portions of the flue gas (and entrained particles) to high energy, high temperature excitation. The LIBS techniques use a focused laser pulse; the ICP technique passes a portion of the flue gas through the center of an inductively coupled plasma. Both excitation mechanisms atomize and ionize the flue gas constituents and stimulate the emission of light from the resulting atoms and ions. The wavelengths and intensities of the emitted light are characteristic of the emitting species, so atomic emission spectrometry (AES) is employed in both cases to determine the kinds and amounts of metals present in the flue gas. 


\section{Test Objectives and Procedures}

The primary objective of the test was to determine the relative accuracy of each instrument at different metal concentrations. The relative accuracy was calculated by comparing CEM measurements to concentrations measured using the EPA reference method (Reference 4). The tests were repeated at least three times for each of the three different metal concentrations.

The metals were introduced into the flue gas by atomizing an aqueous solution of test metals directly into the flame of the rotary kiln secondary combustion chamber. To better simulate incinerator conditions, fly ash particles were also injected into the flue gas just downstream of the rotary kiln.

\section{Test Results}

\section{Relative Accuracy}

Table 2 summarizes the relative accuracy test results and other performance characteristics of the multi-metal CEMs.

\section{Estimated Method Detection Limits}

This test also provided information concerning the estimated MDLs for each CEM.

- To be useful as a multi-metal CEM for monitoring MACT rule compliance, the DIAL and SNL LIBS systems need improved detection capability for all the MACT metals save beryllium.

- The Navy/TJA ICP-AES system had better estimated MDLs than the DIAL and SNL LIBS systems, needing only to improve the MDL for mercury, antimony, and arsenic to achieve target MDLs.

- Although MDLs were not specifically determined during this test, the test results indicate that MDLs for this field work were larger than those the developers had estimated from their laboratory data. The MDLs estimated from laboratory results need to be updated based on the results from this test. 
Table 2. Summary of multi-metal CEM relative accuracy test results and other performance characteristics.

\begin{tabular}{|c|c|c|c|c|c|c|}
\hline \multirow[t]{2}{*}{ CEM } & \multicolumn{3}{|c|}{$\begin{array}{c}\text { AVERAGE RELATIVE } \\
\text { ACCURACY } \\
\text { FOR SOME OR ALL METALS } \\
\text { AT CONCENTRATIONS: }\end{array}$} & \multirow[t]{2}{*}{ QA/QC } & \multirow[t]{2}{*}{$\begin{array}{l}\text { SAMPLING } \\
\text { DUTY CYCLE } \\
\text { (SDC) }\end{array}$} & \multirow[t]{2}{*}{$\begin{array}{l}\text { DATA REPORTING } \\
\text { FREQUENCY }\end{array}$} \\
\hline & $\begin{array}{c}\mathrm{HIGH} \\
\sim 600 \mu \mathrm{g} / \mathrm{m}^{3} \\
\end{array}$ & $\begin{array}{l}\text { MEDIUM } \\
\sim 60 \mu \mathrm{g} / \mathrm{m}^{3} \\
\end{array}$ & $\begin{array}{c}\text { LOW } \\
\sim 15 \mu \mathrm{g} / \mathrm{m}^{3} \\
\end{array}$ & & & \\
\hline $\begin{array}{l}\text { Navy/TJA } \\
\text { ICP-AES }\end{array}$ & $\begin{array}{c}67 \% \\
\text { for all } 7 \\
\text { metals }\end{array}$ & $\begin{array}{c}72 \% \\
\text { for all } 7 \\
\text { metals }\end{array}$ & $\begin{array}{l}74 \% \\
\text { for all } 7 \\
\text { metals }\end{array}$ & $\begin{array}{l}\text { Daily calibration and zero } \\
\text { check. None failed during } \\
\text { test week. Re-profiled } \\
\text { spectrometer every } 30 \\
\text { minutes. }\end{array}$ & $\begin{array}{l}\text { One } 6 \text { to } 7 \text { second sample } \\
\text { taken every } 3.5 \text { minutes. } \\
\text { SDC }=\sim 3 \%\end{array}$ & Every 3.5 minutes \\
\hline $\begin{array}{l}\text { DIAL } \\
\text { LIBS }\end{array}$ & $\begin{array}{l}65 \% \\
\text { for } 4 \text { of } 7 \\
\text { metals }\end{array}$ & $\begin{array}{c}55 \% \\
\text { for } 3 \text { of } 7 \\
\text { metals }\end{array}$ & $\begin{array}{l}152 \% \\
\text { for } 2 \text { of } 7 \\
\text { metals }\end{array}$ & $\begin{array}{l}\text { Daily zero check - record } \\
\text { spectra with no metal } \\
\text { injection. Adjusted } \\
\text { background on Day } 5 \text { of } \\
\text { testing based on zero check. }\end{array}$ & $\begin{array}{l}1010 \text {-nanosecond laser } \\
\text { pulses (samples) per second, } \\
\text { averaged over } 60 \text { to } 260 \\
\text { samples ( } 6 \text { to } 26 \text { seconds) } \\
\text { SDC }=10^{-7} \\
\text { Also, } 3 \text { spectrometer grating } \\
\text { positions were employed - } \\
\text { changed at approximately } 15 \\
\text { minute intervals. }\end{array}$ & $\begin{array}{l}6 \text { seconds to } 26 \text { seconds } \\
\text { depending on averaging } \\
\text { period. } \\
\text { (plus interruption of } \\
\text { approximately } 2 \text { to } 5 \\
\text { minutes when grating } \\
\text { position was changed) }\end{array}$ \\
\hline $\begin{array}{l}\text { SNL } \\
\text { LIBS }\end{array}$ & $\begin{array}{l}169 \% \\
\text { for } 4 \text { of } 7 \\
\text { metals }\end{array}$ & $\begin{array}{l}241 \% \\
\text { for } 2 \text { of } 7 \\
\text { metals }\end{array}$ & $\begin{array}{l}91 \% \\
\text { for } 1 \text { of } 7 \\
\text { metals }\end{array}$ & $\begin{array}{l}\text { Single-time calibration } \\
\text { check using portable } \\
\text { aerosol generator outside } \\
\text { the flue gas duct. } \\
\text { Wavelength calibration } \\
\text { using mercury discharge } \\
\text { lamp several times daily. } \\
\text { Zero check once early in } \\
\text { test week. }\end{array}$ & $\begin{array}{l}2.510 \text {-nanosecond laser } \\
\text { pulses (samples) per second, } \\
\text { averaged over } 25 \text { to } 100 \\
\text { samples ( } 10 \text { to } 40 \text { seconds) } \\
\text { SDC }=0.2510^{-7} \\
\text { Also, } 3 \text { spectrometer grating } \\
\text { positions were employed - } \\
\text { changed at approximately } 10 \\
\text { to } 40 \text { second intervals. }\end{array}$ & $\begin{array}{l}\text { Typically every } 10 \\
\text { seconds or } 40 \text { seconds } \\
\text { (plus interruption of } \\
\text { approximately } 10 \text { seconds } \\
\text { when the grating position } \\
\text { was changed) }\end{array}$ \\
\hline
\end{tabular}




\section{Sampling Duty Cycle and Data Reporting Frequency}

CEM sampling duty cycle and data reporting frequency are important because CEMs must sample continuously or nearly continuously and they must report their measurement results on a sufficiently short time scale to support timely waste feed cut-off or other emissions control actions when a significant emissions problem occurs. Information on these parameters is reported in columns 6 and 7 of Table 2.

\section{Data Availability}

As configured for this test, i.e., with only one spectrometer each, neither the DIAL nor the SNL CEM could simultaneously observe the desired spectral lines for all seven of the target metals ${ }^{1}$. To measure the seven target metals, each of these CEMs used three different grating angle settings. As a result, for any given metal, the DIAL and SNL systems typically recorded data for only about $30 \%$ of each RM measurement period. Depending on how the instruments were operated during particular RM measurement periods, this fraction varied from as low as $10 \%$ to as high as $90 \%$.

The Navy/TJA CEM, on the other hand, was able to simultaneously observe the desired spectral lines for all seven of the target metals. Grating angle changes were not required. The Navy/TJA system recorded data for all the target metals throughout each of the RM measurement periods. The Navy/TJA results were more representative than those of the LIBS instruments because they uniformly covered each RM measurement period for all the metals, whereas, for various metals, the LIBS systems typically covered only the beginning, middle, or end of the RM measurement period.

\section{Data Variability}

When plotted versus time, the thousands of individual data points generated by the CEMs during this test exhibited considerable variability about the average concentration levels. The relative standard deviations were as large as $50 \%$, even for measurements where each of the reported values was already the average of multiple measurements over periods as long as 90 seconds. Under the carefully controlled conditions of this test, such variability was larger than expected. This variability may reflect real variations in the emissions levels, or it may reflect inadequacies in the measurement methods or equipment. This question should be addressed in future tests. The CEM sampling duty cycles and data reporting frequencies should also be compared to the characteristic times of metals concentration changes in the flue gas.

\section{Flue Gas vs. Laboratory Measurements}

Because the simulated flue gas used in this test included the major elemental constituents of fly ash and carbon- and nitrogen-containing species, the atomic emission spectra were more complex than those ordinarily observed under laboratory conditions. As a consequence, all the

1 The single spectrometer configuration employed in the DIAL and SNL LIBS instruments is useful for proof of concept experiments but does not support simultaneous measurement of all the MACT metals. Multi-metal LIBS CEMs may ultimately employ more than one spectrometer of the type used here, or they may employ a different type, allowing simultaneous measurement of all the MACT metals. 
CEM developer teams observed spectral interferences that made the flue gas measurements more challenging than measurements conducted under laboratory conditions.

\section{Conclusions}

This test provided valuable data to quantify the performance of new multi-metal CEMs. The test also promoted technology development by providing a well-defined performance goal for each of the developers, i.e., to measure the concentration of metals at challenging levels in a realistic flue gas environment. The test environment was somewhat competitive, inspiring each developer to perform as well as possible. Simply working next to each other in a laboratory for two weeks stimulated valuable dialogue. Most of these investigators had never been in each other's laboratories, much less compared hardware or shared or discussed technical ideas or practices. It would be desirable to encourage this type of informal collaboration among developers in the future.

The Navy/TJA ICP-AES system clearly out-performed the other instruments, both in the number of metals measured, and in the relative accuracy of those measurements. The Navy/TJA system provided quantitative CEM results for the seven toxic metals at all three test concentration levels. The Navy/TJA CEM performance was also superior to that reported for the Metorex XRF-based CEM tested at the EPA IRF in August 1995 (Reference 5). Even so, however, the Navy/TJA system did not achieve RA values of $20 \%$ or less, which is required to satisfy the EPA draft performance specification for multi-metal CEMs (Reference 6).

The DIAL and SNL LIBS systems provided quantitative CEM results for only four toxic metals at the high concentration level, three and two toxic metals, respectively, at the medium concentration level, and only two and one, respectively, at the low concentration level. The relative accuracy of the DIAL LIBS system was marginally better than that of the SNL LIBS system, but both instruments need substantial performance improvement.

Of the three CEMs tested, only the Navy/TJA system provided quantitative results for mercury. The relative accuracies achieved for mercury were not superior, however, to those achieved by the EcoChem Hg-Mat 2 mercury CEM evaluated in the August 1995 performance tests at the EPA IRF (Reference 5). The Navy/TJA system is a multi-metals CEM, whereas the EcoChem device measures only mercury.

The DIAL and SNL LIBS systems need to dramatically improve detection of lead, mercury, arsenic, and antimony to be useful as a multi-metal CEM for hazardous waste treatment facilities. The target method detection limit for these metals range from 1 to $5 \mu \mathrm{g} / \mathrm{dscm}$. The Navy/TJA system only needs to improve detection for mercury, antimony, and arsenic to meet target method detection limits.

The individual data points generated by the CEMs during this test exhibited considerable variability about the average concentration levels. This variability may reflect real variations in the emissions levels, or it may reflect inadequacies in the measurement methods or equipment. This question should be addressed in future tests. The CEM sampling duty cycles and data reporting frequencies should also be compared to the characteristic times of metals concentration changes in the flue gas. 
Overall, the test results showed the prototype nature of the test CEMs and the need for further development before multi-metal CEMs can succeed in commercial service as envisioned by regulators and citizens. None of the CEMs tested consistently achieved RA values of $20 \%$ or less as required by the draft EPA performance specification for multi-metal CEMs (Reference 6). Instrument size reduction and automation will also likely need additional attention to realize this vision.

\section{Future Work}

Another quantitative performance test should be scheduled as soon as one or more instruments have shown sufficient technical progress to warrant validation. After the instruments are shown to be capable or more nearly capable of satisfying the draft EPA performance specification for multi-metal CEMs, they will likely need to be engineered into smaller, more rugged packages. In addition, to satisfy the requirements of commercial CEM applications, these systems will likely have to provide more user-friendly operational and data analysis capability. 


\section{SECTION 1 INTRODUCTION}

This report summarizes the results of side-by-side testing of CEMs having the potential ability to provide real-time knowledge of the concentrations of toxic elements in flue gas emissions from hazardous waste treatment and combustion devices. This ability can provide assurance that the waste treatment or combustion process is operating properly, i.e., within regulatory compliance standards or indicate changes of operating conditions needed to achieve or maintain operation within compliance. The EPA Office of Solid Waste and the Office of Air Quality Planning and Standards desire such continuous emissions monitoring capability as a means of addressing and allaying the public safety concerns. CEMs can show and provide documentation that good, safe, and clean, i.e., regulatory compliant waste combustion practice is achieved and continuously maintained.

The immediate needs of the waste thermal treatment community include real-time monitoring of organic compounds and metals in stack emissions. Current monitoring procedures involve sample collection over an extended period of time and then sample analysis at a later time. Realtime monitoring, on the other hand, must provide virtually immediate quantitative determination of hazardous emissions. Several developer organizations have produced multi-metal CEMs for real-time monitoring of hazardous trace metal emissions. This project tested the performance of three such CEMs. The tests consisted of comparing the CEM results with results from simultaneous flue gas sampling using conventional EPA reference method sampling trains and analytical procedures.

\subsection{Background}

The impetus for developing CEMs for measuring the concentrations of trace organic compounds in flue gas emissions has existed since the promulgation of the initial hazardous waste incinerator performance standards in 1980 (Reference 7). One requirement of these standards was that an incinerator demonstrate the capability of achieving $99.99 \%$ destruction and removal efficiency (DRE) of the principal organic hazardous constituents (POHCs) in the hazardous waste incinerated. At the time this standard was promulgated, the desire was to require a continuous measurement of POHC DRE. However, flue gas POHC concentrations corresponding to the emission rates associated with $99.99 \% \mathrm{DRE}$ are in the $1 \mu \mathrm{g} / \mathrm{dscm}$ range, or on the order of 0.2 parts per billion by volume. The most sensitive CEM approaches for measuring organic compound concentrations at the time had detection limits in the parts per million range, not nearly sensitive enough. As a consequence, compliance with the $99.99 \%$ DRE standard is ordinarily shown via a trial burn. Continuous compliance with the standard is then assured by constraining incinerator operation to conditions consistent with those tested during the trial burn. This approach, though workable, is clearly less attractive than using CEMs to show continuous compliance.

Similarly, the impetus for developing CEMs for trace metals in flue gas emissions arose with the promulgation of regulations governing the destruction of hazardous wastes in boilers and industrial furnaces in 1991 (Reference 8). These rules, extended to hazardous waste incinerators during permit revisions and reauthorizations under the omnibus authority granted permit writers within the Resource Recovery and Conservation Act (RCRA), limit the emissions of several trace metals from waste combustion devices. Again, at the time these rules were promulgated, 
the ultimate desire was to require continuous monitoring of the emissions of the regulated metals. However, at the time these rules were promulgated, no metal CEMs existed. So again, compliance with the standard had to be shown during the trial burn. Subsequent continuous compliance with the emission rate standards is ensured by limiting the feed rate of each regulated metal to the waste combustor and again constraining its operation to conditions within the range of those previously tested during the trial burn. The metal feed rate limitation, in turn, requires the operator to have detailed knowledge of the metal concentrations in wastes being fed to the waste combustor. In practice this requires extensive waste feed characterization to determine the quantities of regulated metals in the waste.

Given these incentives, government agencies have invested considerable funding to develop CEM approaches that are sufficiently sensitive to detect and quantify low concentrations of hazardous constituents in flue gas from waste treatment facilities. For trace metals, a number of CEM approaches were discussed at the second American Society of Mechanical Engineers (ASME)/EPA joint workshop on metals emissions from hazardous waste combustion systems (Reference 9) in 1993. These approaches were considered sufficiently promising that the A.SME Research Committee on Industrial and Municipal Wastes formed a subcommittee to specifically track the progress in metal CEM development.

More recently, EPA announced a proposed rule under the title, "Revised Standards for Hazardous Waste Combustors" (Reference 2). The proposed rule would promulgate revised emission standards reflecting the performance of Maximum Achievable Control Technologies (MACT) as specified by the Clean Air Act and would clearly establish CEMs as preferred ${ }^{1}$ for compliance monitoring. The proposed rule is often referred to as the proposed MACT rule and the proposed standards as the proposed MACT standards. In May 1997, EPA announced proposed revised technical standards for the same topic (Reference 3). Among other things, the latter proposed action would set lower limits for $\mathrm{Hg}$, semi-volatile metals (SVM), and low volatile metals (LVM) emitted from hazardous waste incinerators, and would remove antimony from specific consideration as one of the LVMs.

Under the proposed MACT rule, the application of continuous emissions monitoring for $\mathrm{HCl}$, $\mathrm{Cl}_{2}, \mathrm{Hg}$, SVMs, and LVMs can replace feedstream analysis for those constituents and can eliminate consideration of those waste constituents during required comprehensive and confirmatory tests. This is especially important in the case of mixed waste, because of ALARA concerns, i.e., a commitment to keep radioactive exposure as low as reasonably achievable, and because both the feedstream analysis and the testing, the latter comparable to the RCRA trial burn, are high cost activities. Only $\mathrm{Hg}$ and particulate matter CEMs would be mandated by the proposed MACT rule.

1 The top tier of the compliance monitoring hierarchy is the use of a continuous emissions monitor for that hazardous air pollutant (HAP) or standard. In the absence of a CEM, the second tier is the use of a CEM for a surrogate of that HAP or standard and, when necessary, setting some operating limits to account for the limitations of using surrogates. Lacking a CEM for either, EPA sets appropriate feedstream and operating parameter limits to ensure compliance and requires periodic testing of the source. 
CEMs can provide several benefits for waste treatment. By providing more complete and more timely information on emission, they can enable better control for safe and compliant operation of treatment facilities, provide documentation of such operation, and help provide greater assurance of the quality of the final waste forms. These benefits address important public concerns regarding the siting and operation of incinerators or other thermal treatment equipment. Consequently, quality CEMs could help reopen the door to public acceptance of such facilities.

Multi-metal CEMs that satisfy the performance specification in the proposed MACT rule (Reference 6) are not yet commercially available. Nevertheless, the need for such CEMs in mixed waste treatment is clear. Development and validation of at least one multi-metals CEM was recommended in the draft CEM Technology Development Strategy report (Reference 10), prepared under the auspices of the DOE EM MWFA and CMST-CP. The need is driven by ALARA concerns, public assurance requirements, a strong budgetary incentive to avoid otherwise required feedstream analysis costs for metals through the application of multi-metals CEMs, and potential future regulatory requirements for CEMs.

As noted above, the development of CEM techniques for the detection and quantification of trace metals has advanced to the point where several prototype instruments have been fabricated and bench tested. The primary objective of this project was to test available prototype multi-metal CEMs in a field environment and determine their Relative Accuracy as defined in the draft EPA PS for multi-metals CEMs. Estimation of the detection limits and determination of the measurement response time for the CEMs were secondary objectives.

The DOE and the EPA jointly sponsored the testing. The DOE sponsorship was through the Characterization, Monitoring, and Sensor Technology Crosscutting Program (CMST-CP) and the Mixed Waste Focus Area (MWFA), both of the Office of Science and Technology, Office of Environmental Management. The EPA sponsorship involved the National Risk Management Research Laboratory, Air Pollution Prevention and Control Division, Research Triangle Park (RTP), North Carolina, and the National Exposure Research Laboratory, Air Measurements Division, RTP, and Characterization Research Division, Las Vegas, Nevada.

The testing described in this report builds upon previous DOE/EPA testing of metal and organic compound CEMs conducted in August 1995 at the EPA Incineration Research Facility (IRF) in Jefferson, Arkansas (Reference 5). The tests described here owe much to the planning and lessons learned from the IRF test program.

Approximately 15 organizations within and outside DOE were invited to provide multi-metal CEM instruments and to participate in the test program. Representatives from four of these organizations attended a kickoff meeting held at the EPA RTP facility on March 15, 1996. After this meeting, teams from three of the four organizations committed to participate. These three teams and their associated technologies are listed in Table 1-1. 
Table 1-1. Multi-metal CEMs test participants.

\begin{tabular}{|c|c|c|c|}
\hline CEM Name & Principle of Operation & $\begin{array}{l}\text { Developer Team } \\
\text { Members } \\
\text { (leader listed first) }\end{array}$ & Affiliation \\
\hline DIAL LIBS & $\begin{array}{l}\text { Laser Induced Breakdown } \\
\text { Spectrometry (LIBS) } \\
\text { The wavelengths and intensities } \\
\text { of light emitted by atoms excited } \\
\text { by laser pulses depend on the } \\
\text { kinds and numbers of atoms } \\
\text { present. }\end{array}$ & $\begin{array}{l}\text { Jagdish Singh } \\
\text { Hansheng Zhang } \\
\text { Fang-Yu Yueh } \\
\text { Bob Cook }\end{array}$ & $\begin{array}{l}\text { Diagnostic } \\
\text { Instrumentation and } \\
\text { Analysis Laboratory } \\
\text { (DIAL) at Mississippi } \\
\text { State University, } \\
\text { Starkville, Mississippi }\end{array}$ \\
\hline $\begin{array}{l}\text { Navy/TJA } \\
\text { ICP-AES }\end{array}$ & $\begin{array}{l}\text { Inductively Coupled Plasma } \\
\text { Atomic Emission Spectrometry } \\
\text { (ICP-AES) } \\
\text { The wavelengths and intensities } \\
\text { of light emitted by atoms excited } \\
\text { when sample gas is passed } \\
\text { through an ICP depend on the } \\
\text { kinds and numbers of atoms } \\
\text { present. }\end{array}$ & $\begin{array}{l}\text { Mike Seltzer } \\
\text { Gerhard Meyer }\end{array}$ & $\begin{array}{l}\text { Naval Air Warfare } \\
\text { Center, China Lake, } \\
\text { California } \\
\text { Thermo Jarrell Ash } \\
\text { Corporation }\end{array}$ \\
\hline SNL LIBS & $\begin{array}{l}\text { Laser Induced Breakdown } \\
\text { Spectrometry (LIBS) } \\
\text { The wavelengths and intensities } \\
\text { of light emitted by atoms excited } \\
\text { by laser pulses depend on the } \\
\text { kinds and numbers of atoms } \\
\text { present. }\end{array}$ & $\begin{array}{l}\text { Bill Flower } \\
\text { Howard Johnson } \\
\text { Ken Hencken }\end{array}$ & $\begin{array}{l}\text { Sandia National } \\
\text { Laboratories, } \\
\text { Livermore, California }\end{array}$ \\
\hline
\end{tabular}

In a further attempt to solicit candidate CEMs for testing, and to identify companies interested in the commercialization of the test systems, an announcement of opportunity was published in the April 2, 1996 Commerce Business Daily.

Each participating CEM developer team was required supply a complete CEM system for testing, including sample lines, equipment stands, instrument calibration materials and equipment, and system operators. In addition, each developer team supplied the program coordinators with:

- a daily report containing all CEM data results, results of zero and span checks, and copies of all operator log book pages;

- a developer team test report containing:

- a technical description of the instrument principles of operation;

- a description of the instrument operating and calibration procedures;

- a tabulation of measured flue gas analyte concentrations averaged over each RMI test period; and

- final zero drift and calibration drift results for each test day. 
Each developer team was offered the opportunity to review the draft of this test report and, based on that review, to submit comments for inclusion, without modification, in the final report.

\subsection{Test Objectives}

The overall objective of the project was to test the performance of prototype CEMs for measuring the concentrations of multiple trace metals in waste combustion flue gas. The testing addressed three measures of performance related to the relative accuracy test audit (RATA) of a CEM as described in 40 CFR 60 Appendix F (Reference 11). These measures are:

- Relative accuracy (RA): the absolute mean difference between the metals concentrations determined by the CEM and the value determined by the RM, plus the 2.5 percent error confidence coefficient of a series of tests, divided by the mean of the RM tests;

- Response time: the time interval between the start of a step change in the concentration of the monitored gas stream and the time when the CEM output reaches 95 percent of the final value; and

- Method detection limits: the metal concentrations for which the method has a signal-to-noise ratio of $3: 1$. Normally, measurements are considered quantitative at 10 times the method detection limit.

The primary project objective was to determine RA values for the metals measured by each CEM tested. Secondary objectives included obtaining measures of response time and estimates of the metals limits of detection for each CEM tested.

Determination of the RA of a metal measurement performed by a CEM requires comparing the monitored analyte concentration reported by the CEM to the concentration determined by the $\mathrm{RM}$ for that analyte. In this test, the RM for trace metals (including mercury) was draft SW-846 Method 0060, Determination of Metals in Stack Emissions (Reference 4).

\subsection{Outline of This Report}

The performance testing and its results are described in this report. Section 2 describes the test facilities, including the EPA Rotary Kiln Incinerator Simulator (RKIS), and the means employed for providing test levels of the analyte metals by both solution injection and fly ash injection, the test program design, the sampling and analysis procedures, and the operating conditions. Section 3 , the core of the report, presents and summarizes the RM and CEM results, the RA results, and observations concerning method detection limits, calibration drift, zero drift, and CEM response times. Section 4 presents some conclusions concerning the state-of-the art of multi-metal CEMs, based on the results reported in Section 3.

Additional information is provided in several appendices. Appendix A describes the organization of the test project and the responsibilities of the participants. Appendix B provides project schedule information. Appendix $C$ provides a quality assurance summary, i.e., how the testing adhered to the Quality Assurance Project Plan. Appendices D, E, and F contain the CEM developer team final reports prepared by the DIAL, Navy/TJA, and SNL teams, respectively. 
Appendix G contains CEM developer team comments based on their participation in the performance testing and their review of the draft version of this report. Appendix $\mathrm{H}$ provides a copy of the official EPA proposed performance specification for multi-metals CEMs. Finally, Appendices I, J, and $\mathrm{K}$ provide copies of the daily logbook pages and CEM data delivered by the CEM developer teams immediately following conclusion of the test, and Appendix L provides a compilation of particle, count, size, and velocity data recorded during the test.

Appendices D through H (Appendix Volume 1) and I through L (Appendix Volume 2) will be distributed separately on request. 


\section{SECTION 2 TEST FACILITIES, PROCEDURES, AND CONDITIONS}

All tests were conducted using a flue gas stream produced by the Rotary Kiln Incinerator Simulator (RKIS) at the U. S. EPA Environmental Research Center, Research Triangle Park, North Carolina. Section 2.1 describes the RKIS and access for flue gas sampling and metals CEM testing. Section 2.2 describes how the target analytes were introduced to produce test flue gas streams with the desired metal concentrations. Section 2.3 describes the test procedure. Section 2.4 describes the Reference Method sampling and analysis procedures. Section 2.5 addresses the procedures employed by the CEM developer teams, and Section 2.6 describes the combustion gas CEM measurements and the CEM test conditions.

\subsection{Rotary Kiln Incinerator Simulator}

A schematic diagram of the RKIS, indicating the locations of key process condition measurement points and the locations of the RM sampling point and test CEMs, is provided in Figure 2-1.

The RKIS consists of a primary combustion chamber, a transition section, and a fired afterburner in the secondary combustion chamber (SCC). Both the kiln and SCC are fitted with 73-kW $(0.25-\mathrm{MMBtu} / \mathrm{h})$ auxiliary fuel burners. Natural gas is the primary fuel, although liquid waste or fuel oil can also be fired. Typical firing rates are 29 to $88 \mathrm{~kW}(0.1$ to $0.3 \mathrm{MMBtu} / \mathrm{h})$ to each of the kiln and the SCC. A more complete listing of the design characteristics of the RKIS is provided in Table 2-1.

For all tests, both the kiln and the SCC were fired with natural gas to achieve typical incineration conditions. No waste or simulated waste was fed to the kiln.

Combustion flue gases exiting the SCC were cooled rapidly to approximately $538^{\circ} \mathrm{C}\left(1000^{\circ} \mathrm{F}\right)$ as they passed through the water-jacketed duct section immediately downstream of the SCC.

Further cooling, to approximately $232^{\circ} \mathrm{C}\left(450^{\circ} \mathrm{F}\right)$, was achieved by adding air via an air dilution damper just upstream of the duct that contained the RM sampling and CEM test access ports. The labels RM, DIAL LIBS, SNL LIBS, and Navy/TJA, in the upper portion of Figure 2-1 indicate the locations of those ports and their uses. 


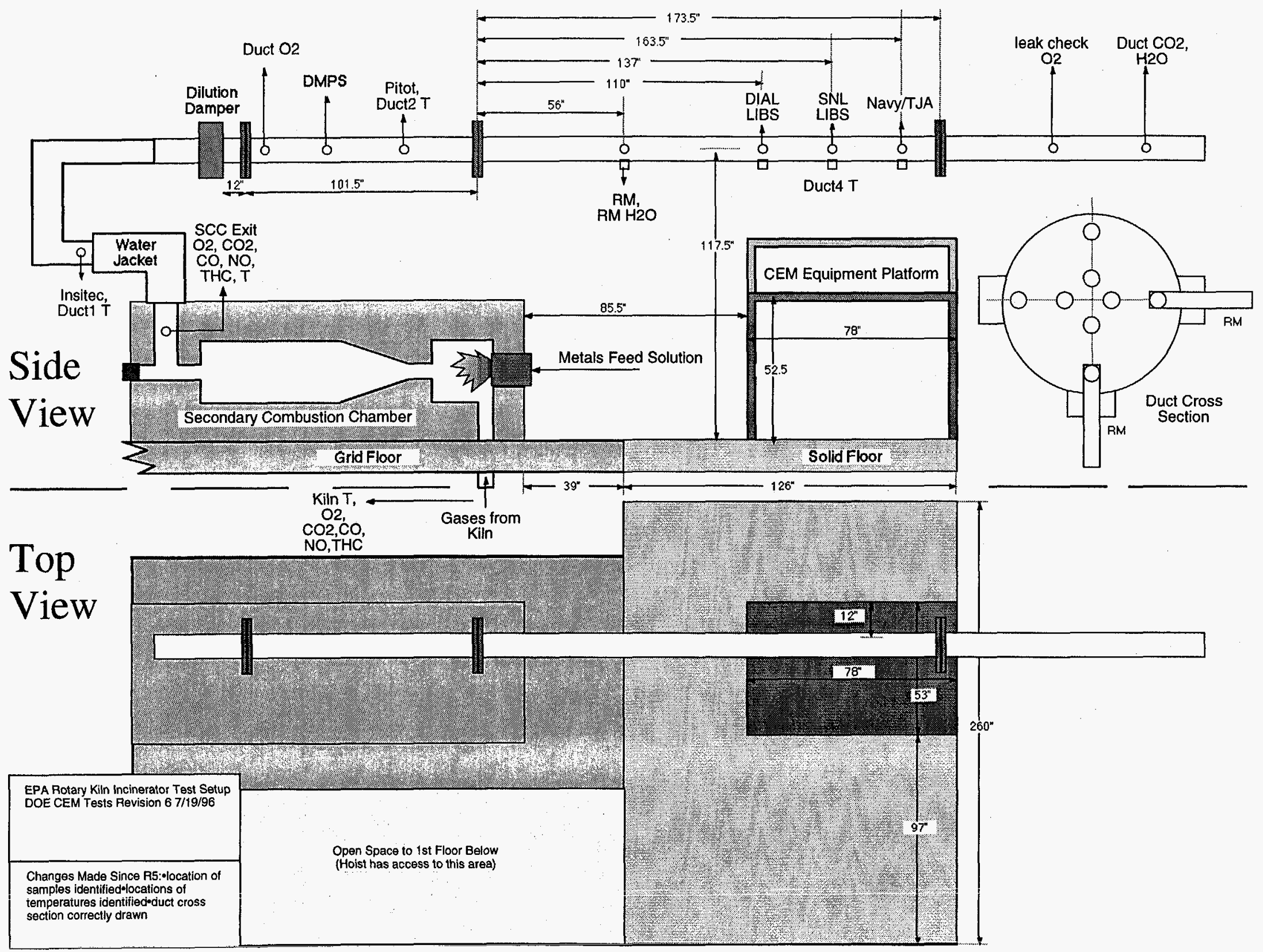

Figure 2-1. Schematic diagram of the RKIS (side view above, top view below). 
Table 2-1. Design characteristics of the RKIS.

\begin{tabular}{|c|c|}
\hline \multicolumn{2}{|r|}{ Characteristics of The Kiln Main Chamber } \\
\hline Length & $1.83 \mathrm{~m}(6-\mathrm{ft})$ \\
\hline Diameter, Outside & $1.22 \mathrm{~m}(4-\mathrm{ft})$ \\
\hline Diameter, Inside & Nominal $0.76 \mathrm{~m}$ (2-ft 6-in) \\
\hline Chamber Volume & $0.28 \mathrm{~m}^{3}\left(9.8-\mathrm{ft}^{3}\right)$ \\
\hline Construction & $0.64 \mathrm{~cm}(0.25$-in) thick cold-rolled steel \\
\hline Refractory & $\begin{array}{l}23 \mathrm{~cm}(9-\text { in) thick high alumina castable refractory at maximum I.D. } \\
\text { point }\end{array}$ \\
\hline Rotation & Counterclockwise, 0.25 to $2 \mathrm{rpm}$ \\
\hline Solids Retention Time & Batch System - Solids remain until physically removed \\
\hline Burner & $\begin{array}{l}\text { Custom burner based on IFRF design rated at } 73 \mathrm{~kW}(0.25 \mathrm{MMBtu} / \mathrm{h}) \\
\text { with liquid feed capability }\end{array}$ \\
\hline Primary Fuel & Natural Gas \\
\hline Feed System: & \\
\hline Liquids & Fuel oil or liquid waste pumped into burner \\
\hline Solids & Manual batch containers fed with ram rod \\
\hline Temperature (max.) & $1,100^{\circ} \mathrm{C}\left(2,000^{\circ} \mathrm{F}\right)$ \\
\hline \multicolumn{2}{|c|}{ Characteristics of the Secondary Combustion Chamber } \\
\hline Length & $3 \mathrm{~m}(10-\mathrm{ft})$ \\
\hline Diameter, Outside & $1.22 \mathrm{~m}(4-\mathrm{ft})$ \\
\hline Diameter, Inside & $0.61 \mathrm{~m}(2-\mathrm{ft})$ \\
\hline \multicolumn{2}{|l|}{ Chamber Volume: } \\
\hline Mixing Chamber & $0.18 \mathrm{~m}^{3}\left(6.3 \mathrm{ft}^{3}\right)$ \\
\hline Plug Flow Chamber & $0.45 \mathrm{~m}^{3}\left(16-\mathrm{ft}^{3}\right)$ \\
\hline Construction & $0.64 \mathrm{~cm}(0.25$-in) thick cold-rolled steel \\
\hline Refractory & $30 \mathrm{~cm}$ (12-in) thick high alumina castable refractory \\
\hline Gas Residence Time & 2 to $5 \mathrm{~s}$ depending on temperature and excess air \\
\hline Burner & Custom burner based on IFRF design rated at $73 \mathrm{~kW}(0.25 \mathrm{MMBtu} / \mathrm{h})$ \\
\hline Primary Fuel & Natural Gas \\
\hline Temperature (max.) & $1,100^{\circ} \mathrm{C}\left(2,000^{\circ} \mathrm{F}\right)$ \\
\hline
\end{tabular}


The duct that contains the RM sampling and CEM test access ports is a straight, $9.9-\mathrm{m}$ (35-ft) long, horizontal run of $20.3-\mathrm{cm}$ (8-inch) diameter, Schedule 10 stainless steel pipe. It runs just below the ceiling of the two-story, high-bay test area that contains the RKIS on the ground level.

The RM sampling and CEM test access ports are configured in four sets of three ports per set. Each set provides access for isokinetic flue gas sampling via a 10.2-cm (4-inch) diameter port opposite a 7.6-cm diameter (3-inch) port and a second 7.6- $\mathrm{cm}$ (3-inch) diameter port at right angles to the other two. The arrangement is illustrated in the duct cross section sketch included in Figure 2-1.

The first set of ports is located 4.3-m down-stream from the air dilution damper. This set was used for Method 0060 sampling, i.e., the RM sampling. The second set of ports is 1.4-m (56inches) down-stream from the first set; two additional sets of ports are located at 0.6-m (24-inch) intervals downstream. As indicated by the labels, DIAL LIBS, SNL LIBS, and Navy/TJA, in the upper portion of Figure 2-1, the test CEMs used the second through fourth sets of ports. Connection to the ports was accomplished with standard NPT couplings.

Flue gas concentrations of $\mathrm{O}_{2}, \mathrm{CO}_{2}, \mathrm{CO}, \mathrm{NO}$, and total hydrocarbon (THC) were measured just downstream of the air dilution damper and again in a section of duct downstream of the fourth set of ports, i.e., downstream of the last of the test CEMs. Comparing the upstream to downstream $\mathrm{O}_{2}$ and $\mathrm{CO}_{2}$ measurement provided verification that neither the tested CEMs nor the RM sampling arrangements caused air in-leakage. The duct at this location is at a negative pressure (draft) of nominally $0.25 \mathrm{kPa}$ (- 1 -in WC). The flow velocities are nominally 1.8 to 2.9 $\mathrm{m} / \mathrm{s}(5.7$ to $9.6-\mathrm{ft} / \mathrm{s})$ and essentially constant across the duct diameter.

The flue gas at the sampling locations had a temperature of approximately $230^{\circ} \mathrm{C}\left(450^{\circ} \mathrm{F}\right)$ and a moisture content between 4.5 and 7.9 percent by volume as measured by EPA Method 0060 . Additional detail concerning the test conditions is provided in Section 2.4.

\subsection{Multi-Metal Introduction}

Two methods were employed for introducing the test analyte metals into the monitored and sampled flue gas: (1) introduction via solution atomization, and (2) injection of fly ash particulates. The two methods are described separately below. During most of the CEM and RM test periods, both methods were employed simultaneously. At other times, to support special test objectives, one method or the other, or neither, was employed.

\subsubsection{Multi-Metal Feed Via Solution Atomization}

In this method of metal introduction, the test analyte metals were introduced into the flue gas by atomizing an aqueous solution of test metals into the afterburner. The solution was atomized at the exit from an annulus inside the afterburner natural gas feed tube, introducing metalcontaining aerosol droplets directly into the burner flame. The droplets evaporated rapidly in the flame, yielding dry particulates containing multiple metals. The apparatus employed for metals injection via solution atomization is shown schematically in Figure 2-2. 


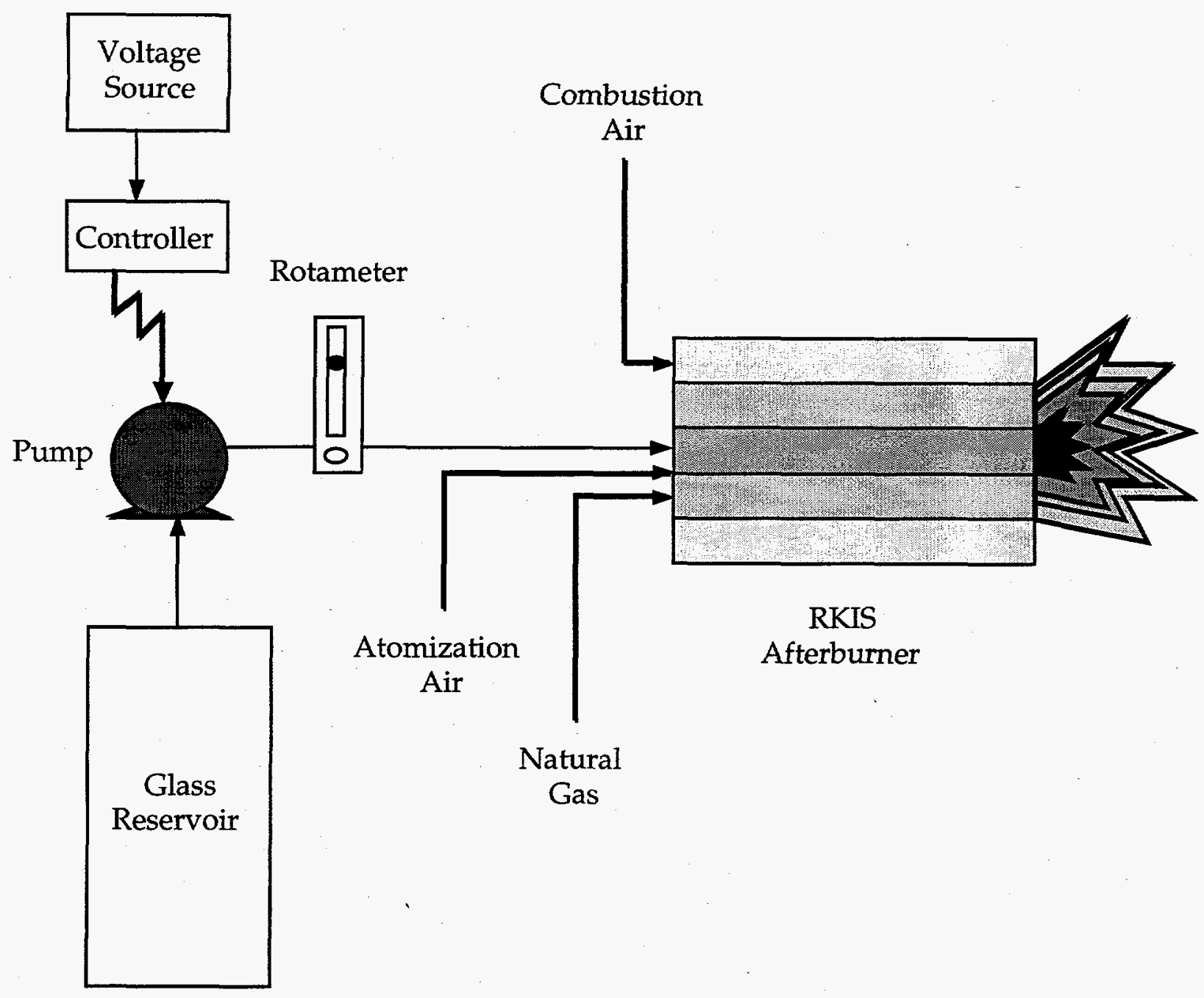

Figure 2-2. Apparatus for metals injection via solution atomization.

The test analyte metals and the three target flue gas concentrations are listed in Table 2-2. All the metals noted, except yttrium, are addressed in the proposed MACT rule for hazardous waste combustors. These standards are expected to be promulgated as 40 CFR Part 63, Subpart EEE, under the authority of both the Clean Air Act and RCRA. (Please see Reference 2, page 17514.) Yttrium was included at a relatively high, fixed concentration in the feed solution so the developers could use this element, which was not expected to be present in significant concentrations in the fly ash, as an internal reference element. Yttrium was expected to be easily measurable by all the CEMs. Thus, it could provide an easily observable check on CEM instrument performance and could be used for instrument calibration based on the ratio of the intensities of analyte and yttrium emission lines. 
Table 2-2. Test metals and target flue gas concentrations.

\begin{tabular}{|c|c|c|c|}
\hline \multirow{2}{*}{ Metal } & \multicolumn{3}{|c|}{ Target Flue Gas Concentration, $\mu \mathrm{g} / \mathrm{dscm}$} \\
\cline { 2 - 4 } & Low & Medium & High \\
\hline $\mathrm{Sb}$ & 15 & 60 & 600 \\
\hline $\mathrm{As}$ & 15 & 60 & 600 \\
\hline $\mathrm{Be}$ & 15 & 60 & 600 \\
\hline $\mathrm{Cd}$ & 15 & 60 & 600 \\
\hline $\mathrm{Cr}$ & 15 & 60 & 600 \\
\hline $\mathrm{Pb}$ & 15 & 60 & 600 \\
\hline $\mathrm{Hg}$ & 25 & 100 & 1000 \\
\hline $\mathrm{Y}$ & 100 & 100 & 100 \\
\hline
\end{tabular}

The composition of the most concentrated metals feed solution is shown in Table 2-3. This most concentrated solution was introduced at a pumping rate of $50 \mathrm{ml} / \mathrm{min}$ for the tests at high metals concentration. The same pumping rate was used for the medium and low concentration tests but the high concentration solution was diluted ten-fold for the former tests and 40 -fold for the latter tests. The yttrium solution concentration was constant for all tests. For the low concentration test, the mercury concentration was one twentieth of the mercury concentration in the high concentration feed solution. Scoping tests performed during the March 26 through April 12 time period confirmed that the high target flue gas metals concentrations could be achieved.

Table 2-3. Metal concentrations in the highest concentration multi-metal feed solution.

\begin{tabular}{|l|l|l|}
\hline Metal & \multicolumn{1}{|c|}{$\begin{array}{c}\text { Metal Concentration } \\
(\mathrm{mg} / \mathrm{l})\end{array}$} & Source Compound \\
\hline Antimony & 204 & $\mathrm{C}_{4} \mathrm{H}_{4} \mathrm{KO}_{7} \mathrm{Sb}$ \\
\hline Arsenic & 204 & $\mathrm{As}_{2} \mathrm{O}_{3}$ \\
\hline Beryllium & 204 & $\mathrm{BeSO}_{4} \cdot 4 \mathrm{H}_{2} \mathrm{O}$ \\
\hline Cadmium & 204 & $\mathrm{Cd}\left(\mathrm{NO}_{3}\right)_{2} \cdot 4 \mathrm{H}_{2} \mathrm{O}$ \\
\hline Chromium & 204 & $\mathrm{Cr}\left(\mathrm{NO}_{3}\right)_{3} \cdot 9 \mathrm{H}_{2} \mathrm{O}$ \\
\hline Lead & 204 & $\mathrm{~Pb}\left(\mathrm{NO}_{3}\right)_{2}$ \\
\hline Mercury & 339 & $\mathrm{Hg}\left(\mathrm{NO}_{3}\right)_{2} \cdot \mathrm{H}_{2} \mathrm{O}$ \\
\hline Yttrium & 34 & $\mathrm{Y}_{2} \mathrm{O}_{3}$ in $4 \% \mathrm{HNO}_{3}$ \\
\hline
\end{tabular}




\subsubsection{Multi-Metal Feed Via Particulate Injection}

To provide a controlled but realistic flue gas environment, a K-Tron mass-controller was employed to inject fly ash particulates directly into the hot flue gas as it exited the kiln. The injected particulates provided a flue gas more like that expected from real waste processing facilities. They provided analyte elements and matrix elements such as iron, aluminum, and silicon, which can potentially interfere with spectrometric determination of the analytes, and they provided surface for the condensation of vapor phase or fume metal as the flue gas cooled after exiting the afterburner area of the SCC.

A schematic representation of the fly ash injection apparatus is shown in Figure 2-3. The feed material was coal fly ash from a utility boiler. This fly ash was thoroughly characterized for both elemental composition and size distribution. The fly ash analyses, for major and trace constituents, are given in Tables 2-4 and 2-5. The particle size distribution data are reported in Table 2-6 and plotted in Figure 2-4.

\footnotetext{
To

SCC
}

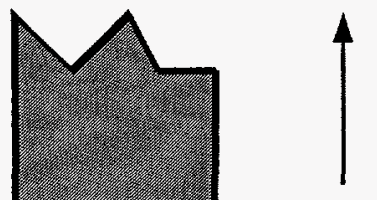

Entrained

Flyash

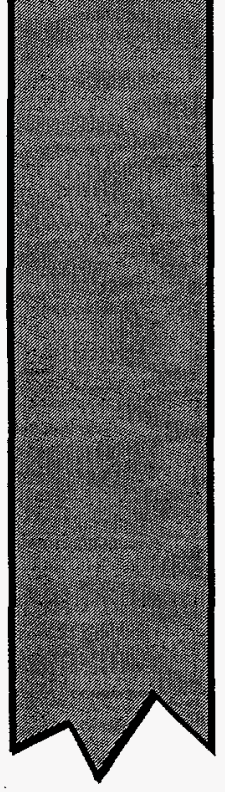

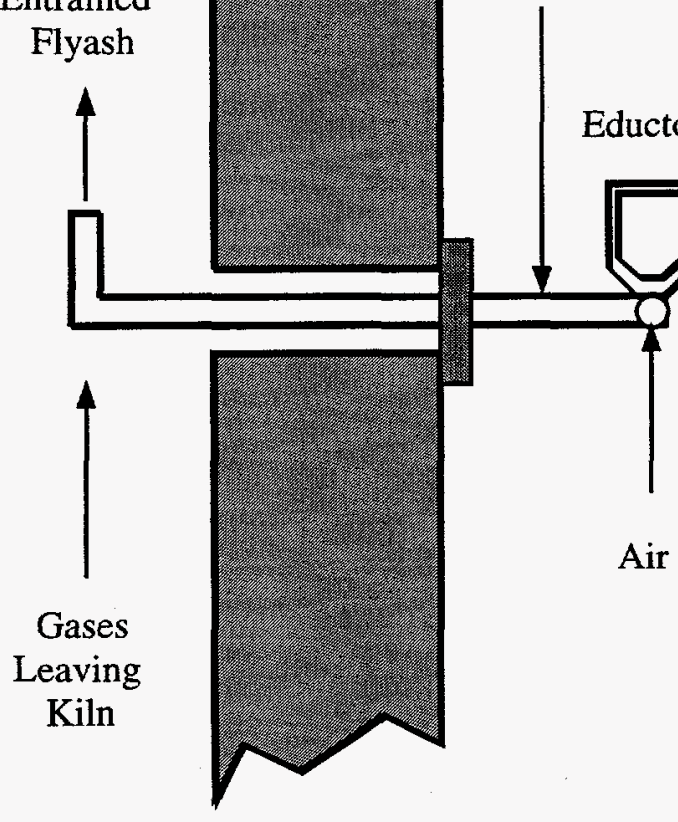

Air
$1 / 4$ " SS tube

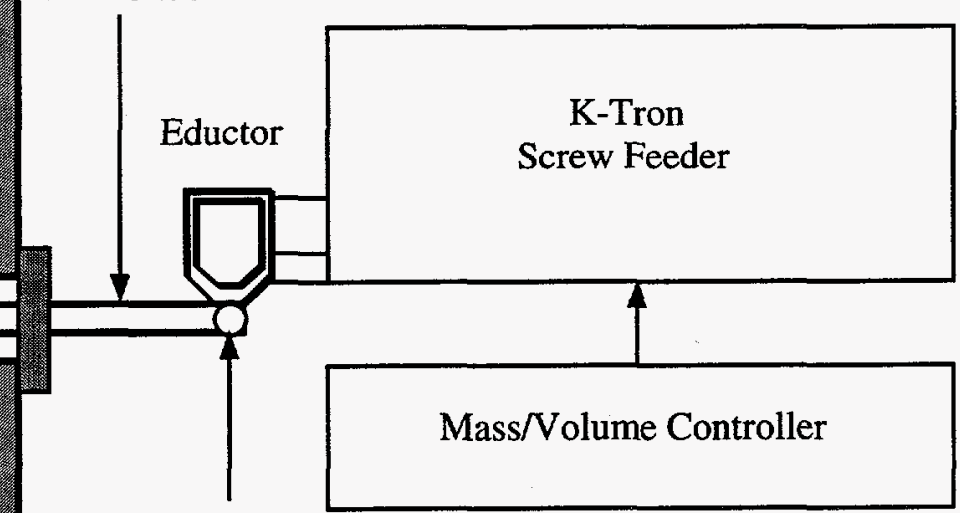

Figure 2-3. Apparatus employed for metals introduction via fly ash injection. 
Table 2-4. Coal fly ash analysis results.

\begin{tabular}{|l|c|}
\hline Analyte & $\begin{array}{c}\text { Analysis Result } \\
\text { (weight \%) }\end{array}$ \\
\hline Silicon dioxide $\left(\mathrm{SiO}_{2}\right)$ & 52.8 \\
\hline Aluminum oxide $\left(\mathrm{Al}_{2} \mathrm{O}_{3}\right)$ & 27.6 \\
\hline Iron oxide $\left(\mathrm{Fe}_{2} \mathrm{O}_{3}\right)$ & 10.2 \\
\hline Calcium oxide $(\mathrm{CaO})$ & 1.5 \\
\hline Magnesium oxide $(\mathrm{MgO})$ & 0.7 \\
\hline Sulfur trioxide $\left(\mathrm{SO}_{3}\right)$ & 0.1 \\
\hline Moisture content & 0.1 \\
\hline Loss on ignition & 2.0 \\
\hline Amount retained on No. 325 sieve & 19.4 \\
\hline Specific gravity & 2.31 \\
\hline
\end{tabular}

Table 2-5. Trace metal concentrations in the injected fly ash.

\begin{tabular}{||l|c|}
\hline Metal & Concentration $(\mathrm{mg} / \mathrm{kg})$ \\
\hline $\mathrm{Sb}$ & 6.90 \\
\hline $\mathrm{As}$ & 101 \\
\hline $\mathrm{Be}$ & 13.6 \\
\hline $\mathrm{Cd}$ & 1.10 \\
\hline $\mathrm{Cr}$ & 83.6 \\
\hline $\mathrm{Pb}$ & 170 \\
\hline $\mathrm{Hg}$ & 0.054 \\
\hline $\mathrm{Ni}$ & 12.6 \\
\hline $\mathrm{Se}$ & 5.25 \\
\hline
\end{tabular}

As shown in Table 2-5, all seven target metals were present in the fly ash. At the fly ash and solution introduction rates employed, the fly ash contribution to the flue gas metals concentrations was highest for $\mathrm{Cr}, 11$ percent of the total $\mathrm{Cr}$ concentration for the high metals concentration case. For the other analyte metals the fly ash contribution ranged from 0.5 percent of the total analyte metal for the high metals concentrations case in the case of $\mathrm{Be}$, to 3.1 percent 
in the case of As. These fly ash contribution values were calculated from the measured results presented later in this report. Please see Table 3-2.

Table 2-6. Sedigraph 5100 particle size data for coal fly ash before it was milled and fed into the flue gas.

\begin{tabular}{|c|c|c|}
\hline $\begin{array}{c}\text { Diameter } \\
(\mathrm{mm})\end{array}$ & $\begin{array}{c}\text { Cumulative Mass Finer } \\
(\%)\end{array}$ & $\begin{array}{c}\text { Mass in Interval } \\
(\%)\end{array}$ \\
\hline 60.00 & 97.1 & 2.9 \\
\hline 50.00 & 95.9 & 1.2 \\
\hline 40.00 & 93.7 & 2.2 \\
\hline 30.00 & 88.6 & 5.1 \\
\hline 25.00 & 84.1 & 4.5 \\
\hline 20.00 & 77.8 & 6.3 \\
\hline 15.00 & 69.0 & 8.8 \\
\hline 10.00 & 54.4 & 14.6 \\
\hline 8.00 & 44.8 & 9.5 \\
\hline 6.00 & 33.0 & 11.9 \\
\hline 5.00 & 26.7 & 6.2 \\
\hline 4.00 & 20.8 & 5.9 \\
\hline 3.00 & 16.0 & 4.8 \\
\hline 2.00 & 12.2 & 3.7 \\
\hline 1.50 & 10.9 & 1.4 \\
\hline 1.00 & 5.9 & 5.0 \\
\hline 0.80 & 3.4 & 2.5 \\
\hline
\end{tabular}

Mass median diameter $=9.01 \mathrm{~mm}$

Modal diameter $=8.26 \mathrm{~mm}$

An Insitec Measurement Systems laser-based particle counter, sizer, velocimeter was employed to perform real-time, in situ particulate measurements during the tests. As indicated in Figure 2-1, the Insitec system was located just downstream of the water-jacketed exit from the secondary combustion chamber.

Particle measurements performed with the Insitec system showed the combined solution and fly ash injections produced particulate loadings in the range of $25 \mathrm{mg} / \mathrm{dscm}(0.011 \mathrm{gr} / \mathrm{dscf})$ to 50 $\mathrm{mg} / \mathrm{dscm}(0.022 \mathrm{gr} / \mathrm{dscf})$ in the sampled and monitored flue gas. Method 5 (Reference 12) measurements were performed during the scoping tests to verify the particulate loading 
measurement results provided by the Insitec system. Those measurements showed that only approximately $33 \mathrm{wt} \%$ of the fly ash fed into the system actually reached the portion of the duct where the CEM and RM measurements were performed. Most of the fly ash settled out in the SCC and the portion of the flue gas duct preceding the CEM and RM measurement ports.



Figure 2-4. Sedigraph 5100 particle size data for coal fly ash before it was milled and fed into the flue gas.

\subsection{Test Procedure}

The three prototype multi-metal CEMs identified in Table 1-1 were tested concurrently. Each CEM under test had access to one set of sampling ports in the duct. The remaining set of ports was dedicated to RM sampling, which was performed by the RKIS staff. The sampling ports were assigned so that the operation of upstream CEMs did not affect the instruments located downstream. Thus, the two laser-based CEMs, being non-intrusive, were assigned to the second and third set of ports, and the ICP-AES CEM to the fourth set of ports. RM sampling employed 
the first set of ports. RM and CEM measurements were performed concurrently for each major test condition.

The test activities that involved the multi-metal CEMs were completed over a two-week period. During the week just preceding the principal test week, the developers set up their CEM equipment and sampling systems and performed shakedown testing. To provide appropriate conditions for initial CEM shakedown and testing immediately following installation, RKIS operation, including particulate feeding and metals feed solution injection, was also conducted during that period.

The planned schedule for the test week is shown in Table 2-7. The primary scheduled test days were.April 22, 24, and 26 (Monday, Wednesday, and Friday). On those days the hot flue gas was spiked both by injecting particulates (coal fly ash) and by injecting an aqueous metals feed solution of appropriate concentration. April 23 and 25 (Tuesday and Thursday) were reserved and employed for on-site data processing and evaluation, for optional sampling runs, minor CEM system maintenance, or for addressing any other test necessities or opportunities that had not been foreseen.

Table 2-7. Planned schedule for the test week.

\begin{tabular}{|l|l|l|l||}
\hline Test Day & $\begin{array}{l}\text { Multi-metals } \\
\text { Concentration }\end{array}$ & $\begin{array}{l}\text { Particulate (fly ash) } \\
\text { Injection }\end{array}$ & Primary CEM Test Day \\
\hline $4 / 22 / 96$ & MEDIUM & YES & YES \\
\hline $4 / 23 / 96$ & MEDIUM & OPTIONAL & OPTIONAL \\
\hline $4 / 24 / 96$ & LOW & YES & YES \\
\hline $4 / 25 / 96$ & LOW & OPTIONAL & OPTIONAL \\
\hline $4 / 26 / 96$ & HIGH & YES & YES \\
\hline
\end{tabular}

The number of RM measurements performed for each test depended on the target metal concentration. The RM sampling time was approximately two hours for the low target concentration test and approximately one hour for the medium and high target concentration tests. This schedule allowed for four RM samples to be collected on the low concentration test day and six RM samples to be collected on the medium and high concentration test days. Typical test day schedule plans are shown in Figure 2-5.

Each of the one to five measurement periods completed during each of the actual test days provided one set of concurrent RM and CEM measurement data. To ensure that the RM and CEM data sets were indeed concurrent and comparable for each period, the developers were notified of the start and stop times of each RM period. They were thus able to report average analyte concentrations for measurement time periods that corresponded directly to the actual RM measurement periods. The actual RM sampling times and concentration levels are reported in Table 2-8. The pauses indicated in Figure 2-5 and Table 2-8 were for switching the RM sampling probes from horizontal to vertical traverse mode as required by the RM. 


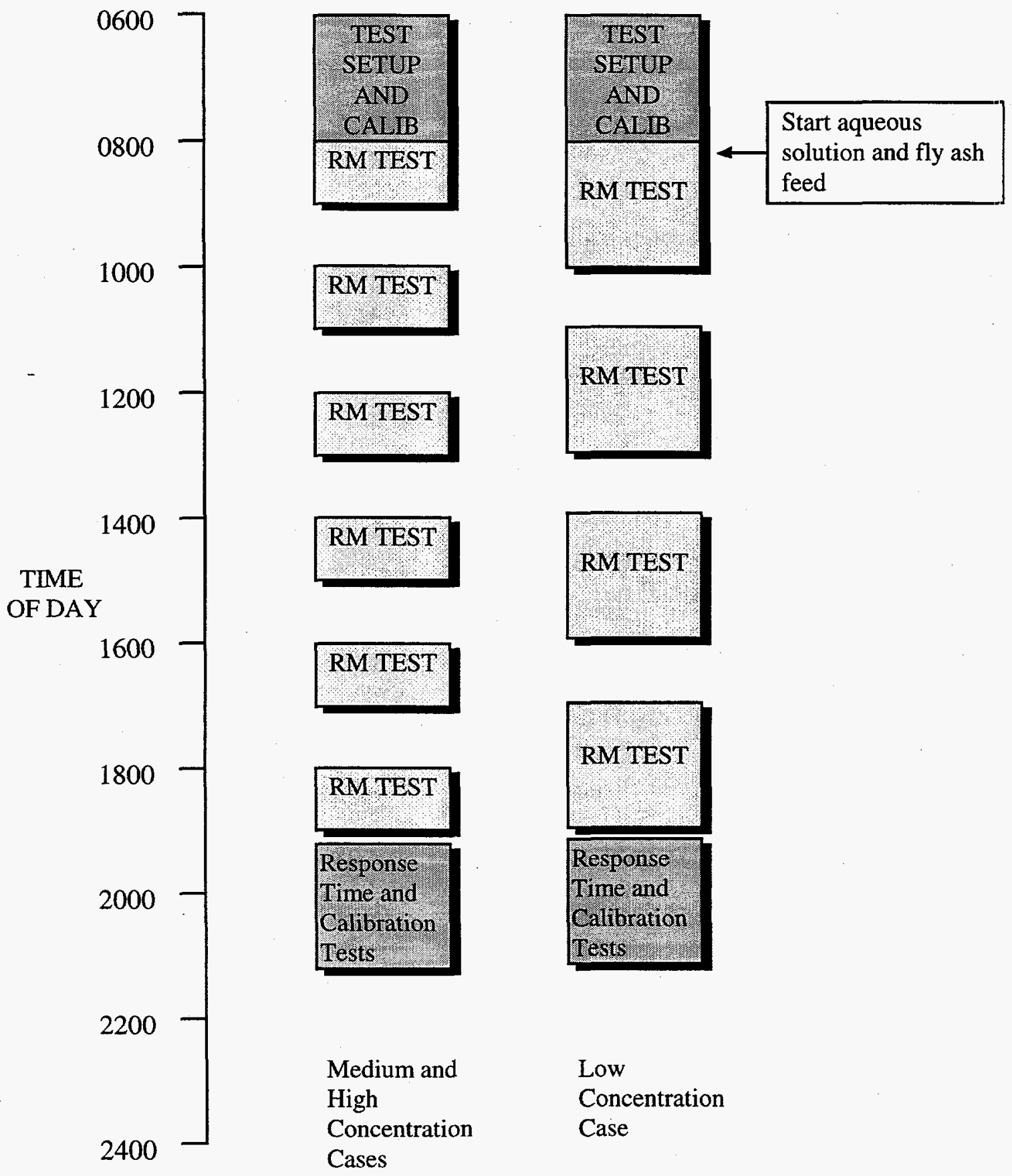

Figure 2-5. Typical test day schedule plans. 
Table 2-8. Test dates, times, and metal concentration levels for reference method sampling periods.

\begin{tabular}{|l|c|c|c|c|c||}
\hline Activity & $\begin{array}{c}4 / 22 / 96 \\
\text { Medium } \\
\text { Concentrations }\end{array}$ & $\begin{array}{c}4 / 23 / 96 \\
\text { Fly ash feed } \\
\text { only }\end{array}$ & $\begin{array}{c}4 / 24 / 96 \\
\text { Low } \\
\text { Concentrations }\end{array}$ & $\begin{array}{c}4 / 25 / 96 \\
\text { Medium } \\
\text { Concentrations }\end{array}$ & $\begin{array}{c}4 / 26 / 96 \\
\text { High } \\
\text { Concentrations }\end{array}$ \\
\hline RM1 Start & 902 & 1055 & 855 & 1035 & 840 \\
RM1 Pause & 932 & 1135 & 955 & - & 910 \\
RM1 Resume & 1010 & 1140 & 1020 & - & 930 \\
RM1 Stop & 1040 & 1200 & 1120 & 1119 & 1000 \\
\hline RM2 Start & 1105 & & 1142 & 1145 & 1020 \\
RM2 Pause & 1135 & & 1242 & - & 1050 \\
RM2 Resume & 1210 & & 1300 & - & 1110 \\
RM2 Stop & 1240 & & 1400 & 1245 & 1140 \\
\hline RM3 Start & 1316 & & 1440 & 1322 & 1202 \\
RM3 Pause & 1346 & & 1540 & - & 1232 \\
RM3 Resume & 1420 & & 1603 & - & 1250 \\
RM3 Stop & 1433 & & 1703 & 1422 & 1320 \\
\hline RM4 Start & 1520 & & 1735 & & 1345 \\
RM4 Pause & 1550 & & 1835 & & 1415 \\
RM4 Resume & 1615 & & 1905 & & 1430 \\
RM4 Stop & 1645 & & 2005 & & 1500 \\
\hline RM5 Start & 1706 & & & & 1530 \\
RM5 Pause & 1736 & & & & - \\
RM5 Resume & 1804 & & & & - \\
RM5 Stop & 1834 & & & & 1630 \\
\hline \hline
\end{tabular}

Except as noted, the specified metal concentration levels were achieved by injection of fly ash and atomization of aqueous solution containing the test metals.

At the beginning of each test day all RM sampling trains were assembled and leak checked, and the RKIS combustion gas CEMs were calibrated in accordance with facility standard operating procedures. During this time, the multi-metals CEM operators calibrated their instruments and the RKIS operators stabilized the RKIS, firing natural gas, at the desired incineration conditions. The incineration conditions provided the following flue gas conditions at the location of the RM and multi-metals CEM sampling ports:

- Flow rate of 3.4 to $5.7 \mathrm{scm} / \mathrm{min}$ (120 to $200 \mathrm{scfm}$ ) with moisture content of 4.5 to 6.7 mole \%

- Temperature of 227 to $236^{\circ} \mathrm{C}\left(440\right.$ to $\left.457^{\circ} \mathrm{F}\right)$

- Duct pressure (negative draft) of $-0.25 \mathrm{kPa}(-1$ inch WC)

- Duct $\mathrm{O}_{2}$ concentration of 15.7 mole \%

After stable RKIS operation was achieved, injection of particulate and metals feed solution to give the target flue gas concentrations was initiated. The multi-metal CEMs began recording 
data as their operators were able to bring them on-line. The RM sampling started at a time previously agreed upon with the CEM developers. The CEM developers were given at least 15 minutes notice prior to initiation of RM sampling. The CEM developers were also informed when the RM probes were switched from the horizontal to vertical traverse mode. This sharing of timing information was necessary so the developers could synchronize their periods of data reporting with the RM sampling periods. To ensure leak-free connections the upstream and downstream $\mathrm{O}_{2}$ and $\mathrm{CO}_{2}$ levels were checked following each such probe switch.

Various procedures were employed to provide stable metals concentrations during the RM and CEM test periods, while minimizing waste and unnecessary emissions. For the tests on April 22, the following procedure was employed:

- Metals injection was initiated at least 5 minutes before the start of each RM sampling period and following the change in RM sampling probe traverse orientation within each RM sampling period.

- The metals solution feed was shut off and water was fed through the liquid injector between RM sampling periods and during the change in sampling probe traverse orientation within each RM sampling period.

Results obtained from the multi-metals CEMs on April 22 and 23 showed, however, that stable metals concentrations were not actually realized until 15 minutes after the start of solution injection. Therefore, for the succeeding test days, the following procedures were employed:

- Metals injection was started at least 15 minutes before the start of the RM sampling periods.

- The metals solution feed was continued during changes in sampling probe traverse orientation.

As noted in Section 2.2, an Insitec Measurement Systems laser-based particle counter, sizer, velocimeter was used to monitor the flue gas particle loading and particle size distribution during the RM sampling periods. The results of the particle loading measurements are summarized in Table 2-9.

Some typical results of the Insitec particle size distribution measurements are shown in Figure 2-6. The particle size analysis indicated that $99 \%$ of the particles were less than $3.5 \mu \mathrm{m}$ in diameter, the mass median diameter was approximately $3.5 \mu \mathrm{m}$, and the number median diameter was approximately $0.5 \mu \mathrm{m}$. A complete compilation of the Insitec count, size, and velocity measurement data is provided in Appendix $L$.

The mass median diameter of the particles in the flue gas stream, as measured by the Insitec system, was considerably less than that of the coal fly ash, as determined by the Sedigraph instrument and shown in Figure 2-4. This is expected because the fly ash was milled (but its particle size distribution was not re-determined) before it was fed into the flue gas. Furthermore, the Insitec results describe the size distribution of the particulates that remained following injection of the milled fly ash into the transition section between the kiln and the SCC and its passage through the SCC. Because of the milling and because the larger particles are more likely to fall out during passage through the SCC, the mass median diameter measured at the exit of the SCC is expected to be considerably smaller than that of the as received fly ash. 
Table 2-9. Results of Insitec real time particle loading measurements.

\begin{tabular}{||c|r|c|c|c|c|c|c||}
\hline $\begin{array}{c}\text { Test } \\
\text { Day }\end{array}$ & $\begin{array}{c}\text { Start } \\
\text { Time }\end{array}$ & $\begin{array}{c}\text { End } \\
\text { Time }\end{array}$ & $\begin{array}{c}\text { Solution } \\
\text { Conc. Level }\end{array}$ & $\begin{array}{c}\text { Fly ash } \\
\text { Feed }\end{array}$ & $n$ & \multicolumn{2}{|c|}{ Particulate Loading (mg/dscm) } \\
\cline { 6 - 8 } & & & & & & Average & $\begin{array}{c}\text { Standard } \\
\text { Deviation }\end{array}$ \\
\hline $4 / 22 / 96$ & $9: 20$ & $18: 29$ & medium & on & 18 & 47.24 & 9.59 \\
$4 / 23 / 96$ & $11: 16$ & $11: 55$ & medium & on & 2 & 26.24 & 3.30 \\
$4 / 24 / 96$ & $9: 26$ & $19: 34$ & low & on & 18 & 30.95 & 3.97 \\
$4 / 25 / 96$ & $10: 59$ & $14: 50$ & medium & on & 6 & 36.90 & 8.48 \\
$4 / 26 / 96$ & $9: 52$ & $16: 03$ & high & on & 8 & 48.98 & 8.88 \\
\hline
\end{tabular}

$\mathrm{n}=$ number of measurements between Start Time and End Time

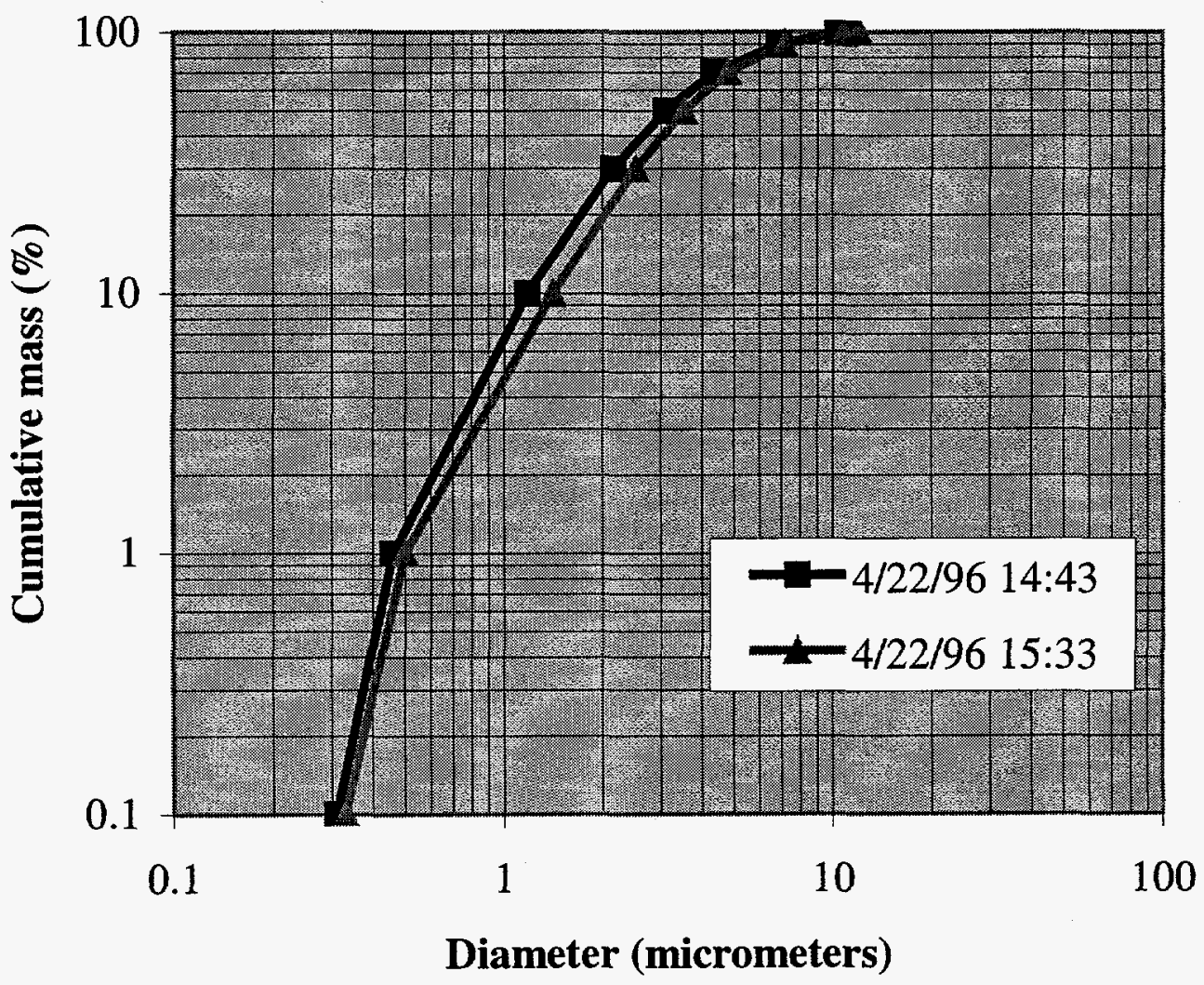

Figure 2-6. Typical results of Insitec measurements of particle size distribution in the flue gas. 
At the end of each test day, after collection of the last RM sample, the injection of the metals feed solution was stopped while the multi-metal CEMs continued to operate. The results of these measurements were used to estimate the response time of the multi-metal CEMs to a sudden decrease in flue gas metal concentrations. After the response time observations were completed, the multi-metal CEM operators performed their instrument calibration checks. These post-test checks provided information concerning instrument calibration drift and zero drift. Separate response time tests measuring increasing concentrations were also performed.

The RKIS was operated continuously during the entire test week. It was not shut down overnight. Such continuous operation was intended to minimize the potential for retention and subsequent release of the test trace metals by the refractory or other components of the RKJS.

\subsection{Reference Method Sampling and Analysis Procedures}

This section provides an overview of the subject procedures. Complete detailed information is available in the Quality Assurance Project Plan (QAPP) for this test (Reference 13).

\subsubsection{Sampling Procedures}

Reference method measurements of the flue gas trace metal concentrations were performed in accordance with EPA SW-846 Method 0060, Determination of Metals in Stack Emissions (Reference 4). One to five Method 0060 samples were collected each test day. The total numbers of Method 0060 trains, blanks, matrix spikes, and matrix spike duplicates employed are shown in Table 2-10. Each Method 0060 sampling train collected nominally $1.4 \mathrm{dscm}$ ( $50 \mathrm{dscf}$ ) of isokinetically sampled gas over an approximately one-hour time period for tests involving the medium and high target flue gas concentrations. Each train collected nominally $2.8 \mathrm{dscm}$ (100 dscf) of isokinetically sampled gas over about a two-hour time period for tests that involved the low target flue gas concentration. Sampling for particulate loading and size distribution measurements was not performed. The moisture content of the flue gas was determined for each test as outlined in Method 0060.

Table 2-10. Method 0060 test matrix.

\begin{tabular}{|c|c|l|c|c|}
\hline Date & Run Number & \multicolumn{1}{|c|}{ Condition } & Fly Ash Injection & $\begin{array}{c}\text { Number of } \\
\text { Method 0060 Trains }\end{array}$ \\
\hline \hline $4 / 22 / 96$ & 33715 & Medium Concentration & Yes & 5 \\
\hline $4 / 23 / 96$ & 33716 & Blank & Yes & 1 \\
\hline $4 / 24 / 96$ & 33717 & Low Concentration & Yes & 4 \\
\hline $4 / 25 / 96$ & 33718 & Medium Concentration & Yes & 3 \\
\hline $4 / 26 / 96$ & 33719 & High Concentration & Yes & 5 \\
\hline & & Field Blanks & & 3 \\
\hline & & Matrix Spikes & & 2 \\
\hline & & Matrix Spike Duplicates & & 2 \\
\hline & & Reagent Blanks & & \\
\hline
\end{tabular}


For most of the Method 0060 tests, the sampling probe was oriented horizontally in the duct for one-half of the sampling period; during that time, the probe traversed the entire duct diameter. At the midpoint of each sampling period, the probe was removed from the duct and reinserted with vertical orientation. For the remainder of the sampling period, the probe traversed the duct in the vertical orientation. As discussed in Section 5.2, only horizontal traverses were performed for the repeat of the medium concentration tests on April 25 and for the last high concentration test on April 26.

Stack gas velocity was measured by two S-type pitots located approximately nine duct diameters upstream of the Method 0060 sampling ports and five duct diameters downstream from the nearest upstream flow disturbance. Please see Figure 2-1. The ports were oriented horizontally and vertically like those at the Method 0060 sampling point. The stack gas velocity was measured at eight points per plane, in accordance with EPA Method 1A, Sample and Velocity Traverses for Stationary Sources with Small Stacks or Ducts (Reference 14).

Prior to the first sampling period on each test day, a pre-run traverse was conducted to ascertain the sampling probe nozzle size required for isokinetic sampling. Velocity measurements were also made simultaneously with every Method 0060 sampling period. The pitot traverse location and orientation corresponded to the traverse location and orientation of the sampling probe during each test. The pitot measurements were used to continuously adjust the sampling flow rate. In the event that the traverse points closest to the duct wall were less than one-half inch or one sampling probe diameter (whichever was larger) from the wall, that traverse point was adjusted to the larger of the two previously mentioned distances. In such cases the Method 0060 sampling points were similarly adjusted.

\subsubsection{Sample Recovery, Shipment, and Custody Procedures}

After the completion of each Method 0060 sampling period, the sample train was leak-checked and then taken to the on-site sample recovery laboratory. There, the train was recovered in accordance with Method 0060. Since particulate concentration measurements (based on the Method 0060 samples) were not made, an acetone rinse of the front half glassware (from the probe up to and including the front half of the filter housing) was not performed. Also, preliminary tests indicated the absence of metals in Method 0060 container number 5C, i.e., the $8 \mathrm{~N} \mathrm{HCl}$ rinse of the potassium permanganate impingers; therefore, ordinarily, no $5 \mathrm{C}$ samples were collected from the test trains. However, when the rinses used in container number $5 \mathrm{~B}$ did not appear to fully recover all of the $\mathrm{KMnO}_{4}$, as indicated by the purple $\mathrm{KMnO}_{4}$ color, then the $8 \mathrm{~N} \mathrm{HCl}$ rinse was used, and a sample $5 \mathrm{C}$ was produced and analyzed according to the Method. Table 2-11 identifies the sample fractions produced by each train and their corresponding Method 0060 container numbers.

During sample recovery, individual samples were labeled and entered into a sample log by the recovery personnel or the Sample Custodian. Each sample generated for this test program was assigned a unique ID number. Individual sample IDs were based upon their corresponding container numbers described in Method 0060. Information regarding the manner in which the sample was prepared or preserved, the solvent in which the sample was collected, and other information pertinent to the analysis was included in the sample log with every sample ID. This 
procedure created a history that included information as to source, time, and procedures employed for each sample.

Table 2-11. Method 0060 sample fractions.

\begin{tabular}{|l|c|}
\hline \hline Sample Fraction & $\begin{array}{c}\text { Method } 0060 \\
\text { Container Number }\end{array}$ \\
\hline \hline Filter & 1 \\
\hline Front half rinse $\left(0.1 \mathrm{~N} \mathrm{HNO}_{3}\right)$ & 3 \\
\hline Back half rinse, $\mathrm{HNO}_{3} / \mathrm{H}_{2} \mathrm{O}_{2}$ impingers and rinses & 4 \\
\hline Knockout impinger contents, $0.1 \mathrm{~N} \mathrm{HNO}_{3}$ rinses & $5 \mathrm{~A}$ \\
\hline $\mathrm{KMnO}_{4}$ impingers contents, $0.1 \mathrm{~N} \mathrm{HNO}_{3}$ rinses & $5 \mathrm{~B}$ \\
\hline Final rinse of $\mathrm{KMnO}_{4}$ impingers $(8 \mathrm{~N} \mathrm{HCl})$ & $5 \mathrm{C}$ \\
\hline Silica Gel & not applicable \\
\hline
\end{tabular}

Table 2-12 identifies the containers used for sample storage until analysis, preservation methods, and maximum allowed hold times. Only new containers were used for sample storage. They were purchased, pre-cleaned to meet EPA standards, from a laboratory supply vendor and were certified by the vendor as appropriate for use in storing trace metal samples. Filters and other sampling train components for the Method 0060 trains were cleaned according to the procedures documented in the analysis methods.

Table 2-12. Sample containers, preservation methods, and hold times.

\begin{tabular}{||l|l|l|c|c|c||}
\hline $\begin{array}{c}\text { Sample } \\
\text { from } \\
\text { Method 0060 train }\end{array}$ & Analyte & \multicolumn{1}{|c||}{$\begin{array}{c}\text { Sample } \\
\text { container }\end{array}$} & $\begin{array}{c}\text { Sample } \\
\text { quantity } \\
\text { reserved or } \\
\text { shipped }\end{array}$ & $\begin{array}{c}\text { Sample } \\
\text { preservation } \\
\text { method }\end{array}$ & Analysis hold time \\
\hline \hline Filter & $\begin{array}{l}\text { Trace } \\
\text { metals } \\
\text { Mercury }\end{array}$ & $\begin{array}{l}\text { Glass petri } \\
\text { dish }\end{array}$ & All & None & 180 days \\
28 days
\end{tabular}

${ }^{\mathrm{a}} \mathrm{G}=$ glass, $\mathrm{P}=$ polyethylene,

${ }^{\mathrm{b}}$ Except mercury

All samples were packaged, labeled, and shipped in compliance with Department of Transportation regulations. Chain of custody forms and other shipping and sample documentation accompanied each shipment. These documents were enclosed in a waterproof plastic bag and taped to the underside of the shipping container lid. 
All analysis procedures selected for these tests had hold times of 28 days or longer. This allowed all samples to be sent to the off-site analytical laboratory in a single shipment. This shipment occurred early in the week following the test week; the samples were delivered to Oxford Laboratories on May 8, 1996.

\subsubsection{Analytical Procedures}

Table 2-13 identifies the analytes determined for each Method 0060 train sample and the analysis methods employed. Oxford Laboratories, a contracted analytical laboratory, performed all analyses. Sample preparation for trace metal analyses was performed according to Method 0060 with analysis by inductively coupled argon plasma mass spectrometry (ICP-MS) according to Method 6020 (Reference 15). Although the QAPP stated Method 6010A (ICP-AES) would be used for those elements, performance audits of candidate analytical laboratories and techniques conducted before the QAPP and test plan were finalized showed superior results for Method 6020 as compared to Method 6010A.

For all metals except mercury, the front and back halves of the 0060 train were digested separately but combined proportionally for a single analysis. For the mercury analyses, sample preparation was according to Method 0060 and analysis was by cold vapor atomic absorption spectrometry (CVAAS) according to Method 7470A (Reference 16). For the mercury analyses, duplicate analyses were performed for each of the separate sample train fractions.

Table 2-13. Trace metals quantitated in Method 0060 train samples.

\begin{tabular}{||l|l||}
\hline Analyte & Analysis Method \\
\hline Antimony & 6020 \\
\hline Arsenic & 6020 \\
\hline Beryllium & 6020 \\
\hline Cadmium & 6020 \\
\hline Chromium & 6020 \\
\hline Iron & 6020 \\
\hline Lead & 6020 \\
\hline Mercury & $7470 \mathrm{~A}$ \\
\hline Yttrium & 6020 \\
\hline
\end{tabular}

\subsection{CEM Developer Procedures}

The test procedures employed by the multi-metal CEM developer teams are described in the final reports provided by those teams. Please see Appendices D, E, and F. 


\subsection{Combustion Gas CEM Measurements and CEM Test Conditions}

The full complement of RKIS combustion gas CEMs, of the types identified in Table 2-14, were operated continuously during all tests. As indicated in Figure 2-1, three sets of these CEMs were in place: one set between the kiln and the secondary combustion chamber, another set downstream of the SCC and upstream of the Method 0060 and CEM access ports; and a final set (less the CO, NO, and THC CEMs) downstream of those access ports. The combustion gas CEM data was recorded continuously by strip chart recorders and an automatic data acquisition system.

Table 2-14. Combustion gas CEMs installed at the RKIS.

\begin{tabular}{|c|c|c|c|}
\hline CEM & Principle & $\begin{array}{c}\text { Accuracy } \\
\text { (\% system bias) }\end{array}$ & $\begin{array}{c}\text { Precision } \\
\text { (\% RPD or \% RSD as } \\
\text { appropriate) }\end{array}$ \\
\hline $\mathrm{O}_{2}$ & Paramagnetic & \pm 5 (of full scale) & \pm 5 (of full scale) \\
\hline $\mathrm{CO}_{2}$ & NDIR $^{\mathrm{a}}$ & \pm 5 & 5 \\
\hline $\mathrm{CO}$ & $\mathrm{NDIR}^{\mathrm{a}}$ & \pm 5 & 5 \\
\hline $\begin{array}{c}\mathrm{THC} \\
\text { (as methane) }\end{array}$ & $\mathrm{FID}^{\mathrm{b}}$ & \pm 5 & 5 \\
\hline Temperature & K-type thermocouple & $\begin{array}{c} \pm 2 \\
\text { (of measured value) }\end{array}$ & $\begin{array}{c} \pm 2 \\
\text { (of measured value) }\end{array}$ \\
\hline NO & chemi-luminescence & \pm 5 & \pm 5 \\
\hline
\end{tabular}

${ }^{\mathrm{a}} \mathrm{NDIR}$ - Nondispersive infrared

${ }^{b}$ FID - Flame ionization detector 


\section{SECTION 3 TEST RESULTS}

\subsection{Facility Data}

The flue gas test conditions as recorded by the EPA RKIS facility flue gas CEMs and thermocouples are an important part of the test results. Those data are presented in Table 3-1.

\subsection{Reference Method Test Results}

During the test we produced three different concentrations of metals under typical combustion flue gas conditions, including fly ash. Comparing RM results (Table 3-2) with target concentrations shows that the target concentrations were approximately realized. The mercury concentration levels on $4 / 24$ and $4 / 25$ are the exception; the reason for this is not understood.

Even taking into consideration a $\pm 20 \%$ repeatability factor for typical $R M$ data, the metal concentrations were not constant during each set of RM measurements. Figure 3-1 shows a plot of RM results as a function of time. There it is apparent the RM results for the various metals were generally well correlated with each other as a function of time and, in particular, with the concentration measured for yttrium, the element included at constant concentration in the metals solution. The RM results for the target analytes did not correlate as well with the concentrations measured for iron, which was only present in the flue gas because it was a constituent of the injected fly ash. This suggests that the variations in test concentration levels were likely caused mostly by variations in the process by which the target analytes present in solution were introduced into the flue gas, not by variations in the fly ash injection rate.

The RM results for mercury are puzzling. They do not seem correlated with those for any other element. The variations from one RM result for mercury to another are fairly large in some instances, and are not understood. They may have originated, at least in part, in the sample handling and analytical procedures employed for the mercury RM measurements. This difficulty is consistent with the experience of others in handling and measuring mercury, as documented by Roberts et. al. (Reference 17). Appendix C reports a specific mercury recovery problem that was seen in the results from the analyses of the matrix spike and matrix spike duplicate samples. 
Table 3-1. Test conditions as recorded by the EPA RKIS facility flue gas CEMs and thermocouples.

\begin{tabular}{|c|c|c|c|c|c|c|c|c|c|c|c|c|c|c|c|c|}
\hline $\begin{array}{l}\text { Run } \\
\text { Date }\end{array}$ & RM & $\begin{array}{l}\text { Kiln } \\
\text { O2 } \\
(\%)\end{array}$ & $\begin{array}{l}\mathrm{Kiln} \\
\mathrm{CO} 2 \\
(\%)\end{array}$ & $\begin{array}{l}\text { Kiln } \\
\mathrm{CO} \\
(\mathrm{ppm})\end{array}$ & $\begin{array}{l}\text { Kiln } \\
\mathrm{NO} \\
(\mathrm{ppm})\end{array}$ & \begin{tabular}{|l|}
$\mathrm{SCC}$ \\
Exit O2 \\
$(\%)$
\end{tabular} & $\begin{array}{l}\text { SCC } \\
\text { Exit } \\
\mathrm{CO} 2 \\
(\%)\end{array}$ & $\begin{array}{l}\text { SCC } \\
\text { Exit } \\
\text { CO } \\
\text { (ppm) }\end{array}$ & $\begin{array}{l}\text { SCC } \\
\text { Exit } \\
\text { NO } \\
\text { (ppm) }\end{array}$ & $\begin{array}{l}\text { SCC } \\
\text { Exit } \\
\text { THC } \\
\text { (ppm) }\end{array}$ & $\begin{array}{l}\text { Duct } \\
\text { O2 } \\
(\%)\end{array}$ & $\begin{array}{l}\text { Duct } \\
\mathrm{CO} 2 \\
(\%)\end{array}$ & $\begin{array}{l}\text { Duct } \\
\mathrm{H} 2 \mathrm{O} \\
(\%)\end{array}$ & $\begin{array}{l}\mathrm{RM} \\
\mathrm{H} 2 \mathrm{O} \\
(\%)\end{array}$ & $\begin{array}{l}\text { Kiln } \\
\mathrm{T} \\
\left({ }^{\circ} \mathrm{C}\right)\end{array}$ & $\begin{array}{l}\mathrm{SCC} \\
\text { Exit T } \\
\left({ }^{\circ} \mathrm{C}\right)\end{array}$ \\
\hline Note & & $\bar{a}$ & $a$ & $b$ & $\mathrm{~b}$ & $a$ & $a$ & $b$ & $b$ & $\mathrm{c}$ & $a$ & $\mathrm{a}$ & $\mathrm{a}$ & $\mathrm{a}$ & & \\
\hline $4 / 22 / 96$ & RM1 & 3.82 & 11.06 & 28.06 & 45.38 & 9.23 & 6.89 & 33.75 & 747 & 3.25 & 16.10 & 2.90 & 7.83 & 6.7 & 945 & 713 \\
\hline $4 / 22 / 96$ & RM2 & 3.87 & 10.76 & 34.17 & 46.76 & 9.24 & 6.91 & 37.70 & 747 & 3.00 & 16.10 & 2.89 & 7.78 & 6.4 & 952 & 720 \\
\hline $4 / 22 / 96$ & RM3 & 3.76 & 9.25 & 25.91 & 48.30 & 9.18 & 6.93 & 36.56 & 761 & 2.57 & 16.10 & 2.87 & 7.80 & 6.5 & 955 & 725 \\
\hline $4 / 22 / 96$ & RM4 & 3.71 & 10.54 & 24.56 & 49.20 & 9.09 & 7.01 & 40.40 & 805 & 2.07 & 16.10 & 2.85 & 7.78 & 6.0 & 961 & 731 \\
\hline $4 / 22 / 96$ & RM5 & 3.76 & 11.07 & 31.73 & 50.00 & 9.11 & 7.00 & 43.52 & 832 & 2.30 & 16.10 & 2.82 & 7.63 & 6.5 & 962 & 734 \\
\hline $4 / 23 / 96$ & RM1 & 7.47 & 8.90 & 19.69 & 46.67 & 11.26 & 5.66 & 37.82 & 582 & 2.35 & 17.20 & 2.25 & 6.49 & 5.8 & 906 & 711 \\
\hline & & & & & & & & & & & & & & & & \\
\hline $4 / 24 / 96$ & RM1 & 6.26 & 11.29 & 23.63 & 58.85 & 9.71 & 6.44 & 33.83 & 727 & 3.28 & 16.10 & 2.69 & 6.19 & 5.1 & 940 & 732 \\
\hline $4 / 24 / 96$ & RM2 & 6.26 & 10.80 & 31.48 & 60.60 & 9.68 & 6.45 & 36.78 & 740 & 3.22 & 16.10 & 2.67 & 6.17 & 5.3 & 946 & 738 \\
\hline $4 / 24 / 96$ & RM3 & 6.10 & 9.80 & 19.65 & 62.72 & 9.62 & 6.45 & 36.10 & 706 & 3.21 & 16.10 & 2.66 & 6.19 & 5.4 & 950 & 742 \\
\hline $4 / 24 / 96$ & RM4 & 5.85 & 9.64 & 17.78 & 64.57 & 9.59 & 6.48 & 37.48 & 708 & 3.28 & 16.10 & 2.67 & 6.21 & 4.5 & 954 & 745 \\
\hline $4 / 25 / 96$ & RM1 & 6.22 & 9.45 & 21.64 & 56.14 & 9.51 & 6.59 & 25.82 & 659 & 2.95 & 16.20 & 2.74 & 6.49 & 4.8 & 925 & 728 \\
\hline $4 / 25 / 96$ & RM2 & 6.29 & 9.38 & 25.45 & 56.94 & 9.36 & 6.67 & 28.19 & 677 & 3.00 & 16.20 & 2.73 & 6.43 & 5.3 & 932 & 735 \\
\hline $4 / 25 / 96$ & RM3 & 6.29 & 9.44 & 32.90 & 58.50 & 9.39 & 6.65 & 30.37 & 683 & 3.03 & 16.20 & 2.71 & 6.35 & 5.3 & 936 & 740 \\
\hline $4 / 26 / 96$ & RM1 & 6.05 & 9.45 & 21.60 & 49.23 & 8.77 & 6.95 & 28.17 & 661 & 3.13 & 15.70 & 2.84 & 7.16 & 6.0 & 927 & 738 \\
\hline $4 / 26 / 96$ & RM2 & 5.73 & 9.86 & 21.87 & 49.93 & 8.66 & 7.03 & 32.97 & 679 & 3.63 & 15.80 & 2.86 & 7.23 & 5.7 & 944 & 748 \\
\hline $4 / 26 / 96$ & RM3 & 5.85 & 9.88 & 22.63 & 49.07 & 8.78 & 6.98 & 33.70 & 666 & 3.03 & 16.00 & 2.86 & 7.11 & 6.0 & 951 & 751 \\
\hline $4 / 26 / 96$ & RM4 & 6.06 & 9.68 & 22.44 & 49.01 & 9.17 & 6.71 & 32.41 & 647 & 3.09 & 15.90 & 2.77 & 6.92 & 6.2 & 950 & 749 \\
\hline $4 / 26 / 96$ & RM5 & 6.10 & 9.75 & 21.13 & 49.83 & 9.09 & 6.79 & 33.90 & 653 & 3.03 & 15.90 & 2.77 & 6.94 & 6.3 & 953 & 755 \\
\hline
\end{tabular}

The locations of the temperature and gas measurement points are indicated in Figure 2-1.

a The concentration is in mole fraction, expressed as percent.

$b$ The concentration is expressed as parts-per-million by volume.

c The concentration is expressed as parts-per-million by volume on a wet basis.

d Temperature at the RM sampling point. 
Table 3-2. Results from Reference Method measurements.

\begin{tabular}{|c|c|c|c|c|c|c|c|c|c|c|c|}
\hline \multirow[t]{2}{*}{ Date } & \multirow[t]{2}{*}{ Test } & Test & \multicolumn{2}{|c|}{ Metal Concentration $(\mu \mathrm{g} / \mathrm{dscm})$} & \multirow[b]{2}{*}{ Beryllium } & \multirow[b]{2}{*}{ Cadmium } & \multirow[b]{2}{*}{ Chromium } & \multirow[b]{2}{*}{ Iron } & \multirow[b]{2}{*}{ Lead } & \multirow[b]{2}{*}{ Mercury } & \multirow[b]{2}{*}{ Yttrium } \\
\hline & & Concentrations & Antimony & Arsenic & & & & & & & \\
\hline $4 / 22 / 96$ & 1 & Medium & 60.9 & 71.2 & 50.0 & 54.7 & 65.7 & 4203 & 91.9 & 60.4 & 100 \\
\hline $4 / 22 / 96$ & 2 & Medium & 62.4 & 73.4 & 61.6 & 59.5 & 61.0 & 3213 & 80.0 & 68.1 & 119 \\
\hline $4 / 22 / 96$ & 3 & Medium & 53.4 & 67.8 & 55.2 & 54.4 & 56.9 & 2721 & 74.0 & 54.9 & 110 \\
\hline $4 / 22 / 96$ & 4 & Medium & 49.3 & 63.7 & 53.8 & 51.7 & 52.3 & 1759 & 72.3 & 77.9 & 105 \\
\hline \multirow[t]{3}{*}{$4 / 22 / 96$} & 5 & Medium & 43.4 & 57.1 & 47.7 & 46.1 & 47.2 & 2867 & 69.8 & 46.2 & 92.2 \\
\hline & Average & & 53.9 & 66.6 & 53.7 & 53.3 & 56.6 & 2953 & 77.6 & 61.5 & 105 \\
\hline & & Target & 60 & 60 & 60 & 60 & 60 & $N T$ & 60 & 100 & 100 \\
\hline $4 / 23 / 96$ & Blank & Blank w/flyash & 4.8 & 12 & 2.3 & 4.2 & 20.2 & 2212 & 12.2 & NA & 7.6 \\
\hline $4 / 24 / 96$ & 1 & Low & 15.0 & 20.1 & 14.5 & 12.6 & 19.0 & 2212 & 18.7 & 2.8 & 115 \\
\hline $4 / 24 / 96$ & 2 & Low & 14.1 & 17.4 & 12.8 & 10.7 & 20.1 & 2737 & 17.8 & 1.9 & 99.8 \\
\hline $4 / 24 / 96$ & 3 & Low & 15.3 & 16.2 & 12.3 & 9.6 & 19.8 & 2279 & 15.5 & 1.4 & 97.2 \\
\hline \multirow[t]{3}{*}{$4 / 24 / 96$} & 4 & Low & 10.5 & 14.4 & 11.0 & 8.5 & 13.7 & 1671 & 14.9 & 1.4 & 91.7 \\
\hline & Average & & 13.7 & 17.0 & 12.7 & 10.4 & 18.2 & 2225 & 16.7 & 1.9 & 101 \\
\hline & & Target & 15 & 15 & 15 & 15 & 15 & $N T$ & 15 & 25 & 100 \\
\hline $4 / 25 / 96$ & 1 & Medium & 56.0 & 47.4 & 52.1 & 45.5 & 33.0 & 2269 & 51.1 & 6.2 & 110 \\
\hline $4 / 25 / 96$ & 2 & Medium & 63.2 & 54.8 & 52.6 & 46.0 & 38.1 & 2389 & 57.7 & 5.8 & 114 \\
\hline \multirow[t]{3}{*}{$4 / 25 / 96$} & 3 & Medium & 61.3 & 50.2 & 51.6 & 43.8 & 35.0 & 2178 & 52.2 & 7.4 & 112 \\
\hline & Average & & 60.2 & 50.8 & 52.1 & 45.1 & 35.4 & 2279 & 53.7 & 6.5 & 112 \\
\hline & & Target & 60 & 60 & 60 & 60 & 60 & $N T$ & 60 & 100 & 100 \\
\hline $4 / 26 / 96$ & 1 & High & 269 & 334 & 272 & 356 & 176 & 2311 & 375 & 311 & 59.7 \\
\hline $4 / 26 / 96$ & 2 & High & 376 & 396 & 474 & 447 & 180 & 2698 & 458 & 251 & 90.8 \\
\hline $4 / 26 / 96$ & 3 & High & 337 & 338 & 436 & 377 & 153 & 1935 & 375 & 420 & 89.0 \\
\hline $4 / 26 / 96$ & 4 & High & 413 & 402 & 509 & 441 & 169 & 1542 & 446 & 423 & 95.4 \\
\hline \multirow[t]{3}{*}{$4 / 26 / 96$} & 5 & High & 433 & 460 & 549 & 500 & 216 & 2327 & 489 & 222 & 93.4 \\
\hline & Average & & 366 & 386 & 448 & 424 & 179 & 2163 & 429 & 325 & 85.7 \\
\hline & & Target & 600 & 600 & 600 & 600 & 600 & $N T$ & 600 & 1000 & 100 \\
\hline
\end{tabular}

NT $=\quad$ No Target 


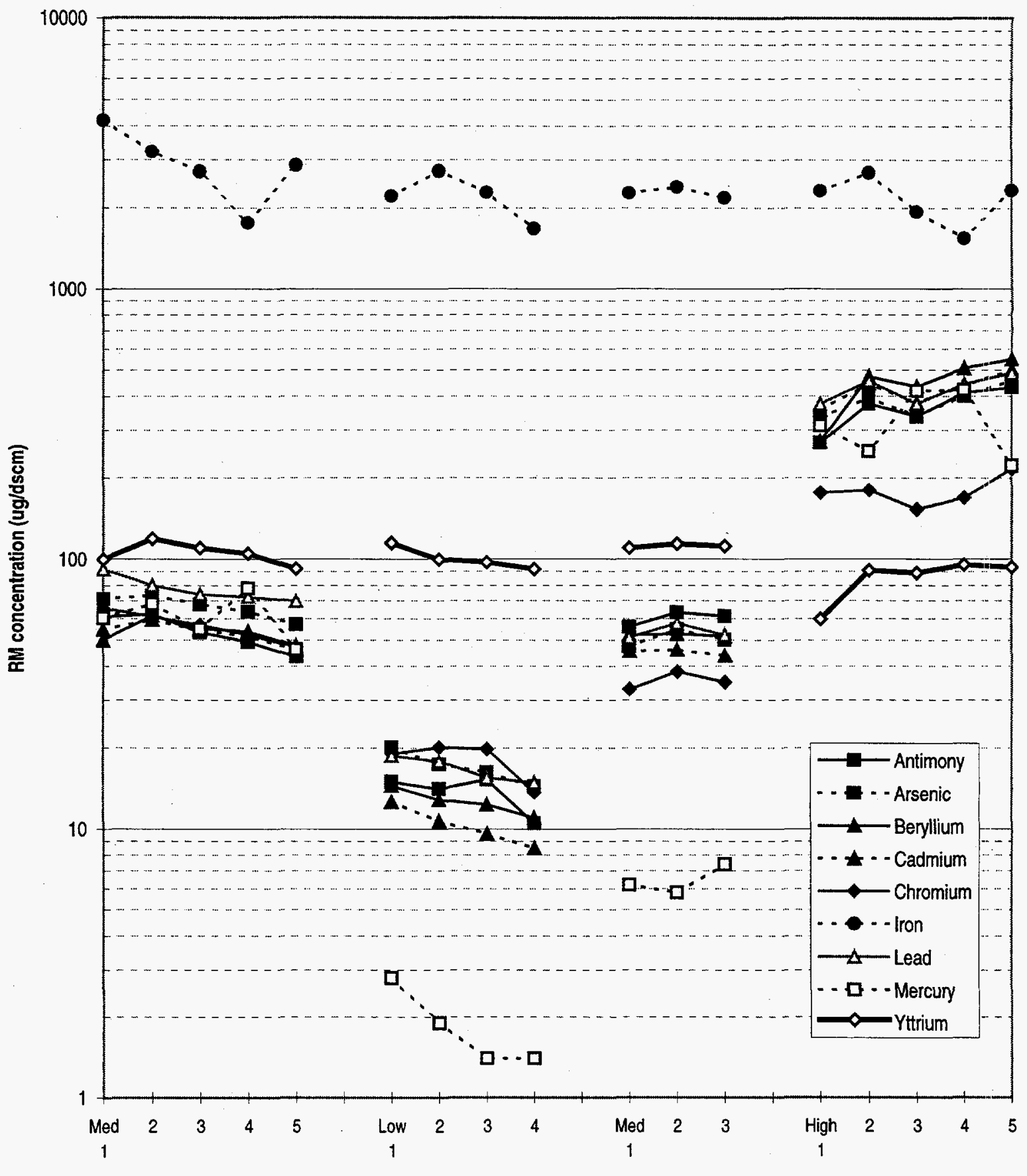

4/22, 4/24, 4/25, and 4/26 RM test

Figure 3-1. Logarithmic plot showing correlation of RM results for the analyte elements in different RM measurement periods. 


\subsection{Multi-Metal CEM Results}

The multi-metal CEM data was generated in near real time by the CEM developer teams. Each test day, prior to the beginning of the day's measurements, each CEM developer team delivered a diskette containing the results of the previous day's measurements to the program committee. The results were provided in tabular format, with a measurement time and corresponding measured metal concentration for each CEM data point.

On the first day after the conclusion of the CEM testing described here, each developer team delivered a complete data and operating information package to the EPA RKIS Facility Manager. Those packages, Appendices I, J, and $\mathrm{K}$ of this report, included:

- Daily CEM raw data and flue gas concentration data;

- Results of all zero and span checks;

- Plots and/or tables of metals concentrations in the flue gas versus time; and

- Copy of daily logbook pages including all significant observations, maintenance activities, and downtime.

In addition, each CEM developer team delivered a written final report to the report coordinator on or before May 10, 1996. The developer final reports, Appendices D, E, and F of this report, addressed the following items:

- Technical description of the system tested;

- Standard operating procedures;

- QA/QC procedures and results;

- Data interpretation; and

- Evaluation of this test program and the performance of the CEM instrument system, including strengths, weaknesses, lessons learned, and recommendations for future work.

\subsubsection{Real-Time Data}

Although the primary purpose of this test was to establish the accuracy of the CEM data as compared to the results of EPA reference method measurements, it is also important to appreciate the discrete, and near real-time nature of the CEM measurements. Until now, toxic metal emissions from waste treatment processes have not been observed on time scales less than approximately one hour.

Figure 3-2 shows plots of beryllium concentrations measured by three CEMs during the second RM measurement period (RM2) on April 26. Beryllium results are illustrated because in general the CEMs performed better for beryllium than for the other metals of interest. The RM2 period on April 26 was selected because the highest metal concentrations were provided on that day and, of all the RM periods on April 26, RM2 is the one that contained the greatest number of $\mathrm{Be}$ results for the three CEMs. 


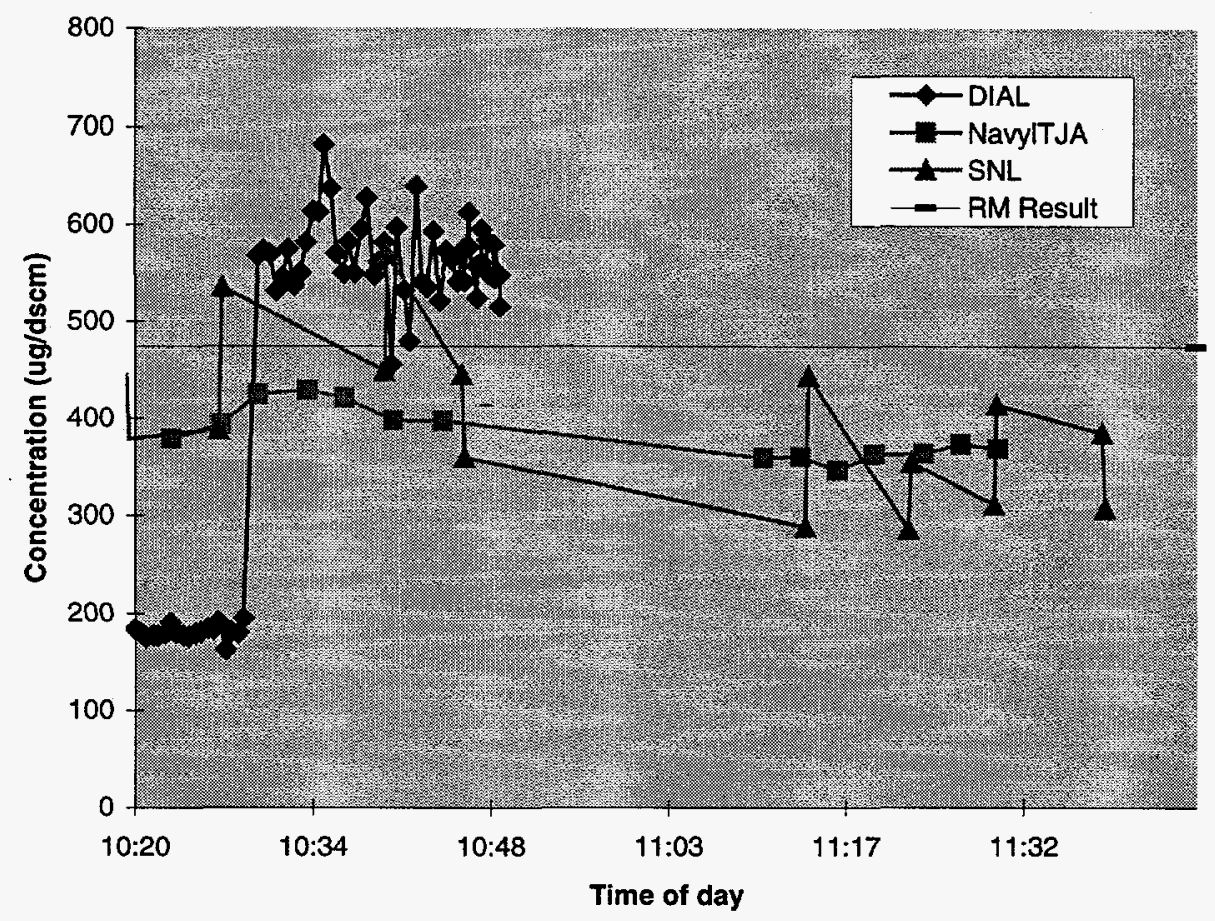

Figure 3-2. Beryllium concentrations vs. time from the DIAL, Navy/TJA, and SNL CEMs during the second Reference Method measurement period on April 26. The solid line indicates the RM result obtained during same time period.

Several aspects of the data shown in Figure 3-2 merit discussion because they are typical of the performance observed throughout this CEM performance evaluation:

- The DIAL CEM produced measurement results more frequently than either the Navy/TJA or the SNL CEM.

- The CEM data had considerable variability over time within an RM measurement period. For beryllium, typical standard deviations were on the order of 5 to $15 \%$ for the DIAL instrument, approximately $7 \%$ for the Navy/TJA instrument, and approximately $20 \%$ for the SNL instrument.

- The DIAL results shown in Figure 3-2 exhibited a large step increase at 10:30 a.m. This time coincides with an apparent change in the way the DIAL CEM was being operated. Before 10:30, during RM2, only beryllium results were reported. After 10:30, both cadmium and beryllium were reported. The step increase in the beryllium results may have been caused by a deliberate change in the wavelength setting of the spectrometer to gain cadmium measurement capability in addition to beryllium measurement capability.

\subsubsection{Data Variability}

The three multi-metal CEMs provided thousands of individual data points during this test. When these were plotted vs. time, as shown in Figure 3-2 and in the CEM developer reports 
(Appendices D, E, and F), we saw considerable variability about the average concentration levels. The relative standard deviations were as large as $50 \%$, even for measurements where each of the reported values was already the average of multiple measurements over periods as long as 90 seconds.

Measurements near the limit of detection are expected to have considerable variability because the noise is nearly comparable to the net signal. At higher concentrations, however, much less variability is expected because the net signal level is much larger. Under the carefully controlled conditions of this test, the variability of the individual CEM measurement results seems larger than expected. This variability may reflect real, changes in the emissions levels, or it may reflect inadequacies in the measurement methods or equipment. For this test, the metals were injected and the operating conditions were such that, at the CEM measurement locations, the metals were expected to be present principally as discrete particles entrained in the flue gas ${ }^{1}$. Based on the discrete nature of the metal presence, it is possible that some variability could result from whether or not a laser pulse hit a metal-containing particle, from the size of the particle, and from how thoroughly the pulse atomized and excited its constituents. In the absence of measurements for which the metal content of the flue gas stream is known to be homogeneous and constant (as might be made if a suitable "calibration gas" were available), we do not know the cause. Depending on the time interval(s) EPA and the stakeholders ultimately decide is (are) important for monitoring and documenting compliance with emissions standards, it is clear that the CEM minimum reporting interval and data variability will be important CEM performance measures.

Another interesting observation can be made from the plots of CEM data points vs. time. In some such plots, Figure A.7 in the SNL final report, for example, the distribution of the data is clearly not Gaussian. The distribution is skewed, clearly with a tail that extends much further above the median than below. The reason for this is not understood.

\subsubsection{Relative Accuracy}

Relative accuracy compares CEM averages and RM results for $n$ time periods during which both CEM and RM data are collected. The relative accuracy is described in the draft EPA "Performance Specification 10 (PS 10) - Specifications and test procedures for multi-metals continuous monitoring systems in stationary sources" (Reference 6). A copy of this specification is included as Appendix H. Note that this reference contains a typing error: the term, d-bar, should be absolute value of $d$-bar.

\footnotetext{
${ }^{1}$ Mercury is a possible exception. Vapor state elemental mercury may be present in the flue gas.
} 


\subsubsection{Relative Accuracy Computation}

The RA was calculated using equation 3-1.

$$
R A=\frac{|\bar{d}|+\frac{t_{0.975}}{\sqrt{n}}(S D)}{R_{R M}}
$$

Equation (3-1)

$\mathrm{R}_{\mathrm{RM}}$-bar is equal to either the average of the $n$ RM measurement results, calculated according to Equation (3-2), or the value of the emission standard, as applicable (see section 4.2 of PS 10).

$$
\overline{R M}=\frac{1}{n} \sum_{i=1}^{n} R M_{i}
$$

In equation (3-1), $t_{0.975}$ is the $t$-value at 2.5 percent error confidence, as listed in Table 3-3

Table 3-3. $t$-values.

\begin{tabular}{||c|c|}
\hline$n$ & $t_{0.975}$ \\
\hline \hline 2 & 12.706 \\
\hline 3 & 4.303 \\
\hline 4 & 3.182 \\
\hline 5 & 2.776 \\
\hline 6 & 2.571 \\
\hline 7 & 2.447 \\
\hline 8 & 2.365 \\
\hline 9 & 2.306 \\
\hline 10 & 2.262 \\
\hline 11 & 2.228 \\
\hline 12 & 2.201 \\
\hline
\end{tabular}

In equation (3-1), d-bar is equal to the arithmetic mean of the differences, $d_{i}$, for the $n$ CEM and RM data pairs, calculated according to equations 3-3 and 3-4.

$$
d_{i}=C E M_{i}-R M_{i}
$$

Note that $C E M_{i}$ is the arithmetic average of the $m$ CEM data points, $C E M_{i j}$, taken in real-time or close to real-time over the time corresponding to the measurement period for the $i^{\text {th }} \mathrm{RM}$ measurement:

$$
C E M_{i}=\frac{1}{m} \sum_{j=1}^{m} C E M_{i j}
$$


and the arithmetic mean of the differences, d-bar, is equal to:

$$
\bar{d}=\frac{1}{n} \sum_{i=1}^{n} d_{i}
$$

$S D$ is the standard deviation calculated according to Equation (3-6).

$$
S D=\sqrt{\frac{\sum_{i=1}^{n} d_{i}^{2}-\left[\frac{1}{n}\left(\sum_{i=1}^{n} d_{i}\right)^{2}\right]}{n-1}}
$$

Equation (3-6)

\subsubsection{Relative Accuracy (RA) Results}

The RA results for the DIAL, Navy/TJA, and SNL systems are reported in Tables 3-4, 3-5, and 3-6, respectively, together with the RM and average CEM concentration values that were used in the RA calculations.

A key result from Tables 3-4 through 3-6 is that RA values of 20 percent or lower, required for multi-metals CEMs meeting PS 10, were rarely achieved. The DIAL system had none, the Navy/TJA system had three, and the SNL system had one. In part, this may be due to the limited number of CEM and RM measurement pairs used for the RA calculation. This issue will be discussed later in this report. For now, it is sufficient to note that these systems, in these tests, did not show they could generally perform with RA levels that satisfy the draft PS.

The large amount of information provided in Tables 3-4 through 3-6 can be summarized in two different ways. Table 3-7 summarizes the relative accuracies achieved by the three CEMs for the seven target metals at the high, medium and low concentrations levels. The relative accuracy values are from Tables 3-4 through 3-6. With the exception of the RA value listed for the DIAL instrument in the case of chromium at medium concentration, Table 3-7 does not include RA values determined from measurements conducted on $4 / 25$. Those data are not included in Table 3-7 because, according to the test schedule, 4/25 was not an official performance evaluation day.

Table 3-8 lists the number of analyte elements each CEM was able to measure for the various test concentration levels; Table 3-9 reports the average of the RA values for the analyte elements the CEMs were able to measure at each of the different concentration levels. The summary results show that, for all test days and concentration levels, the Navy/TJA system provided concentration measurements for more target analytes than the other two systems, and at the same time achieved the lowest or next to lowest average RA values. 
Table 3-4. DIAL CEM, RM, and RA results. Analyte concentrations $(\mu \mathrm{g} / \mathrm{dscm})$ as determined by the DIAL CEM system and by the Reference Method; Relative Accuracies of the DIAL CEM results are shown in bold type.

\begin{tabular}{|c|c|c|c|c|c|c|c|c|c|c|c|}
\hline Date & Test & $\begin{array}{c}\overline{\mathrm{Be}} \\
(\mathrm{CEM})\end{array}$ & $\begin{array}{c}\mathrm{Be} \\
(\mathrm{RM})\end{array}$ & $\begin{array}{c}\mathrm{Cd} \\
(\mathrm{CEM})\end{array}$ & $\begin{array}{c}\mathrm{Cd} \\
(\mathrm{RM})\end{array}$ & $\begin{array}{c}\mathrm{Cr} \\
(\mathrm{CEM})\end{array}$ & $\begin{array}{c}\mathrm{Cr} \\
(\mathrm{RM})\end{array}$ & $\begin{array}{c}\mathrm{Pb} \\
(\mathrm{CEM})\end{array}$ & $\begin{array}{c}\mathrm{Pb} \\
(\mathrm{RM})\end{array}$ & $\begin{array}{c}\bar{Y} \\
(\mathrm{CEM})\end{array}$ & $\begin{array}{c}\mathrm{Y} \\
(\mathrm{RM})\end{array}$ \\
\hline $4 / 22 / 96$ & 1 & 38.2 & 50.0 & & & 69.7 & 65.7 & & & 66.9 & 100 \\
\hline $4 / 22 / 96$ & 2 & 39.0 & 61.6 & & & 43.7 & 61.0 & & & 27.3 & 119 \\
\hline $4 / 22 / 96$ & 3 & 41.9 & 55.2 & & & 31.0 & 56.9 & & & 24.4 & 110 \\
\hline $4 / 22 / 96$ & 4 & 40.3 & 53.8 & & & 29.3 & 52.3 & & & 85.0 & 105 \\
\hline $4 / 22 / 96$ & 5 & $\begin{array}{r}32.8 \\
38 \%\end{array}$ & 47.7 & & & $\begin{array}{r}30.9 \\
53 \%\end{array}$ & 47.2 & & & $\begin{array}{r}68.8 \\
\mathbf{8 9 \%}\end{array}$ & 92.2 \\
\hline $4 / 24 / 96$ & 1 & 29.2 & 14.5 & & & 22.6 & 19.0 & & & 202.6 & 115 \\
\hline $4 / 24 / 96$ & 2 & 20.1 & 12.8 & & & 17.0 & 20.1 & & & 133.4 & 99.8 \\
\hline $4 / 24 / 96$ & 3 & 33.0 & 12.3 & & & 16.8 & 19.8 & & & 108.3 & 97.2 \\
\hline $4 / 24 / 96$ & 4 & $\begin{array}{r}42.3 \\
\mathbf{2 7 3 \%}\end{array}$ & 11.0 & & & $\begin{array}{r}15.4 \\
\mathbf{3 1 \%}\end{array}$ & 13.7 & & & $\begin{array}{r}96.1 \\
93 \%\end{array}$ & 91.7 \\
\hline $4 / 25 / 96$ & 1 & $\overline{73.8}$ & 52.1 & $\overline{55.8}$ & 45.5 & 17.5 & 33.0 & & & 108.6 & 110 \\
\hline $4 / 25 / 96$ & 2 & 65.7 & 52.6 & 52.4 & 46.0 & 27.7 & 38.1 & & & 100.5 & 114 \\
\hline $4 / 25 / 96$ & 3 & $\begin{array}{r}45.5 \\
86 \%\end{array}$ & 51.6 & $73 \%$ & 43.8 & $\begin{array}{l}18.5 \\
61 \%\end{array}$ & 35.0 & & & $\begin{array}{r}55.4 \\
86 \%\end{array}$ & 112 \\
\hline $4 / 26 / 96$ & 1 & 103 & 272 & & 356 & 197 & 176 & 275 & 375 & & \\
\hline $4 / 26 / 96$ & 2 & 490 & 474 & 631 & 447 & 276 & 180 & 536 & 458 & & \\
\hline $4 / 26 / 96$ & 3 & 526 & 436 & 554 & 377 & 299 & 153 & 608 & 375 & & \\
\hline $4 / 26 / 96$ & 4 & & 509 & & 441 & 236 & 169 & 488 & 446 & & \\
\hline $4 / 26 / 96$ & 5 & 398 & 549 & 534 & 500 & 272 & 216 & 540 & 489 & & \\
\hline & & $57 \%$ & & $77 \%$ & & $76 \%$ & & $49 \%$ & & & \\
\hline
\end{tabular}


Table 3-5. Navy/TJA CEM, RM, and RA results. Analyte concentrations ( $\mu \mathrm{g} / \mathrm{dscm})$ as determined by the Navy/TJA CEM system and by the Reference Method; Relative Accuracies of the Navy/TJA CEM results are shown in bold type.

\begin{tabular}{|c|c|c|c|c|c|c|c|c|c|c|c|c|c|c|c|c|c|}
\hline Date & Test & $\begin{array}{c}\mathrm{As} \\
(\mathrm{CEM})\end{array}$ & $\begin{array}{c}\text { As } \\
\text { (RM) }\end{array}$ & $\begin{array}{c}\mathrm{Be} \\
(\mathrm{CEM})\end{array}$ & $\begin{array}{c}\mathrm{Be} \\
(\mathrm{RM})\end{array}$ & $\begin{array}{c}\text { Cd } \\
\text { (CEM) }\end{array}$ & $\begin{array}{c}\mathrm{Cd} \\
(\mathrm{RM})\end{array}$ & $\begin{array}{c}\mathrm{Cr} \\
\text { (CEM) }\end{array}$ & $\begin{array}{c}\mathrm{Cr} \\
(\mathrm{RM})\end{array}$ & $\begin{array}{c}\mathrm{Hg} \\
(\mathrm{CEM})\end{array}$ & $\begin{array}{c}\mathrm{Hg} \\
(\mathrm{RM})\end{array}$ & $\begin{array}{c}\mathrm{Pb} \\
(\mathrm{CEM})\end{array}$ & $\begin{array}{c}\mathrm{Pb} \\
(\mathrm{RM})\end{array}$ & $\begin{array}{c}\mathrm{Sb} \\
(\mathrm{CEM})\end{array}$ & $\begin{array}{c}\mathrm{Sb} \\
(\mathrm{RM})\end{array}$ & $\begin{array}{c}\mathrm{Y} \\
(\mathrm{CEM})\end{array}$ & $\begin{array}{c}\mathrm{Y} \\
(\mathrm{RM})\end{array}$ \\
\hline $4 / 22 / 96$ & 1 & 44.4 & 71.2 & 29.2 & 50.0 & 32.5 & 54.7 & 26.4 & 65.7 & 8.2 & 60.4 & 35.5 & 91.9 & 38.8 & 60.9 & 57.6 & 100.0 \\
\hline $4 / 22 / 96$ & 2 & 44.9 & 73.4 & 26.1 & 61.6 & 25.5 & 59.5 & 12.9 & 61.0 & 3.7 & 68.1 & 22.6 & 80.0 & 37.4 & 62.4 & 53.8 & 119.0 \\
\hline $4 / 22 / 96$ & 3 & 36.1 & 67.8 & 23.1 & 55.2 & 24.0 & 54.4 & 15.1 & 56.9 & 2.8 & 54.9 & 26.3 & 74.0 & 31.1 & 53.4 & 48.7 & 110.0 \\
\hline $4 / 22 / 96$ & 4 & 51.5 & 63.7 & 29.8 & 53.8 & 28.7 & 51.7 & 13.5 & 52.3 & 4.1 & 77.9 & 23.8 & 72.3 & 39.3 & 49.3 & 55.8 & 105.0 \\
\hline $4 / 22 / 96$ & 5 & $\begin{array}{r}52.4 \\
53 \%\end{array}$ & 57.1 & $\begin{array}{l}20.8 \\
66 \%\end{array}$ & 47.7 & $\begin{array}{l}20.3 \\
63 \%\end{array}$ & 46.1 & $\begin{array}{r}13.5 \\
\mathbf{8 3 \%}\end{array}$ & 47.2 & $\begin{array}{r}2.3 \\
117 \%\end{array}$ & 46.2 & $\begin{array}{r}18.5 \\
74 \%\end{array}$ & 69.8 & $\begin{array}{c}33.7 \\
50 \%\end{array}$ & 43.4 & $\begin{array}{l}40.1 \\
62 \%\end{array}$ & 92.2 \\
\hline $4 / 24 / 96$ & 1 & 14.5 & 20.1 & 9.4 & 14.5 & 7.0 & 12.6 & 6.5 & 19.0 & 1.3 & 2.8 & 5.4 & 18.7 & 23.5 & 15.0 & 73.7 & 115.0 \\
\hline $4 / 24 / 96$ & 2 & 21.7 & 17.4 & 9.7 & 12.8 & 7.0 & 10.7 & 6.4 & 20.1 & 1.1 & 1.9 & 5.6 & 17.8 & 19.2 & 14.1 & 77.0 & 99.8 \\
\hline $4 / 24 / 96$ & 3 & 25.6 & 16.2 & 10.7 & 12.3 & 8.0 & 9.6 & 7.4 & 19.8 & 1.1 & 1.4 & 6.8 & 15.5 & 20.9 & 15.3 & 86.1 & 97.2 \\
\hline $4 / 24 / 96$ & 4 & $\begin{array}{r}23.2 \\
90 \%\end{array}$ & 14.4 & $\begin{array}{r}8.9 \\
43 \% \\
\end{array}$ & 11.0 & $\begin{array}{r}6.6 \\
59 \%\end{array}$ & 8.5 & $\begin{array}{r}6.5 \\
88 \%\end{array}$ & 13.7 & $\begin{array}{r}0.9 \\
86 \%\end{array}$ & 1.4 & $\begin{array}{r}5.6 \\
86 \%\end{array}$ & 14.9 & $\begin{array}{r}17.0 \\
64 \%\end{array}$ & 10.5 & $\begin{array}{r}79.3 \\
44 \%\end{array}$ & 91.7 \\
\hline $4 / 25 / 96$ & 1 & 65.7 & 47.4 & 52.5 & 52.1 & 42.4 & 45.5 & 12.0 & 33.0 & 8.3 & 6.2 & 23.9 & 51.1 & 65.1 & 56.0 & 75.1 & 110 \\
\hline $4 / 25 / 96$ & 2 & 66.9 & 54.8 & 52.2 & 52.6 & 41.9 & 46.0 & 11.4 & 38.1 & 6.8 & 5.8 & 22.2 & 57.7 & 61.7 & 63.2 & 77.3 & 114 \\
\hline $4 / 25 / 96$ & 3 & $\begin{array}{r}24.6 \\
119 \%\end{array}$ & 50.2 & $\begin{array}{r}49.2 \\
8 \% \\
\end{array}$ & 51.6 & $\begin{array}{r}38.3 \\
16 \% \\
\end{array}$ & 43.8 & $\begin{array}{r}10.4 \\
\mathbf{8 8 \%}\end{array}$ & 35.0 & $\begin{array}{r}5.6 \\
86 \% \\
\end{array}$ & 7.4 & $\begin{array}{r}18.9 \\
79 \%\end{array}$ & 52.2 & $\begin{array}{r}65.3 \\
28 \%\end{array}$ & 61.3 & $\begin{array}{r}75.2 \\
\mathbf{3 5 \%}\end{array}$ & 112 \\
\hline $4 / 26 / 96$ & 1 & NM & 334 & NM & 272 & NM & 356 & NM & 176 & NM & 311 & NM & 375 & NM & 269 & NM & 59.7 \\
\hline $4 / 26 / 96$ & 2 & 294 & 396 & 385 & 474 & 295 & 447 & 71.8 & 180 & 23.9 & 251 & 154 & 458 & 373 & 376 & 53 & 90.8 \\
\hline $4 / 26 / 96$ & 3 & 305 & 338 & 383 & 436 & 262 & 377 & 58.4 & 153 & 26.9 & 420 & 140 & 375 & 345 & 337 & 50 & 89.0 \\
\hline $4 / 26 / 96$ & 4 & 331 & 402 & 439 & 509 & 301 & 441 & 65.3 & 169 & 28.5 & 423 & 164 & 446 & 419 & 413 & 57 & 95.4 \\
\hline $4 / 26 / 96$ & 5 & 298 & 460 & 399 & 549 & 278 & 500 & 51.9 & 216 & 26.4 & 222 & 125 & 489 & 373 & 433 & 52 & 93.4 \\
\hline & & $45 \%$ & & $32 \%$ & & $52 \%$ & & $93 \%$ & & $143 \%$ & & $86 \%$ & & $16 \%$ & & $45 \%$ & \\
\hline
\end{tabular}

$\mathrm{NM}=$ Not measured 
Table 3-6. SNL CEM, RM, and RA results. Analyte concentrations ( $\mu \mathrm{g} / \mathrm{dscm})$ as determined by the SNL CEM system for various analysis wavelengths and scripts and by the Reference Method. The Relative Accuracies of the SNL CEM results are shown in bold type.

\begin{tabular}{|c|c|c|c|c|c|c|c|c|c|c|c|c|c|c|c|}
\hline & Script & $\begin{array}{r}\text { Be } 265.1 \\
265 / 4 \\
\end{array}$ & $\begin{array}{r}\text { Be } 265.1 \\
280 / 4\end{array}$ & $\begin{array}{r}\mathrm{Be} 313.1 \\
300 / 1\end{array}$ & $\begin{array}{r}\mathrm{Be} 313.1 \\
300 / 4\end{array}$ & $\begin{array}{r}\text { Be } 313.1 \\
320 / 4\end{array}$ & \begin{tabular}{r|}
$\mathrm{Be}$ \\
$\mathrm{RM}$
\end{tabular} & $\begin{array}{r}\mathrm{Cd} 226.5 \\
230 / 4\end{array}$ & \begin{tabular}{r|}
$\mathrm{Cd}$ \\
$\mathrm{RM}$
\end{tabular} & $\begin{array}{r}\text { Cr } 267.7 \\
280 / 4 \\
\end{array}$ & $\begin{array}{r}\text { Cr } 283.6 \\
300 / 1 \\
\end{array}$ & $\begin{array}{r}\mathrm{Cr} 283.6 \\
300 / 4\end{array}$ & $\begin{array}{r}\mathrm{Cr} \\
\mathrm{RM}\end{array}$ & $\begin{array}{r}\mathrm{Pb} 220.4 \\
230 / 4\end{array}$ & $\begin{array}{r}\mathrm{Pb} \\
\mathrm{RM}\end{array}$ \\
\hline Date & Test & & & & & & & & & & & & & & \\
\hline $4 / 22 / 96$ & 3 & 68.8 & 22.5 & & & 69.8 & 55.2 & 182.2 & 54.4 & & & & & & \\
\hline $4 / 22 / 96$ & 4 & 46.2 & 25.0 & & 50.8 & 44.6 & 53.8 & 97.7 & 51.7 & & & & & & \\
\hline $4 / 22 / 96$ & 5 & 32.4 & 14.9 & & 23.3 & 38.2 & 47.7 & 58.4 & 46.1 & & & & & & \\
\hline & & $77 \%$ & $66 \%$ & & $296 \%$ & $68 \%$ & & $413 \%$ & & & & & & & \\
\hline $4 / 24 / 96$ & 1 & & & & & 24.9 & 14.5 & & & & & & & & \\
\hline $4 / 24 / 96$ & 2 & & & & & 23.5 & 12.8 & & & & & & & & \\
\hline $4 / 24 / 96$ & 3 & & & & & 20.4 & 12.3 & & & & & & & & \\
\hline $4 / 24 / 96$ & 4 & & & & & 19.4 & 11.0 & & & & & & & & \\
\hline & & & & & & $91 \%$ & & & & & & & & & \\
\hline $4 / 25 / 96$ & 1 & & & & & 54.5 & 52.1 & 182.9 & 45.5 & & & & & & \\
\hline $4 / 25 / 96$ & 2 & & & & & 55.0 & 52.6 & 160.7 & 46.0 & & & & & & \\
\hline $4 / 25 / 96$ & 3 & & & & & & 51.6 & & 43.8 & & & & & & \\
\hline & & & & & & $5 \%$ & & $591 \%$ & & & & & & & \\
\hline $4 / 26 / 96$ & 1 & 386.3 & 72.4 & 380.6 & 465.6 & & 272 & 866.3 & 356 & 182.8 & 233.7 & 389.6 & 176 & 2235 & 375 \\
\hline $4 / 26 / 96$ & 2 & & 64.0 & & & & 474 & 583.4 & 447 & 180.4 & 215.0 & & 180 & 1514 & 458 \\
\hline $4 / 26 / 96$ & 3 & & 49.2 & 276.3 & & & 436 & 478.0 & 377 & & & & 153 & 1361 & 375 \\
\hline $4 / 26 / 96$ & 4 & & 51.8 & 265.6 & 243.4 & & 509 & 355.6 & 441 & 124.2 & 108.2 & 125.9 & 169 & 1135 & 446 \\
\hline $4 / 26 / 96$ & 5 & 167.6 & 40.4 & 214.3 & 197.2 & & 549 & 342.1 & 500 & 807.4 & 95.2 & 3943.8 & 216 & 1131 & 489 \\
\hline & & $800 \%$ & $120 \%$ & $105 \%$ & $196 \%$ & & & $100 \%$ & & $335 \%$ & $84 \%$ & 3494\% & & $386 \%$ & \\
\hline
\end{tabular}

The analysis wavelength is indicated immediately after the chemical symbol for the analyte at the head of each column. The script, indicated by $\mathrm{nnn} / \mathrm{m}$, specifies the wavelength in $\mathrm{nm}(\mathrm{nnn})$ at the spectrometer window center and the number (m) of CCD array rows binned together for measurement. As indicated elsewhere, individual measurements based on averages of 25 and 100 laser pulses were performed during these test periods. 
Table 3-7. Relative accuracy results and average of RA results (\%) for the target metals at high, medium, and low concentrations. Each relative accuracy was determined using two to five (CEM, RM) data pairs.

\begin{tabular}{|c|c|c|c|c|c|c|c|c|c|}
\hline \multirow[b]{2}{*}{ METAL } & \multicolumn{3}{|c|}{$\begin{array}{l}\text { Navy/TJA } \\
\text { ICP-AES }\end{array}$} & \multicolumn{3}{|c|}{$\begin{array}{l}\text { DIAL } \\
\text { LIBS }\end{array}$} & \multicolumn{3}{|c|}{$\begin{array}{l}\text { SNL } \\
\text { LIBS }\end{array}$} \\
\hline & High & Medium & Low & High & Medium & Low & High & Medium & Low \\
\hline Arsenic & 45 & 53 & 90 & & & & & & \\
\hline Beryllium & 32 & 66 & 43 & 57 & 38 & 273 & $105^{* *}$ & $68 * *$ & 91 \\
\hline Cadmium & 52 & 63 & 59 & 77 & $73^{*}$ & & 100 & 413 & \\
\hline Chromium & 93 & 83 & 88 & 76 & 53 & 31 & $84 * *$ & & \\
\hline Mercury & 143 & 117 & 86 & & & & & & \\
\hline Lead & 86 & 74 & 86 & 49 & & & 386 & & \\
\hline Antimony & 16 & 50 & 64 & & & & & & \\
\hline AVERAGE & 67 & 72 & 74 & 65 & 55 & 152 & 169 & 241 & 91 \\
\hline
\end{tabular}

* This DIAL RA value was determined from two (CEM, RM) data pairs measured on 4/25. It is included for completeness, and is included in the average.

** For beryllium and chromium, the SNL team submitted results obtained with various measurement scripts but did not indicate which results should be used for the RA determination. The values included here provided the best agreement with the reference method results. 
Table 3-8. Summary of CEM performance test results - Number of analytes measured.

\begin{tabular}{||l|c|c|c|}
\cline { 2 - 4 } \multicolumn{1}{c|}{} & \multicolumn{3}{c||}{ CEM system under test } \\
\hline \begin{tabular}{|ll|c|c|} 
Test Date \& \\
Concentration Level
\end{tabular} & $\begin{array}{c}\text { Navy/TJA } \\
\text { ICP-AES }\end{array}$ & $\begin{array}{c}\text { DIAL } \\
\text { LIBS }\end{array}$ & $\begin{array}{c}\text { SNL } \\
\text { LIBS }\end{array}$ \\
\hline \hline $4 / 24 \quad$ Low & 7 & 2 & 1 \\
\hline $4 / 22 \quad$ Medium & 7 & $3^{*}$ & 2 \\
\hline $4 / 26 \quad$ High & 7 & 4 & 4 \\
\hline
\end{tabular}

Includes one metal measured on $4 / 25$.

Table 3-9. Summary of CEM performance test results - Average RA (\%) .

\begin{tabular}{|l|c|c|c|}
\cline { 2 - 4 } \multicolumn{1}{c|}{} & \multicolumn{3}{c|}{ CEM system under test } \\
\hline $\begin{array}{l}\text { Test Date \& } \\
\text { Concentration Level }\end{array}$ & $\begin{array}{c}\text { Navy/TJA } \\
\text { ICP-AES }\end{array}$ & $\begin{array}{c}\text { DIAL } \\
\text { LIBS }\end{array}$ & $\begin{array}{c}\text { SNL } \\
\text { LIBS }\end{array}$ \\
\hline \hline $4 / 24$ Low & 74 & 152 & 91 \\
\hline $4 / 22$ Medium & 72 & 55 & 240 \\
\hline $4 / 26$ High & 67 & 65 & 169 \\
\hline
\end{tabular}

${ }^{a}$ The value reported is the average of the RAs observed for the individual analytes. Please see Table 3-7.

The results presented in this report are based on the data reported by the developers the day after each test. In their final report submitted weeks after the test, the SNL team multiplied all their original measurements by a factor of 0.72 to account for post-test calibration of their laboratory calibration source. They had been using a factory-supplied efficiency factor for their aerosol generator, instead of their own measured efficiency factor. In their report, the SNL team also deleted some data after the test because of suspicions of spectral interference from combustion gases. After this deletion and correction, the SNL results compared more favorably with the RM results.

\subsubsection{Number of Data Pairs in Relative Accuracy Calculations}

The RA calculation specified in the RATA for a combustion gas CEM requires a minimum of nine pairs of corresponding CEM and RM results, i.e., (CEM, RM) measurement pairs, for the RA calculation. Ideally, nine measurement pairs should be obtained at each concentration level in a single, extended measurement period - perhaps over two or more shifts on a single test day. Nine measurement pairs were not obtained in this work, principally because of the appreciable sampling time that was required to obtain quality RM concentration determinations. 
This test program was designed to obtain a total of 17 (RM, CEM) data pairs over four test days. Of these 17 pairs, 5 pairs were at medium concentrations on $4 / 22,4$ pairs were at low concentrations on $4 / 24,3$ more pairs at medium concentrations on $4 / 25$, and 5 pairs at high concentrations on 4/26). As a result, each RA calculation included at most 5 (CEM,RM) measurement pairs. As discussed in "Testing the Performance of Real-Time Incinerator Emission Monitors," (Reference 5), such calculations, using less than nine measurement pairs, bias the determination (actually, estimation) of RA toward larger, more conservative, values. According to the analysis presented in Reference 5, the effect of such bias for the RA determinations performed here and reported in Tables 3-4 through 3-7 and 3-9 may have been to produce RA values that are up to 3.2 times as large as would have resulted from calculations using nine (CEM, RM) measurement pairs. This factor is worst case for 3 pairs versus 9 pairs; the corresponding worst case factors for 4 pairs versus 9 and 5 pairs versus 9 are 2.9 and 1.6, respectively ${ }^{1}$. Interestingly, application of the 3.2 worst case factor to the results reported in Table 3-9 only produces one value less than 20 percent. Hence, even if nine measurement pairs had been obtained in these tests, it seems unlikely that any of the CEMs tested would have met the 20 percent RA requirement stated in the PS.

\subsubsection{Method Detection Limits and Test Results}

This test also provides information concerning the Method Detection Limits (MDLs) for each CEM. The MDL is defined by EPA as, "the minimum concentration of a substance that can be measured and reported with $99 \%$ confidence that the analyte concentration is greater than zero and is determined from analysis of a sample in a given matrix type containing the analyte." (Reference 1). The MDL is essentially equivalent to the Detection Limit (DL) or Limit of Detection (LOD) commonly employed by analytical chemists (Reference 18). The DL or LOD is normally stated to be the amount or concentration of analyte that yields a signal-to-noise ratio of 3:1. MDLs are important because 1) analytes cannot be detected with high confidence at levels less than the MDL and 2) quantitative measurements of amounts or concentrations of analytes can normally be performed with acceptable precision and accuracy at levels equal to or greater than 10 times the MDL. This level is referred to in EPA SW-846 as the Estimated Quantitation Limit (EQL).

Table 3-10 compares target and estimated MDLs with metal concentrations measured by the EPA reference method and by the three tested CEMs. The target MDL is $1 / 10$ the proposed MACT emission standard level for hazardous waste incinerators (Reference 3). When the MACT standard addresses a group of metals, as in SVM and LVM, the target MDL is further divided by the number of metals in the group. If the target MDL is achieved, quantitative measurements should be possible at ten times that value, i.e., at the proposed MACT emission standard level. The target MDLs range from approximatly 2 to $5 \mu \mathrm{g} / \mathrm{dscm}$.

The next three columns show estimated MDLs for each CEM tested, as provided in the developer team final reports (Appendices D, E, and F). The estimates were determined in the

1 The SNL data for beryllium on 4/22, consisting of only 2 (CEM, RM) pairs, exemplifies the strong dependence of RA on the number of data pairs. In this case, the RA is $296 \%$ although the CEM - RM relative differences for the two data pairs are only $6 \%$ and $51 \%$. 
developers' laboratories by extrapolating measurements to metal concentrations at which the signal-to-noise ratio is $3: 1$.

The next three columns in Table 3-10 compare estimated MDLs to target MDLs to show where better (lower) MDLs are needed to address the hazardous metals addressed by the proposed MACT rule. If the estimated MDL for a metal is greater than the target MDL, then the estirnated MDL needs to be improved (decreased). The Navy/TJA system has superior estimated MDLs, only needing improvement for antimony, arsenic, and mercury. As noted in the discussion two paragraphs below, however, the data from this test seem to justify downward revision of the Navy/TJA estimated MDL for mercury. In contrast, to be useful as a multi-metal CEM for MACT rule compliance monitoring, the DIAL and SNL LIBS systems need substantial improvement in detection capability for all the MACT metals except beryllium and chromium.

The next three columns in Table 3-10 show which metals should have been detected by the CEMs during this test, but were not. These metals should have been detected because the concentration measured by the reference method was greater than the estimated MDL. For example, the DIAL LIBS system should have been able to detect antimony at high concentration (approximately $370 \mu \mathrm{g} / \mathrm{dscm}$ ). The conclusion is the estimated MDL for antimony needs to be revised upward for this system.

The final three columns in Table 3-10 identify two cases where a metal concentration was measured at a concentration less than the estimated MDL. The DIAL LIBS system reported measured cadmium concentrations of 55.8 and $52.4 \mu \mathrm{g} / \mathrm{dscm}$, although the DIAL estimated MDL for cadmium was $240 \mu \mathrm{g} / \mathrm{dscm}$. The Navy/TJA system reported measured mercury concentrations of 0.9 to $4.1 \mu \mathrm{g} / \mathrm{dscm}$, although the estimated MDL for that system was 5 $\mu \mathrm{g} / \mathrm{dscm}$. For these cases, the conclusion is that the estimated MDLs need to be revised downward. 
Table 3-10. Comparison of target and estimated MDLs ${ }^{a}$ with metal concentrations measured by the EPA reference method and by the Navy/TJA, DIAL and SNL CEMs.

\begin{tabular}{|c|c|c|c|c|c|c|c|c|c|c|c|c|c|}
\hline \multirow[t]{2}{*}{ Element } & \multirow[t]{2}{*}{$\begin{array}{c}\text { Target } \\
\text { MDL } \\
(\mu \mathrm{g} / \mathrm{dscm})\end{array}$} & \multicolumn{3}{|c|}{$\begin{array}{l}\text { Estimated MDL } \\
(\mu \mathrm{g} / \mathrm{dscm})\end{array}$} & \multicolumn{3}{|c|}{$\begin{array}{l}\text { Estimated MDL > Target } \\
\text { MDL? } \\
\text { Need to improve (decrease) } \\
\text { estimated MDL }\end{array}$} & \multicolumn{3}{|c|}{$\begin{array}{l}\text { Reference Method Result > } \\
\text { Estimated MDL but the metal } \\
\text { was not measured. }\end{array}$} & \multicolumn{3}{|c|}{$\begin{array}{l}\text { CEM Measurement Result } \\
\text { Estimated MDL? }\end{array}$} \\
\hline & & Navy/TJA & DIAL & SNL & Navy & DIAL & SNL & Navy & DIAL & SNL & Navy & DIAL & SNL \\
\hline As & 2 & 2.2 & 1200 & 900 & yes & yes & yes & & & & & & \\
\hline $\mathrm{Be}$ & 2 & 0.02 & 2 & 4 & & & yes & & & & & & \\
\hline $\mathrm{Cd}$ & 5 & 0.03 & 240 & 40 & & yes & yes & & & & & yes & \\
\hline $\mathrm{Cr}$ & 2 & 0.20 & 12 & 60 & & yes & yes & & & & & & \\
\hline $\mathrm{Hg}$ & 4 & 5.0 & 1360 & 1800 & yes & yes & yes & & & & yes & & \\
\hline $\mathrm{Pb}$ & 5 & 0.30 & 136 & 400 & & yes & yes & & & & & & \\
\hline $\mathrm{Sb}^{b}$ & 1.5 & 3.3 & 240 & 500 & yes $^{\mathrm{b}}$ & yes $^{b}$ & $\mathrm{yes}^{\mathrm{b}}$ & & yes $^{b}$ & & & & \\
\hline
\end{tabular}

${ }^{\mathrm{a}}$ The MDLs reported by the developers in $\mu \mathrm{g} / \mathrm{acm}$ at test conditions (atmospheric pressure, 7 mole $\%$ water, $232^{\circ} \mathrm{C}$ ) were multiplied by 2 to convert to $\mu \mathrm{g} / \mathrm{dscm}$.

${ }^{b}$ EPA has proposed removing Sb from consideration as one of the LVMs (Reference 3). 


\subsubsection{Response Times}

There were numerous opportunities to observe changes in the multi-metals CEM responses because the metals injection was started and stopped frequently during this test. Figure 3-3 shows how the DIAL CEM responded to starts and stops of the metals injection. In this example, the measurement interval was 18 seconds and it appears the DIAL CEM took approximately 72 seconds to reach a steady value following a substantial change. As noted in Section 2.3, however, other results from the multi-metals CEMs showed that stable metals concentrations in the flue gas were not actually realized until up to 15 minutes after the start of metals injection. As shown in Figure 3-3, the CEMs are clearly capable of measuring changes that occur over times much shorter than 15 minutes. However, because of the flow characteristics of the RKIS, and absent the ability to introduce a metals calibration gas just upstream of the CEMs, we were not able to cause rapid changes in metals concentrations at the CEMs. Consequently, we were not actually able to measure response time as defined in the draft PS. This situation is likely to prevail at every hazardous waste combustor. Nevertheless, PS 10 , as currently proposed, requires a response time of 2 minutes or less.

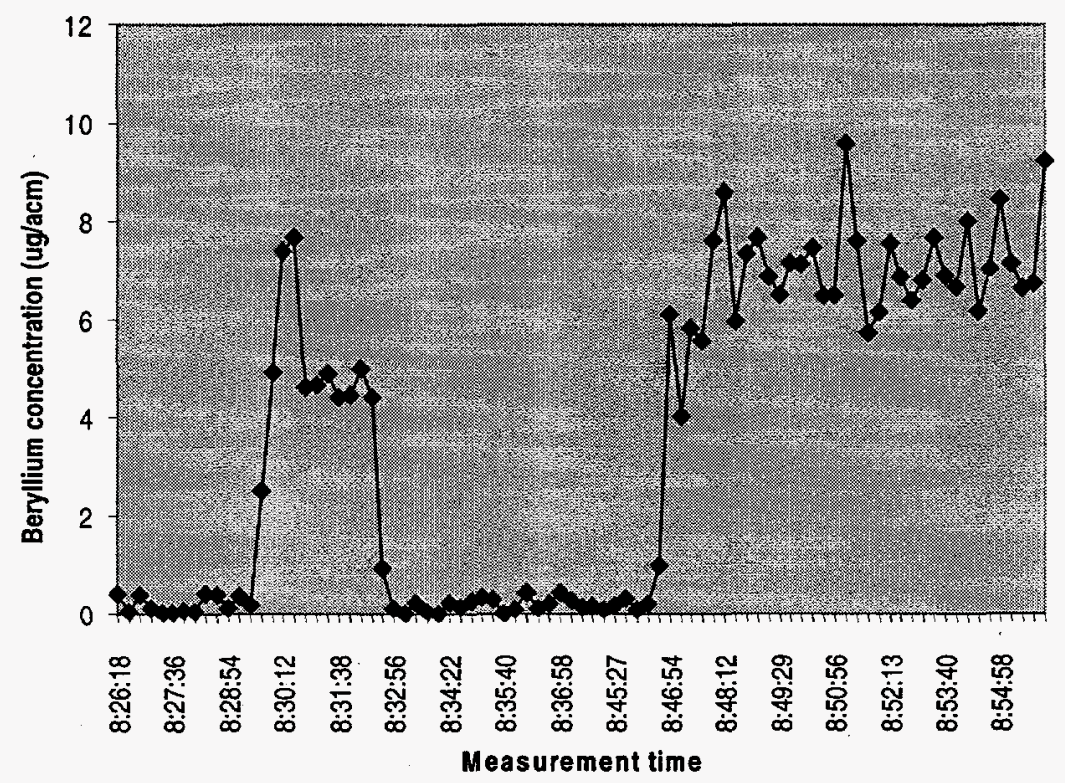

Figure 3-3. Response of DIAL CEM to instantaneous changes in beryllium concentration.

The measurement interval for the Navy/TJA system was 3.5 minutes. For that system, illustrations similar to that shown above for the DIAL system are provided in Appendix E.

In the case of the SNL LIBS CEM, signal-averaging periods of 10 seconds were used for some of the work and 40-second periods were used at other times during the test. The response of the SNL LIBS system might therefore be expected to be somewhat similar to that of the DIAL LIBS system. This is not known for sure, however, because the data acquisition periods used by the 
SNL team were not consecutive for any emission line wavelength or analyte element. As indicated by the data in Table 3-5, this was because at least two separate spectrometer central wavelength settings had to be employed to measure the four elements addressed there. In addition, as also suggested by the data in Table 3-5, the SNL team was experimenting with various analyte wavelengths and measurement scripts, attempting to find optimum combinations.

\subsubsection{Calibration Drift and Zero Drift Checks}

Each developer team was expected to conduct and report on daily calibration drift and zero drift checks. The procedures for performing the checks and the limitations on acceptable drift are detailed in the draft PS (Appendix $\mathbf{H}$ ).

The DIAL CEM was calibrated using an ultrasonic nebulizer system at the DIAL home laboratory. During this test, calibration for Cr was performed at the RKIS site after the shakedown test on April 19 and at the conclusion of each of the test days. The Cd 228.8-nm response on April 25 and 26 was scaled to that observed for Cr. The Be 234.8-nm response on April 26 was scaled to that observed for the Be $313.3-\mathrm{nm}$ line. The DIAL report (Appendix D) does not mention zero drift checks.

The Navy/TJA team performed a calibration drift check and a zero drift check at the end of each test day. According to the Navy/TJA report (Appendix E), none of those checks failed QC requirements during the week of April 22-26, 1996.

The SNL team performed zero checks prior to the first addition of metals in the morning and after the metals feed had been turned off for 20 to 30 minutes at the end of the day. These checks were performed morning and evening early in the test week, but only occasionally later in the test week. According to the SNL report (Appendix F), no non-zero concentrations were found, i.e., no zero drift was observed. According to the same report, the SNL team did not perform on-site instrument calibrations or calibration checks during the test week.

\subsubsection{Data Availability}

As configured for this test, i.e., with only one spectrometer each, neither the DIAL nor the SNL CEM could simultaneously observe the desired spectral lines for all seven of the target metals. This is reflected in the test results for these instruments, which show only one to three metals measured at any given time. To measure the seven target metals, each of these CEMs used three physically different grating angle settings. As a result, for any given metal, the DIAL and SNL systems typically recorded data for only about $30 \%$ of each RM measurement period.

Depending on how the instruments were being operated during particular RM measurement periods, this fraction varied from as low as $10 \%$ to as high as $90 \%$.

The Navy/TJA CEM, on the other hand, was able to simultaneously observe the desired spectral lines for all seven of the target metals. Grating angle changes were not required. The Navy/TJA system recorded data for all the target metals throughout each of the RM measurement periods. Furthermore, the Navy/TJA results were more representative than those of the LIBS instruments because they uniformly covered each RM measurement period for all the metals, whereas, for various metals, the LIBS systems typically covered only the beginning, middle, or end of the RM measurement period. 
The Navy/TJA system also demonstrated the ability to simultaneously monitor additional elements such as $\mathrm{Al}, \mathrm{Fe}, \mathrm{Mg}$, and $\mathrm{Y}$. In the case of $\mathrm{Al}$ and $\mathrm{Fe}$, which are expected in fly ash and are potential sources of spectral interference, this ability potentially supports the application of accurate corrections for interferences from those elements. The ability to monitor $\mathrm{Mg}$ and $\mathrm{Y}$ while simultaneously monitoring the hazardous analytes enables the continuous monitoring and optimization of plasma and spectrometer performance.

\subsubsection{Spectral Interferences}

All three of the CEM developer teams observed some spectral line interferences.

The DIAL team noted a Ti 326.16-nm line next to the Cd 326.15-nm line and an Fe 259.8-nm line next to the $\mathrm{Sb} 259.81-\mathrm{nm}$ line. The DIAL team monitored the $\mathrm{Pb} 405-\mathrm{nm}$ region but did not report concentrations "due to problems of spectral interference and target concentration near the LIBS detection limit." Please see Appendix D.

The Navy/TJA team noted that spectral interferences caused by molecular emissions from CO, $\mathrm{NO}$, and $\mathrm{CN}$ in the plasma were significant, especially during the low concentration measurement periods. The full text of the Navy/TJA team comments is included in Appendix G.

The SNL team also observed several instances of spectral interference:

- Cd interfered with the As 228.8-nm line;

- $\mathrm{Mg}$ interfered with As lines near $280 \mathrm{~nm}$;

- Fe interfered with the Sb 259.8-nm line; and

- Cd interfered with the Sb 226.3-nm line.

The SNL team also noted that emission from the $\mathrm{Hg} 253.7-\mathrm{nm}$ line was likely affected by selfabsorption. Please see Appendix F.

\subsubsection{Sampling Duty Cycle and Data Reporting Frequency}

CEM sampling duty cycle and data reporting frequency are important because CEMs must sample continuously or nearly continuously and they must report their measurement results on a sufficiently short time scale to support timely feed stream shut-off or other emissions control actions when a significant emissions problem occurs. Information on these parameters is reported in Table 3-11.

The CEMs tested had dramatically different sampling duty cycles (SDCs). The DIAL and SNL LIBS instruments had SDCs on the order of $10^{-7}$. The Navy/TJA instrument had an SDC of approximately $3 \%$. The SDC is the fraction of total CEM running time in which the CEM actually samples the flue gas. For both the LIBS and ICP-AES instruments tested here, observation of the signals caused by the laser excitation or passage of sample through the ICP occurs over a longer period than the actual sampling. In the DIAL and SNL LIBS instruments sampling only occurs during the 10-nanosecond laser pulses. In the Navy/TJA ICP-AES system, sampling only occurs during the 6 or 7 second flue gas sampling period that is employed for each of its 3.5 minute measurement and reporting periods. 
Table 3-11. CEM sampling duty cycles and data reporting frequencies.

\begin{tabular}{|c|c|c|}
\hline CEM & $\begin{array}{l}\text { SAMPLING DUTY CYCLE } \\
(\mathrm{SDC})\end{array}$ & DATA REPORTING FREQUENCY \\
\hline $\begin{array}{l}\text { Navy/TJA } \\
\text { ICP-AES }\end{array}$ & $\begin{array}{l}\text { One } 6 \text { to } 7 \text { second sample taken every } \\
3.5 \text { minutes } \\
\text { SDC }=\sim 3 \%\end{array}$ & Every 3.5 minutes \\
\hline $\begin{array}{l}\text { DIAL } \\
\text { LIBS }\end{array}$ & $\begin{array}{l}1010 \text {-nanosecond laser pulses (samples) } \\
\text { per second, averaged over } 60 \text { to } 260 \\
\text { samples ( } 6 \text { to } 26 \text { seconds). } \\
\text { SDC }=10^{-7} \\
\text { Also, } 3 \text { spectrometer grating positions } \\
\text { were employed - changed at } \\
\text { approximately } 15 \text { minute intervals. }\end{array}$ & $\begin{array}{l}6 \text { seconds to } 26 \text { seconds depending on } \\
\text { averaging period. } \\
\text { (plus interruption of approximately } 2 \\
\text { to } 5 \text { minutes when grating position } \\
\text { was changed) }\end{array}$ \\
\hline $\begin{array}{l}\text { SNL } \\
\text { LIBS }\end{array}$ & $\begin{array}{l}2.510 \text {-nanosecond laser pulses } \\
\text { (samples) per second, averaged over } 25 \\
\text { to } 100 \text { samples ( } 10 \text { to } 40 \text { seconds). } \\
\text { SDC }=0.2510^{-7} \\
\text { Also, } 3 \text { spectrometer grating positions } \\
\text { were employed - changed at } \\
\text { approximately } 10 \text { to } 40 \text { second intervals. }\end{array}$ & $\begin{array}{l}\text { Typically every } 10 \text { seconds or } 40 \\
\text { seconds } \\
\text { (plus interruption of approximately } 10 \\
\text { seconds when grating position was } \\
\text { changed) }\end{array}$ \\
\hline
\end{tabular}

\subsubsection{Equipment Durability}

The DIAL developer team final report noted that, at the end of the tests, they found that the laser optics harmonic separator mirror was seriously damaged and the lens was dirty. It is not known how such damage affected the results. The DIAL team attributed the mirror damage to high humidity and will avoid such damage in the future by providing a dry nitrogen gas purge. A nitrogen purge will also be used to keep the lens clean.

A large electrical transformer within the Navy/TJA instrument tore loose of its mounting when the trailer it is normally housed and transported in was towed from California to the EPA RKIS site in North Carolina. 


\section{SECTION 4 CONCLUSIONS}

This test provided valuable data to quantify the performance of new multi-metal CEMs. The test also promoted technology development by providing a well-defined performance goal for each of the developers, i.e., to measure the concentration of metals at challenging levels in a realistic flue gas environment. The test environment was somewhat competitive, inspiring each developer to perform as well as possible. Simply working next to each other in a laboratory for two weeks stimulated valuable dialogue. Most of these investigators had never been in each other's laboratories, much less compared hardware or shared or discussed technical ideas or practices. It would be desirable to encourage this type of informal collaboration among developers in the future.

None of the three CEMs tested consistently achieved RA values of $20 \%$ or less as required by the EPA draft performance specification for multi-metals CEMs (Reference 6).

One instrument, the Navy/TJA ICP-AES system, clearly out-performed the other instruments, both in the number of metals measured, and in the relative accuracy of those measurements. The Navy/TJA system provided quantitative CEM results for the seven toxic metals at all three test concentration levels. For the seven metals, the Navy/TJA system achieved average relative accuracies of 74, 72, and $67 \%$ for the low, medium, and high concentration levels, respectively. Overall, the RA values achieved by the Navy/TJA system ranged between $16 \%$ and $143 \%$. The Navy/TJA RAs were also superior to those reported for the Metorex XRF-based CEM tested at the EPA IRF in August 1995 (Reference 5). Even so, however, the Navy/TJA system did not achieve RA values of $20 \%$ of less, which is required to satisfy the EPA draft performance specification for multi-metal CEMs.

The DIAL and SNL LIBS systems provided quantitative CEM results for only four toxic metals at the high concentration level, three and two toxic metals, respectively, at the medium concentration level, and only two and one, respectively, at the low concentration level. The LIBS system achieved average relative accuracies of 152,55 , and $65 \%$ for the low, medium and high concentration levels, respectively. The DIAL LIBS RA values ranged from 31 to $273 \%$. The SNL LIBS system achieved average relative accuracies of 91,241 , and $169 \%$ for the low, medium, and high concentration levels, respectively. The SNL LIBS RA values ranged from 68 to $413 \%$.

The relative accuracy of the DIAL LIBS system was marginally better than that of the SNL LIBS system, but both instruments need more work before they will be ready for additional field validation. In addition, it was difficult to draw conclusions on relative accuracy from the SNL LIBS data because the SNL team measured some metals at several different wavelengths and reported different concentrations for the different wavelengths.

Of the three CEMs tested, only the Navy/TJA system provided quantitative results for mercury. The relative accuracies achieved for mercury were not superior, however, to those achieved by the EcoChem Hg-Mat 2 mercury CEM evaluated in the August 1995 performance tests at the EPA IRF (Reference 5). The Navy/TJA system tested here is a multi-metals CEM, whereas the EcoChem device measures only mercury. 
Of the seven metals addressed in the proposed MACT rule, beryllium is the easiest to measure by atomic emission spectrometry because it has a strong signal. Consequently, all three CEMs achieved best relative accuracy for their beryllium measurements. Lead and mercury were the hardest to measure, and had the worst relative accuracies.

Method detection limits estimated from laboratory results need to be updated based on the results from this test. To be useful as a multi-metal CEM for MACT rule compliance monitoring, the DIAL and SNL LIBS systems need substantial improvement in detection capability for all the MACT metals except beryllium and chromium. The target method detection limit for these metals range from 1 to $5 \mu \mathrm{g} / \mathrm{dscm}$. The Navy/TJA system only needs to improve detection for mercury, antimony, and arsenic to meet target method detection limits.

For any given metal, the DIAL and SNL LIBS systems typically recorded data for only about $30 \%$ of each 1 to 3 hour RM measurement period. Depending on how the instruments were operated during particular RM measurement periods, this fraction varied from as low as $10 \%$ to as high as $90 \%$. The Navy/TJA CEM, on the other hand, was able to simultaneously observe the desired spectral lines for all seven of the target metals. This system recorded data for all the target metals during $100 \%$ of each RM measurement period. Furthermore, the Navy/TJA results were more representative than those of the LIBS instruments because they uniformly covered each RM measurement period, for all the metals, whereas, for various metals, the LIBS systems typically covered only the beginning, middle, or end of the RM measurement period.

Because the simulated flue gas used in this test included the major elemental constituents of fly ash and carbon- and nitrogen-containing species, the atomic emission spectra were more complex than those ordinarily observed under laboratory conditions. As a consequence, all the CEM developer teams observed spectral interferences that made the flue gas measurements more challenging than measurements conducted under laboratory conditions.

When the thousands of individual data points generated by the CEMs during this test were plotted vs. time, we saw considerable variability about the average concentration levels. The variability was larger than was expected under the carefully controlled test conditions. This variability may reflect real variations in the emissions levels, or it may reflect inadequacies in the measurement methods or equipment. This question should be addressed in future tests. The CEM data sampling duty cycles and data reporting frequencies should also be compared to the characteristic times of metals concentration changes in the flue gas.

Additional lessons learned included the following:

- The CEMs must be rugged enough to withstand the abuses normally encountered in transportation.

- The RKIS did not appear to come to steady state until approximately 15 minutes after metals injection was started. This observation is contrary to expectations based on observation of the CO CEM, which reached steady state only minutes after the start of metals injection.

- It is useful to dedicate a computer to real-time data processing whenever possible.

- Test data must be converted to dry-standard-cubic-meters (dscm) in a consistent way. (Engineers consider standard temperature to be $20^{\circ} \mathrm{C}$, whereas physical scientists consider it to be $0^{\circ} \mathrm{C}$.) For the test conditions of this work (atmospheric pressure, 7 mole 
$\%$ water, $232^{\circ} \mathrm{C}$ ), the metal concentration of gas with $\mathrm{X}$ micrograms of metal per actual cubic meter $(\mathrm{acm})$ is approximately the same as that of gas with $1.99 \mathrm{X}$ micrograms of metal per dry standard cubic meter $(\mathrm{dscm})$.

- The mercury atomic emission line at $253.7 \mathrm{~nm}$ suffers from self-absorption.

Overall, the test results showed the prototype nature of the test CEMs and the need for further development before multi-metal CEMs can succeed in commercial service as envisioned by regulators and citizens. None of the CEMs tested consistently achieved RA values of $20 \%$ or less as required by the draft EPA performance specification for multi-metal CEMs (Reference 6). Instrument size reduction and automation will also likely need additional attention to realize this vision.

Another quantitative performance test should be scheduled as soon as one or more instruments have shown sufficient technical progress to warrant validation. After the instruments are shown to be capable or more nearly capable of satisfying the EPA PS for multi-metal CEMs, they will likely need to be engineered into smaller, more rugged packages. In addition, to satisfy the requirements of commercial CEM applications, these systems will likely have to provide more user-friendly operational and data analysis capability. 


\section{REFERENCES}

1. U.S. EPA, 1994. “Test Methods for Evaluating Solid Waste: Physical/Chemical Methods," EPA SW-846, Laboratory Manual, Vol 1, page ONE-24, -26

2. U.S. EPA Proposed Rule "Hazardous Waste Combustors; Maximum Achievable Control Technologies Performance Standards," in Federal Register, Volume 61, pp. 17357 - 17536 , April 19, 1996.

3. U.S. EPA Notice of data availability and request for comments "Revised Technical Standards for Hazardous Waste Combustion Facilities," in Federal Register, Volume 62, pp. 24211 - 24254, May 2, 1997.

4. U.S. EPA, "Test Methods for Evaluating Solid Waste: Physical/Chemical Methods," EPA SW-846, Method 0060 "Determination of Metals in Stack Emissions," 3rd edition, Revision 2, September 1994.

5. "Testing the Performance of Real-Time Incinerator Emission Monitors," S. B. Ghorishi, W. E. Wentworth, Jr., C. G. Goldman, and L. R. Waterland, National Risk Management Research Laboratory, U. S. EPA, Cincinnati, Ohio, June 1996.

6. U.S. EPA Proposed Rule "Hazardous Waste Combustors; Maximum Achievable Control Technologies Performance Standards (Performance Specification 10 - Specifications and test procedures for multi-metals continuous monitoring systems in stationary sources)," in Federal Register, Volume 61, pp. 17499 - 17502, April 19, 1996.

7. 40 CFR 264, Standards for Owners and Operators of Hazardous Waste Treatment, Storage and Disposal Facilities, Subpart O, Incinerators.

8. U.S. EPA, 1996. "Standards for the Management of Specific Hazardous Wastes and Hazardous Waste Management Facilities - Hazardous Waste Burned in Boilers and Industrial Furnaces," in 40 CFR PART 266, Subpart H, U.S. Government Printing Office, Washington, DC, July 1, 1996.

9. Continuous Performance Assurance for Metals Emissions from Hazardous Waste Combustion Systems: An ASME/EPA Joint Workshop, Cincinnati, Ohio, September 1993.

10. "CEM Technology Development Strategy: A Process and Supporting Information to Establish a CEM Technology Development Strategy," draft in review, September 1996.

11. 40 CFR 60, Standards of Performance for New Stationary Sources, Appendix F, Quality Assurance Procedures.

12. EPA Test Method 5, "Determination of Particulate Emissions from Stationary Sources," 40 CFR 60, Appendix A, U.S. Government Printing Office, Washington, DC, July 1994. 
13. "Quality Assurance Project Plan for the Performance Testing of Multi-Metal Continuous Emission Monitors," prepared for National Risk Management Research Laboratory, U. S. Environmental Protection Agency, Air Pollution Prevention and Control Division, Research Triangle Park, North Carolina, by Acurex Environmental Corporation, under EPA Contract No. D4-0005, Work Assignment No. 8916, Acurex Work Assignment No. 8916, April 1996.

14. EPA Test Method 1A, "Sample and Velocity Traverses for Stationary Sources with Small Ducts or Stacks," 40 CFR 60, Appendix A, U. S. Government Printing Office, Washington, DC, July 1994.

15. U.S. EPA, "Test Methods for Evaluating Solid Waste: Physical/Chemical Methods," EPA SW-846, Method 6020, "Inductively Coupled Plasma-Mass Spectrometry," 3rd edition, September 1994.

16. "Test Methods for Evaluating Solid Waste: Physical/Chemical Methods," EPA SW-846, Method 7470A, "Mercury in Liquid Waste, Manual Cold Vapor Technique," September 1994.

17. Roberts, D., Anderson, G., Sagan, F., Stewart, R., 1996. "Continuous Monitoring of Mercury: Beyond the Analyzer," in Proceedings of the International Conference on Incineration and Thermal Treatment Technologies, University of California, Irvine, California, p. 403.

18. Commission on Spectrochemical and Other Procedures for Analysis, Analytical Chemistry Division, International Union of Pure and Applied Chemistry, "Nomenclature, Symbols, Units and Their Usage in Spectrochemical Analysis-II. Data Interpretation," Anal. Chem., 482294 (1976). 


\section{APPENDIX A PROJECT ORGANIZATION AND PARTICIPANT RESPONSIBILITIES}

The project organization for the subject CEM test is shown in Figure A-1. The DOE and the EPA jointly sponsored the project. A CEM Test Program Committee (PC) was formed consisting of the persons identified in Table A-2. The responsibilities of the individuals named in Figure A-1 are listed more fully in Table A-3. The PC, co-chaired by Bill Haas and Cliff Brown, had overall responsibility for coordinating the multi-metals CEMs test, including communication among the participants and development, review, and approval of the initial test plan, the Quality Assurance Project Plan (QAPP), and this final test report.

The off-site laboratory, Oxford Laboratories, was required to follow EPA-approved protocols at all times.

The Test Report Integration and Preparation function was managed by Bill Haas and staffed by a team as indicated in Figure A-1. This team was responsible for preparation of the comprehensive final test report for this project, publication of project results on the World Wide Web, and for coordinating the preparation of journal article(s) or publication(s) resulting from this project. This team was also responsible for the daily reduction and analysis of available data during the test week. These intermediate test results provided the basis for continuing the Test Plan as written on the next test day, or making mid-course changes in the Test Plan to enhance the chance for a successful test.

The Public/Stakeholder/Regulator/User Interface function addressed interaction with these entities throughout the project. Specifically, a stakeholder review of the QAPP was conducted, press releases were disseminated, and visitors' day activities were coordinated during the test week.

Communication between the PC co-chairs and the DOE/EM sponsors occurred at least once a week. Communication between the PC co-chairs, EPA and Contractor Facility Managers, EPA Project QA Representative, Test Report Integration and Reporting, and the CEM developers was conducted as needed prior to the test week, and with at least one meeting per test day during the test week. Communication with the off-site laboratory and the Contractor Laboratory Manager occurred on an as needed basis via telephone during the period when samples were being analyzed 


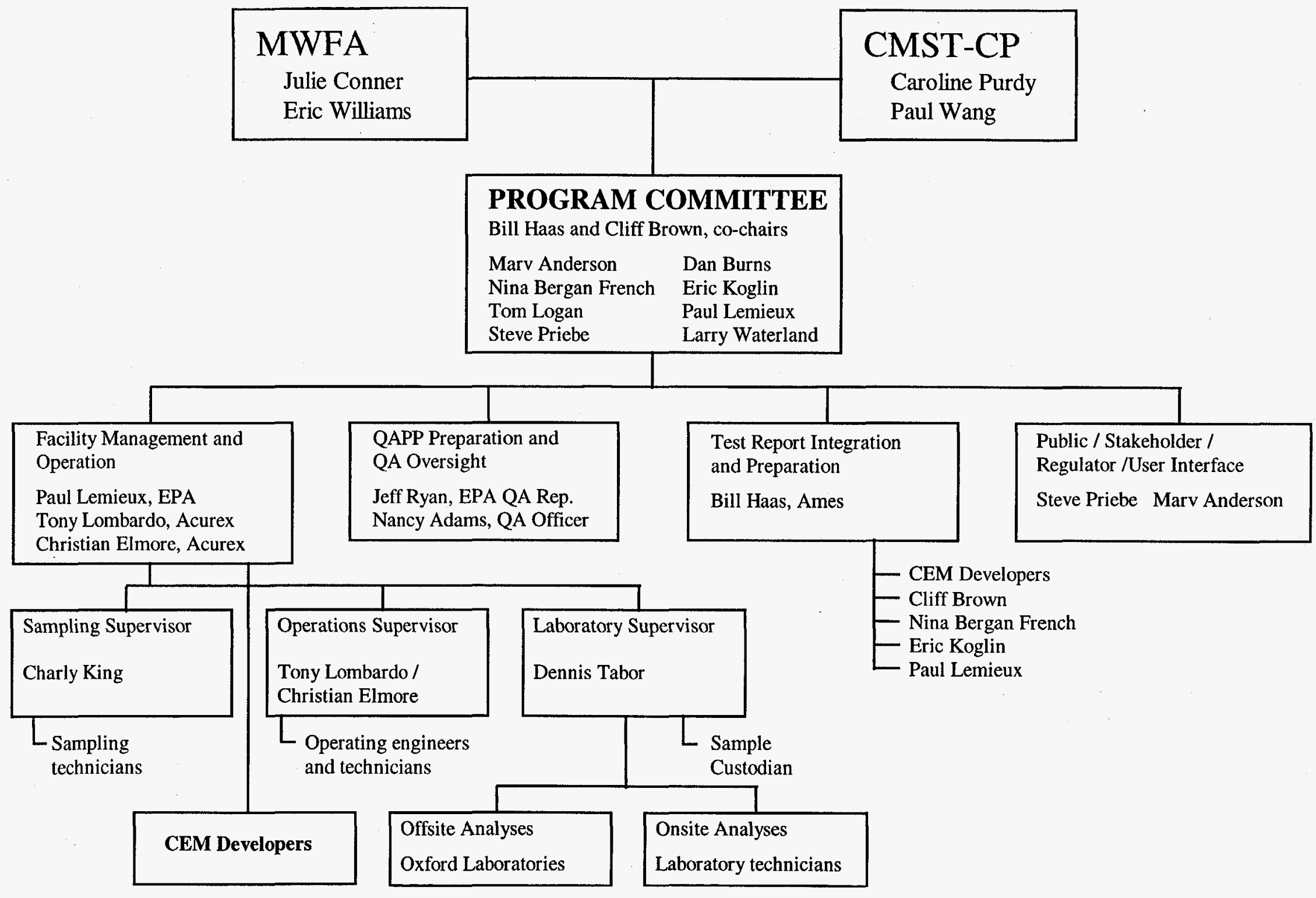

Figure A-1 CEM test organization. 
Table A-2. CEM test program committee

\begin{tabular}{|l|l|}
\hline Marvin Anderson & $\begin{array}{l}\text { DOE Characterization, Monitoring, and Sensor Technology } \\
\text { Crosscutting Program }\end{array}$ \\
\hline Cliff Brown & DOE Mixed Waste Focus Area \\
\hline Nina Bergan French & Sky+, Engineering Technologies \& Consulting Company \\
\hline Bill Haas & $\begin{array}{l}\text { DOE Characterization, Monitoring, and Sensor Technology } \\
\text { Crosscutting Program }\end{array}$ \\
\hline Dan Burns & Westinghouse Savannah River Company \\
\hline Eric Koglin & $\begin{array}{l}\text { EPA National Exposure Research Laboratory, Characterization } \\
\text { Division, Las Vegas, NV }\end{array}$ \\
\hline Paul Lemieux & $\begin{array}{l}\text { EPA National Risk Management Research Laboratory, Air } \\
\text { Pollution Prevention and Control Division, } \\
\text { Research Triangle Park, NC }\end{array}$ \\
\hline Tom Logan & $\begin{array}{l}\text { EPA National Exposure Research Laboratory, Office of Air } \\
\text { Quality Planning and Standards, } \\
\text { Research Triangle Park, NC }\end{array}$ \\
\hline The following provided significant technical input to the program committee. \\
\hline Steve Priebe & DOE Mixed Waste Focus Area \\
\hline Larry Waterland & \begin{tabular}{l} 
Acurex Environmental Corporation \\
\hline Acurex Environmental Corporation
\end{tabular} \\
\hline
\end{tabular}


Table A-3. CEM test participants and responsibilities.

\begin{tabular}{|c|c|}
\hline $\begin{array}{l}\text { Position } \\
\text { - Person }\end{array}$ & Responsibilities \\
\hline Program Committee & $\begin{array}{l}\text { Provide overall project/program and technical management. } \\
\text { Review and approve test planning documents and QAPP. } \\
\text { Interact and coordinate activities with the facility manager, QA } \\
\text { oversight personnel, test report preparers, technology developers, and } \\
\text { provide communication interface with the public / stakeholders / } \\
\text { regulators / users. } \\
\text { Review final data interpretation and data quality assessment. } \\
\text { Review and approve test final report. } \\
\text { Interact and coordinate with program sponsors in EPA, the DOE } \\
\text { Mixed Waste Focus Area, and the DOE Characterization, Monitoring, } \\
\text { and Sensor Technology Crosscutting Program. }\end{array}$ \\
\hline $\begin{array}{l}\text { EPA RKIS Facility Manager, Work } \\
\text { Assignment Manager, and Project } \\
\text { Principal Investigator } \\
\text { - Paul Lemieux }\end{array}$ & $\begin{array}{l}\text { Provide oversight and management of kiln operations, sampling, and } \\
\text { laboratory activities. } \\
\text { Interact with program committee to set program technical activities. } \\
\text { Review and provide input to QAPP. } \\
\text { Coordinate test preparation activities. } \\
\text { Oversee test performance. } \\
\text { Provide integrated system operation and analytical report to the Test } \\
\text { Report Function. } \\
\text { Input to test data evaluation, interpretation, and engineering analysis. } \\
\text { Provide interface with the CEM developers. } \\
\text { Collect, reduce, validate, and report test system operating data. }\end{array}$ \\
\hline $\begin{array}{l}\text { EPA Project QA Representative } \\
\text { - Jeff Ryan }\end{array}$ & $\begin{array}{l}\text { Responsible for fulfillment of sampling and analytical technical } \\
\text { requirements. } \\
\text { Coordinate and monitor project QA activities, including internal audits } \\
\text { and routine inspections. } \\
\text { Prepare matrix spike samples. } \\
\text { Ensure implementation of the QAPP and technical requirements. } \\
\text { Evaluate the quality of process operation and analytical data. } \\
\text { Review QA data in terms of the QAPP. } \\
\text { Draft the QA section of the test report. } \\
\text { Ensure the implementation of any corrective actions resulting from } \\
\text { discrepancies. } \\
\text { Provide written approval of any deviation from the QAPP-specified } \\
\text { analysis procedures. }\end{array}$ \\
\hline $\begin{array}{l}\text { EPA QA Manager } \\
\text { - Nancy Adams }\end{array}$ & $\begin{array}{l}\text { Coordinate and implement EPA APPCD QA requirements. } \\
\text { Coordinate review and approval of the Project QA Test Plan. } \\
\text { Provide independent project QA support. } \\
\text { Coordinate external audits (if any). } \\
\text { Provide QA reports. } \\
\text { Monitor QA activities. }\end{array}$ \\
\hline $\begin{array}{l}\text { Contractor Project Manager } \\
-\quad \text { Kevin Bruce, Acurex } \\
\end{array}$ & Responsible for contractor activities during the test. \\
\hline
\end{tabular}


Table A-3. CEM test participants and responsibilities (continued).

\begin{tabular}{|c|c|}
\hline $\begin{array}{l}\text { Contractor Work Assignment Manager } \\
\text { and Test Engineer } \\
\text { - Tony Lombardo, Acurex } \\
\text { - Christian Elmore, Acurex, } \\
\text { alternate }\end{array}$ & $\begin{array}{l}\text { Direct test system preparations and operation prior to and during the } \\
\text { test. } \\
\text { Coordinate activities of contractor operations technicians. } \\
\text { Coordinate activities of contractor sampling team. } \\
\text { Coordinate with EPA Facility Manager for analytical data reporting. }\end{array}$ \\
\hline $\begin{array}{l}\text { Contractor Technical Consultant } \\
\text { - Larry Waterland, Acurex } \\
\end{array}$ & $\begin{array}{l}\text { Prepare QAPP. } \\
\text { Review test final report. }\end{array}$ \\
\hline $\begin{array}{l}\text { Contractor QA Officer } \\
\text { - Libby Beach, Acurex }\end{array}$ & $\begin{array}{l}\text { Oversee the project QA program. } \\
\text { Provide internal QA audits and routine inspections. } \\
\text { Review and approve the QAPP. } \\
\text { Provide QA reports. } \\
\text { Monitor QA activities of off-site laboratories. } \\
\text { Ensure implementation of the QAPP and technical requirements. } \\
\text { Evaluate the quality of process operation and analytical data. } \\
\text { Review QA data in terms of the QAPP. } \\
\text { Input to QA section of the test report. } \\
\text { Ensure the implementation of any corrective actions resulting from QA } \\
\text { discrepancies. } \\
\text { Coordinate external audits. }\end{array}$ \\
\hline $\begin{array}{l}\text { Contractor Sampling Team Lead } \\
\text { - Charly King, Acurex }\end{array}$ & $\begin{array}{l}\text { Train staff in sampling techniques. } \\
\text { Supervise maintenance, calibration, and operation of sampling } \\
\text { equipment. } \\
\text { Maintain documentation concerning calibrations. } \\
\text { Responsible for recovery of samples from the sampling equipment. } \\
\text { Collect, reduce, validate, and report sampling measurement data. } \\
\text { Ensure completion of all planned sampling. } \\
\text { Review project sampling data and report. }\end{array}$ \\
\hline $\begin{array}{l}\text { Contractor Laboratory Manager } \\
\text { - Dennis Tabor, Acurex }\end{array}$ & $\begin{array}{l}\text { Prepare metals feed solutions. } \\
\text { Ensure that proper chain of custody procedures are followed. } \\
\text { Coordinate with off-site laboratories for sample analyses. } \\
\text { Ensure that off-site laboratories satisfy the QA requirements specified } \\
\text { in the QAPP. } \\
\text { Track progress of sample analyses by off-site laboratories. } \\
\text { Supervise activities of the Sample Custodian. } \\
\text { Review analytical data. }\end{array}$ \\
\hline $\begin{array}{l}\text { Sample Custodian } \\
\text { - Ray Thomas }\end{array}$ & $\begin{array}{l}\text { Accept custody of all samples collected during test. } \\
\text { Implement proper preservation and on site storage of samples. } \\
\text { Distribute samples for preparation/analysis. } \\
\text { Responsible for sample packing, shipment, and custody documentation } \\
\text { for off-site analyses. }\end{array}$ \\
\hline $\begin{array}{l}\text { Test Report Integration and } \\
\text { Preparation Coordinator } \\
\text { - Bill Haas, Ames Laboratory }\end{array}$ & $\begin{array}{l}\text { Coordinate preparation of comprehensive final project report, virtual } \\
\text { town meeting, and journal publications(s) resulting from the project. } \\
\text { Responsible for day-to-day analysis of system operation and CEM data } \\
\text { to aid in day-to-day setting of test objectives and any adjustments in } \\
\text { the written Test Plan. }\end{array}$ \\
\hline $\begin{array}{l}\text { Public / Stakeholder / Regulator / User } \\
\text { interface } \\
\text { - Marv Anderson, Ames Laboratory } \\
\text { - Steve Priebe, Idaho National } \\
\text { Engineering Laboratory } \\
\end{array}$ & $\begin{array}{l}\text { Responsible for stakeholder, end user, public, and regulatory } \\
\text { interactions relative to CEM technology and subject test. } \\
\text { Coordinate stakeholder review of QAPP. } \\
\text { Coordinate press release(s) and visitor day(s). }\end{array}$ \\
\hline
\end{tabular}




\section{APPENDIX B PROJECT SCHEDULE}

This test program was performed on an accelerated schedule to meet programmatic requirements. The initial planning meeting to identify persons who would be asked to serve on the Program Committee occurred on February 7, 1996 at CMST-CP support offices in Ames, Iowa. The members of the CEM Program Committee were identified and they began identifying and addressing the issues and details that defined this test and evaluation project. Test facilities that might be used and multi-metal CEMs that might be candidates for testing were identified. Instruments being developed under DOE and DoD sponsorship were considered and several instrument manufacturer and field analytical service companies were queried to identify other multi-metal CEMs that might be ready for field testing. The goal was to conduct the test program during April 1996, so the findings could affect FY 1997 funding decisions.

On February 15, 1996, members of the Program Committee visited the EPA National Risk Management Research Laboratory at Research Triangle Park, North Carolina. On February 19, 1996, Program Committee members visited the SAIC STAR Center in Idaho Falls, Idaho. In both cases the purpose was to gather information on facilities, equipment, and experience required for support of the simultaneous testing of multi-metal CEMs under well-characterized and well-controlled conditions. At the EPA facility they received briefings on the Rotary Kiln Incinerator Simulator (RKIS) and other supporting equipment and facilities. At the STAR Center they received briefings on the Plasma Hearth facility and associated air pollution control equipment. At both sites, the Program Committee members viewed current and potential future arrangements for hot gas sampling and CEM testing. Other potential test sites that were considered but not visited included facilities at the Western Environmental Technology Office in Butte, Montana, and the Toxic Substances Control Act (TSCA) Incinerator in Oak Ridge, Tennessee. After careful consideration of criteria designed to identify the site best suited for performing the CEM tests, the Program Committee recommended that the tests be conducted at the EPA RKIS facility.

Members of the Program Committee continued detailed planning by telephone, fax, and electronic mail, ultimately convening March 13, in Atlanta, and March 14 and 15, at the EPA Environmental Research Center in RTP. These last two meetings were held in conjunction with the CEM test kickoff meeting. At the kickoff meeting, which was primarily for the benefit of the prospective CEM developers, the developers were provided with additional particulars concerning the test, a tour of the facility, and answers to many of their questions and concerns. The tour of the facility allowed the developers to see and ask questions concerning their instrument setup locations and the available utilities.

Facility preparation, characterization, and scoping testing began on March 25 . These activities required approximately four weeks. This work provided information and data on RKIS operating conditions and flue gas characteristics, including metals concentrations, particulate loading, and particle size distribution, and verified the ability to achieve and maintain the target test conditions before the start of any CEM testing. Participant Hazardous Waste Operations and Emergency Response training and CEM setup and shakedown testing were accomplished during the week of April 15. The CEM testing was performed the week of April 22. 


\section{APPENDIX C QUALITY ASSURANCE SUMMARY}

\section{C.1 General}

This appendix addresses how the testing described in this report fulfilled the elements of the "Quality Assurance Project Plan (QAPP) for the Performance Testing of Multi-Metal Continuous Emission Monitors" (Reference 1), and what problems, if any, may exist with the data. All testing described in this report, including the QA aspects of the work, was carried out in accordance with the QAPP, except as noted below.

The primary objective of the project was to measure the RA of each CEM tested. Secondary objectives were to obtain measures of response time and detection limits for each CEM tested. The project fully met the primary objective. RAs were measured for each CEM for at least some of the metals on all tests.

The secondary objectives were met qualitatively. Response times for the instruments were not determined quantitatively. However, qualitative information from the multi-metals CEMs provided useful system diagnostic information and helped uncover problems prior to initiation of testing. For example, one CEM developer recognized a deficiency in the iron concentration, which led to the discovery that the fly ash feeder had plugged. The plug was removed and fly ash feed was restored prior to initiation of the RM test. In another case, two CEM developers recognized that the system was taking longer than anticipated to come to steady-state.

Consequently, corrective action was taken to stabilize the system for a longer period of time prior to initiation of RM sampling. All of the multi-metals CEMs reported a near-instantaneous decline to zero of measured metals concentrations when metals doping was ceased. Based on these observations, the response time for all of the multi-metals CEMs appeared to be faster than the characteristic response times for the RKIS to adjust to changes in metals concentrations.

The RCRA permit that the RKIS operates under limits the feed amount of certain compounds, particularly mercury, to a yearly limit. Since other research facilities at this site needed to feed mercury for their experiments, an effort was made to minimize the amount of time that the metals feed was being introduced to the RKIS. As such, on April 22, 1996, metals were fed for five minutes prior to initiation of RM sampling. After this first day of testing, more than one of the CEM developers noted that the metals concentrations appeared to trend upward for approximately 20-30 minutes after initiation of the metals feed, until a steady-state was reached. It took approximately 15 minutes to reach approximately $80 \%$ of the steady-state level. After April 22, therefore, the metals feed was run for 15 minutes prior to initiation of RM sampling.

Numerous QA procedures were followed to assess the quality of the measurements. These included blank sample analyses, and matrix spike (MS) and matrix spike duplicate (MSD) sample analyses. Table C-1 summarizes the critical measurement Quality Assurance Objectives (QAOs) for precision, accuracy, and completeness. The results of the QA procedures performed for the critical laboratory measurements are discussed in the following subsections. 
Table C-1. Precision, Accuracy, and Completeness QAOs for Critical Measurements.

\begin{tabular}{|c|c|c|c|}
\hline $\begin{array}{c}\text { Critical } \\
\text { Measurement }\end{array}$ & $\begin{array}{c}\text { Precision, } \\
\text { Relative } \% \text { difference }\end{array}$ & $\begin{array}{c}\text { Accuracy, } \\
\%\end{array}$ & $\begin{array}{c}\text { Completeness, } \\
\%\end{array}$ \\
\hline $\begin{array}{l}\text { Trace metals in flue } \\
\text { gas samples }\end{array}$ & less than \pm 30 & 70 to 130 & 75 \\
\hline
\end{tabular}

\section{C.2 Adherence to RM Procedures}

All RM sampling was performed isokinetically. Isokinetic variations ranged between 95.8 and $102.5 \%$. All trains underwent a pre-test and post-test leak check. All train leaks were less than $0.02 \mathrm{cfm}$ at the maximum vacuum encountered.

All RM samples reported here were taken at the RKIS by members of the RKIS operating staff. All samples were collected and/or recovered in accordance with the methods appropriate to their analysis. After preservation, the samples were relinquished to the custody of the on-site Sample Custodian. The Sample Custodian subsequently directed the splitting of samples and the transport of these to the appropriate laboratories for analysis. The sample chain-of-custody procedures described in the QAPP were followed. No compromise in sample integrity occurred.

RM sampling procedures were followed in all cases, excepting the following traverse deviations:

- Three tests were repeated for the medium level tests on April 25, 1996. For these tests the trains only traversed the horizontal port, rather than both the horizontal and vertical port. This was done so the metals feed could remain at a constant level throughout entire duration of the three RM runs. For the preceding medium level tests, on April 22, to minimize reagent use, the metals feed had been shut off between each RM sampling period and during probe orientation changes.

- A burner flameout on RM2 of April 25, 1996, resulted in traversing three, not four, points. The RM sampling was halted when the burner flamed out; the EPA Principal Investigator decided that sufficient sample was acquired prior to interruption of sampling for the run to be complete.

- RM3 on April 22, 1996, traversed 7 out of 8 points before the probe broke during adjustment of the traverse position. The sampling was halted when the probe broke. Again, the EPAA Principal Investigator determined that sufficient sample had been acquired to complete the run.

- RM4 on April 26, 1996, traversed 7 out of 8 points due to evacuation of the building due to a fire alarm. The probe was left in a single traverse point during the fire alarm and moved afterwards. The point that would have been taken during the fire alarm was skipped.

- For RM5 of April 26, 1996, only the horizontal port was traversed.

The sample holding times were within specifications. Samples were collected between April 22 and May 3, 1996, and were delivered to Oxford Laboratories on May 8, 1996. Analysis began immediately and the results were reported on May 21. 
Analytical procedures were followed as described in the methods cited previously. The analytical reports provided by the subcontracted laboratory included complete calibration reports, results of calibration checks, duplicates, sample spikes, and detection limits. While not presented here due to their large number, all calibration checks were within the specified 90 $110 \%$ of actual concentration. In addition, all sample spikes performed were within the specified $75-125 \%$ recovery of actual spiked amount.

\section{C.3 Completeness of Sampling}

RM sampling was performed to an acceptable level of completeness. The trains and field blanks exceeded the $75 \%$ completeness QAO. Table C-2, below, summarizes the RM samples planned and performed.

Table C-2. Kinds and numbers of RM samples planned and performed.

\begin{tabular}{|l|c|c|}
\hline Samples & Number Planned & Number Performed \\
\hline $\begin{array}{l}\text { RM samples at Medium } \\
\text { concentration }\end{array}$ & 4 to 6 & 8 \\
\hline $\begin{array}{l}\text { RM samples at Low } \\
\text { concentration }\end{array}$ & 3 to 4 & 4 \\
\hline $\begin{array}{l}\text { RM samples at High } \\
\text { concentration }\end{array}$ & 4 to 6 & 3 \\
\hline Field blanks & 3 & 2 \\
\hline Matrix spikes & 2 & 2 \\
\hline Matrix spike duplicates & 2 & 3 \\
\hline Reagent blanks & 2 & 3 \\
\hline
\end{tabular}

\section{C.4 Calibrations}

- Dry gas meters, thermocouples, orifice meters, nozzle diameters and pitot tubes were pre-test calibrated.

- Dry gas meters and nozzle diameters were post-test calibrated.

- The liquid injection system was calibrated at the beginning of each test day by using a graduated cylinder and a stop watch to set the $50 \mathrm{ml} / \mathrm{min}$ feed rate.

- The fly ash feeder was not calibrated; however, prior to initiation of the tests, appropriate feed rates were developed using the Insitec particle counter, sizer, velocimeter and Method 5 to determine the feeder settings required to generate the desired particulate loading at the sample location.

- The Insitec equipment was calibrated by using the measured bulk fly ash density.

- All RKIS fixed gas CEMs were calibrated with a 3-point calibration (zero, mid-range, highrange) prior to initiation of the first day of testing. Each day, the RKIS CEMs were calibrated with a 2 point calibration (zero, span) prior to initiation of the day's sampling. After the day's sampling was completed, the instruments were tested with zero gas and span 
gas to check for calibration drift. All instruments functioned acceptably except the THC analyzer at the kiln exit, which malfunctioned prior to the tests and was not used. The Bodenseewerk MCS analyzer reported $\mathrm{H}_{2} \mathrm{O}$ concentrations that were consistently about 1 mole \% higher than that determined using the RM.

- In addition to the zero and span checks on the RKIS CEMs, $\mathrm{O}_{2}$ and $\mathrm{CO}_{2}$ concentrations were monitored upstream and downstream of the RM and multi-metals CEM sample ports prior to initiation of each RM sample and during RM probe location switches to assure that no significant air in-leakage was occurring where the probes were inserted.

- System bias checks were performed for each RKIS combustion CEM prior to testing. All system biases were less than the data quality indicator goal of $\pm 5 \%$.

\section{C.5 Laboratory Audit}

Prior to testing, the subcontracted analytical laboratory participated in an independent technical systems audit (TSA) conducted by the EPA APPCD Quality Assurance Office. This audit included the analysis of several performance evaluation samples representative of the analytes and analyte concentrations targeted by this performance evaluation.

The TSA consisted of reviews of the subcontracted laboratory's analytical operations and issues including QA management system planning and implementation, management and training, selection and use of analytical methodologies, incorporation of quality control measures, sample custody and documentation, analysis and data processing procedures, and accessibility of the QA and procedural documents to the analyst. All reviews were found to be satisfactory.

The performance evaluation audit consisted of three audit samples: an acid solution spiked with mercury only, a quartz filter spiked with nine target analytes, and fly ash (NIST SRM 1633). As specified in the QAPP (Reference 1), the acceptance criterion for spike measurements, i.e., within $\pm 30 \%$ of the true value, was based on the acceptance criteria for metals emissions measurements contained in the Handbook of Quality Assurance/Quality Control Procedures for Hazardous Waste Incineration (Reference 2).

All audit measurements were within specified goals. Analysis of the mercury audit sample deviated by $+29 \%$ from the true spiked value. Results for the filter and fly ash samples are presented in Tables C-3 and C-4, respectively. 
Table C-3. Performance evaluation audit results for the spiked filter samples.

\begin{tabular}{|l|r|}
\hline \hline Element & Percent deviation from the true value \\
\hline \hline Arsenic & -13.12 \\
\hline Beryllium & -14.67 \\
\hline Cadmium & 2.00 \\
\hline Chromium & 10.63 \\
\hline Lead & 4.80 \\
\hline Manganese & 12.38 \\
\hline Nickel & 0.27 \\
\hline Selenium & -18.27 \\
\hline Antimony & 13.00 \\
\hline
\end{tabular}

Table C-4. Performance evaluation audit results for the NIST SRM 1633 fly ash analysis.

\begin{tabular}{||l|c|}
\hline Element & Percent deviation from the true value \\
\hline Arsenic & -19.4 \\
\hline Beryllium & -7.6 \\
\hline Cadmium & 16.4 \\
\hline Chromium & 4.3 \\
\hline Lead & -7.3 \\
\hline Manganese & 2.1 \\
\hline Nickel & 10.7 \\
\hline Selenium & 11.9 \\
\hline Antimony & 17.5 \\
\hline
\end{tabular}

\section{C.6 Field and Reagent Blanks}

Multiple field blank and reagent blank samples were collected and analyzed as part of the quality assurance procedure. The analytical results are presented in Table C-5. For the most part, the target metals were either not detected or were detected at concentrations 20 to 300 times less than the total mass present in the RM samples. Consequently, no corrections for analytes in the blanks were applied to the analytical results obtained for the RM samples.

It should be noted that a significant amount of mercury was found in the potassium permanganate fraction for one of the field blank samples collected during the medium level concentration tests. However, no mercury was detected in this fraction for either of the other field blank samples. The amount detected in the field blank for the medium level concentration test was less than $20 \%$ of the total mass of mercury measured in the RM sample for the same test. This anomalous occurrence is not understood. It does not mean that any or all RM samples have been contaminated, only that a possibility exists. As a consequence, no corrections for 
analytes present in the field blanks were applied to the analytical results obtained for the RM samples.

Table C-5. Analytical results for reagent blank and field blank samples (total analyte mass, micrograms)

\begin{tabular}{|l|c|c|c|c|c|c|c|c||}
\hline & $\mathrm{Sb}$ & $\mathrm{As}$ & $\mathrm{Be}$ & $\mathrm{Cd}$ & $\mathrm{Cr}$ & $\mathrm{Fe}$ & $\mathrm{Pb}$ & $\mathrm{Hg}$ \\
\hline \hline Reagent Blank 1 & $<1.00$ & $<1.00$ & $<0.40$ & $<0.80$ & 2.05 & 37.3 & $<1.00$ & $<5.21$ \\
\hline Reagent Blank 2 & $<1.00$ & $<1.00$ & $<0.40$ & $<0.80$ & 2.07 & 37.3 & $<1.00$ & $<5.21$ \\
\hline Field Blank 1 & $<1.00$ & $<1.00$ & $<0.40$ & $<0.80$ & 4.50 & 57.3 & 1.23 & 18.7 \\
\hline Field Blank 2 & 3.53 & $<1.00$ & $<0.40$ & $<0.80$ & 4.37 & 83.2 & 1.95 & $<5.21$ \\
\hline Field Blank 3 & $<1.00$ & $<1.00$ & $<0.40$ & $<0.80$ & 4.64 & 67.3 & 1.44 & $<5.64$ \\
\hline
\end{tabular}

\section{C.7 Matrix Spikes}

Trace metal analysis precision and accuracy were assessed by preparing and analyzing matrix spike and matrix spike duplicate (MS/MSD) quality control check samples and measuring the percent recovery. MS/MSD QC check samples were prepared for all target metal analytes. A total of four MS/MSD samples were prepared at two different metals concentrations representative of the concentration ranges anticipated in test samples. For the non-mercury target analyte MS/MSD samples, the filter and acid impinger fractions comprising the Method 0060 train were spiked separately in equal amounts. The two sample fractions were combined during analysis resulting in a single reported mass for each combined sample. For the mercury MS/MSD samples, the four individual fractions comprising the Method 0060 train were spiked and analyzed individually.

The results of the MS/MSD sample analyses are presented in Tables C-6 through C-9. All non-mercury metal target analytes achieved the data quality indicator goals for accuracy (between $70 \%$ and $130 \%$ recovery) and precision (less than $\pm 30 \%$ relative percent difference) at both spiking concentrations. Three of the four mercury fractions achieved the same data quality indicator goals for accuracy and precision at both spiking concentrations. However, the potassium permanganate $\left(\mathrm{KMnO}_{4}\right)$ fraction demonstrated unacceptable recovery performance at both spiking concentrations. At the low level spiking concentration, mercury was not detected in either sample. At the high level spiking concentration, mercury recoveries were less than $2 \%$ in each sample. The reason for the unacceptably low mercury recoveries in the potassium permanganate fraction has not been identified so far. Efforts continue to identify the source of the problem; repeat spike tests have demonstrated acceptable recovery. Until the recovery problem is resolved, the potassium permanganate fractions of actual samples should be viewed as suspect. 
Table C-6. Analytical results for Low Level Matrix Spikes/Matrix Spike Duplicates.

\begin{tabular}{||l|c|c||}
\hline Metal & $\begin{array}{c}\text { Average Recovery } \\
\%\end{array}$ & $\begin{array}{c}\text { Precision } \\
\text { Relative \% difference }\end{array}$ \\
\hline Antimony & 88.3 & 1.1 \\
\hline Arsenic & 88.5 & 2.6 \\
\hline Beryllium & 88.3 & 4.1 \\
\hline Cadmium & 84.6 & 1.0 \\
\hline Chromium & 113. & 5.0 \\
\hline Lead & 95.9 & 5.2 \\
\hline Yttrium & 94.9 & 0.0 \\
\hline Iron & 125. & 4.0 \\
\hline
\end{tabular}

Table C-7. Analytical results for High Level Matrix Spikes/Matrix Spike Duplicates.

\begin{tabular}{||l|c|c||}
\hline \hline Metal & $\begin{array}{c}\text { Average Recovery } \\
\%\end{array}$ & $\begin{array}{c}\text { Precision } \\
\text { Relative \% difference }\end{array}$ \\
\hline Antimony & 81.3 & 2.2 \\
\hline Arsenic & 92.8 & 0.43 \\
\hline Beryllium & 89.0 & 0.67 \\
\hline Cadmium & 91.2 & 3.7 \\
\hline Chromium & 92.4 & 1.5 \\
\hline Lead & 89.2 & 1.6 \\
\hline Yttrium & 85.7 & 4.1 \\
\hline Iron & 113. & 0.88 \\
\hline
\end{tabular}


Table C-8. Analytical results for Low Level Mercury Matrix Spikes/Matrix Spike Duplicates.

\begin{tabular}{||l|c|c|}
\hline \hline Sample & $\begin{array}{c}\text { Average Recovery } \\
\%\end{array}$ & $\begin{array}{c}\text { Precision } \\
\text { Relative \% difference }\end{array}$ \\
\hline Filter & 76.9 & 0.78 \\
\hline Acid Impinger & 84.3 & 7.8 \\
\hline Nitric Rinse & 115. & 0.35 \\
\hline $\mathrm{KMnO}_{4}$ Impinger & 0 & Not applicable \\
\hline
\end{tabular}

Table C-9. Analytical results for High Level Mercury Matrix Spikes/Matrix Spike Duplicates.

\begin{tabular}{||l|c|c|}
\hline \hline Sample & $\begin{array}{c}\text { Average Recovery } \\
\%\end{array}$ & $\begin{array}{c}\text { Precision } \\
\text { Relative \% difference }\end{array}$ \\
\hline Filter & 90.1 & 1.1 \\
\hline Acid Impinger & 100. & 3.9 \\
\hline Nitric Rinse & 103. & 3.4 \\
\hline $\mathrm{KMnO}_{4}$ Impinger & 1.5 & 23. \\
\hline
\end{tabular}

\section{C.8 Temperature, Moisture, $\mathrm{O}_{2}$ Conversions; RA Calculations}

The usual calculations were employed for converting observed quantities to standard temperature and zero moisture conditions for reporting (Reference 3). Another member of the project team independently checked the calculations. Conversion to standard pressure was not performed because all the measurements were performed at ambient pressure and therefore all the corrections were small and similar to each other. The analyte concentrations reported for the multi-metal CEMs for each of the RM measurement periods were calculated by Bill Haas, taking the averages of the analyte concentrations reported by the CEM developers for those periods. The RA calculations were also performed by Haas, using the procedure described in Reference 4. All of the concentration results and RA calculation results were provided to the CEM developers for checking; they stated the results were in agreement with their own calculations.

\section{C.9 References}

1. "Quality Assurance Project Plan for the Performance Testing of Multi-Metal Continuous Emission Monitors," prepared for National Risk Management Research Laboratory, U. S. Environmental Protection Agency, Air Pollution Prevention and Control Division, Research Triangle Park, North Carolina, by Acurex Environmental Corporation, under EPA Contract No. D4-0005, Work Assignment No. 8916, Acurex Work Assignment No. 8916, April 1996.

2. U. S. EPA, 1990, "Handbook of Quality Assurance/Quality Control Procedures for Hazardous Waste Incineration." EPA/625/6-89/023. (NTIS Order No. PB91-145979). 
3. David M. Himmelblau. 1996. "Basic Principles and Calculations in Chemical Engineering," 6th edition. Prentice Hall, Upper Saddle River, New Jersey.

4. U.S. EPA Proposed Rule "Hazardous Waste Combustors; Maximum Achievable Control Technologies Performance Standards (Performance Specification 10 - Specifications and Test Procedures for Multi-Metals Continuous Monitoring Systems in Stationary Sources)," in Federal Register, Volume 61, pp. 17499 - 17502, April 19, 1996. 